ENTREPRENEURIAL ECOSYSTEMS:

\title{
A STUDY OF ORGANIZATIONAL INTERACTIONS AND INTERRELATIONS IN ENTREPRENEURIAL ECOSYSTEMS
}

BY

\author{
YOSEPH S. AYELE
}

\begin{abstract}
A thesis
submitted to the Victoria University of Wellington

in fulfillment of the requirements for the degree of

Master of Commerce and Administration

in Management
\end{abstract}

Victoria University of Wellington

2014 
Entrepreneurial ecosystems are emerging around the world, and their relevance in business and management is increasing. Practitioners and researchers are using biological metaphors to understand collaborative aspects of entrepreneurial ecosystems. This thesis explores the use of bio-ecological metaphors to study interactions and interrelations taking place in entrepreneurial ecosystems. Specifically, it examines the characteristics of an ecosystem that influence interactions and interrelations within ecosystems. This thesis is part of a qualitative ethnographic research that employs an inductive approach to data analyses. It studies a New Zealand based ecosystem and presents findings on three characteristics that influence interactions and interrelations in ecosystems: interdependence, diversity, and organizational birth and death cycles. In doing so, this thesis makes a number of contributions to management theory and practice. Firstly, it combines aspects of organizational ecology and open-systems theory to develop an ecosystem-level unit of analysis. By using an ecosystem lens, researchers can better observe collaborative aspects of organizations. Secondly, findings suggest that increasing the degree of interdependency and diversity and facilitating organizational birth and death cycles can enhance levels of interaction and interrelations in ecosystems. This implies that more skills, knowledge, ideas, resources, and different forms of support can be exchanged within ecosystems. Such exchange can enrich ecosystems. 


\section{ACKNOWLEDGEMENTS}

I wish to acknowledge and thank all the members of Enspiral for inviting me to their community and allowing me to write this research about them. I would not have been able to learn as much as I did about Enspiral without the kind generosity of all the individuals I interviewed. I would like to specifically thank Joshua Vial and Alanna Krause from Enspiral for providing me so much valuable information, answering many questions I had, and for being very supportive of my research.

I am also very appreciative of the support, advice, and guidance I received from Todd Bridgman, my thesis supervisor. Todd was very accommodating to many of the untraditional approaches I took in writing this thesis, and he has been a great partner to brainstorm with.

I also wish to thank all my friends who supported my work, and tolerated my absence during the final weeks of my thesis project. I am indebted to you. 


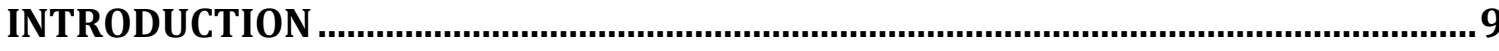

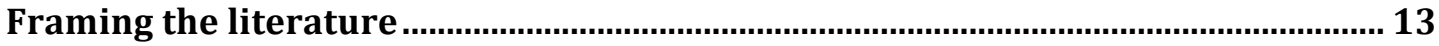

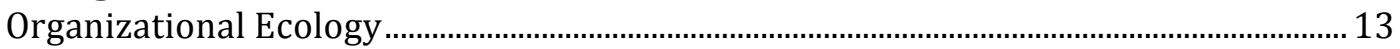

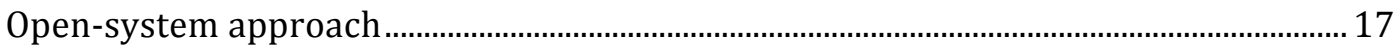

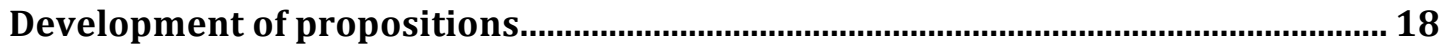

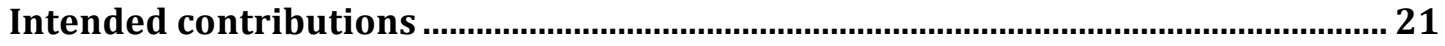

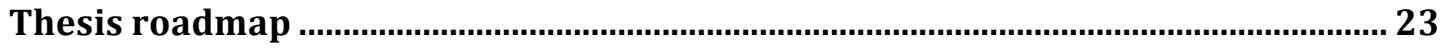

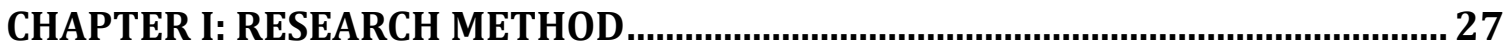

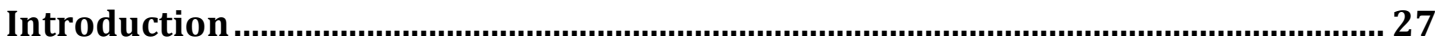

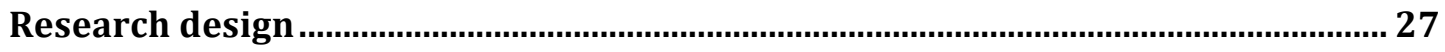

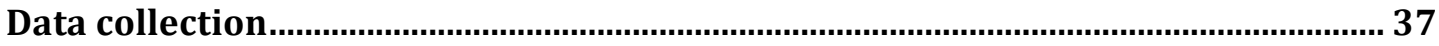

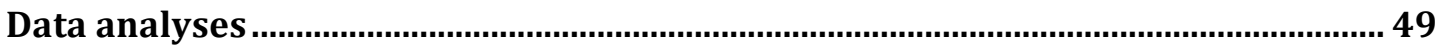

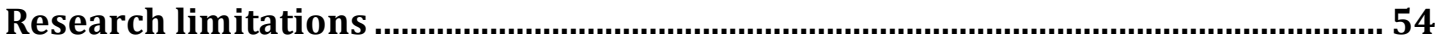

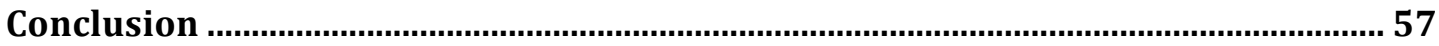

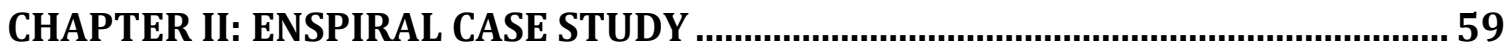

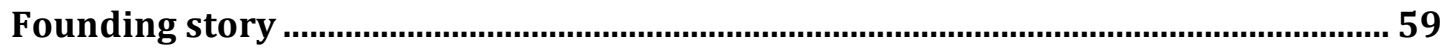

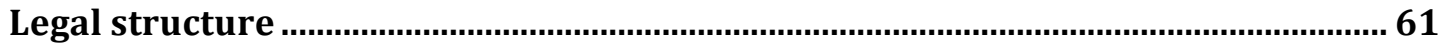

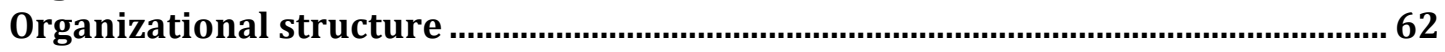

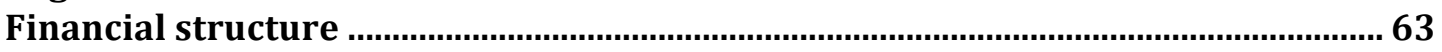

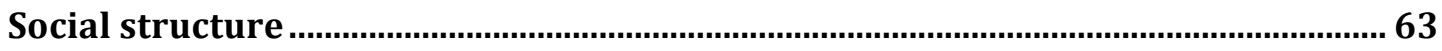

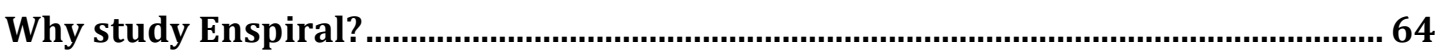

CHAPTER III: LITERATURE REVIEW AND DISCUSSION .......................................69

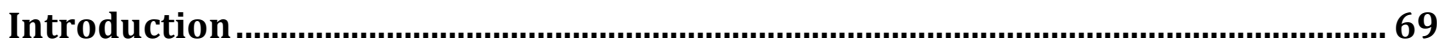

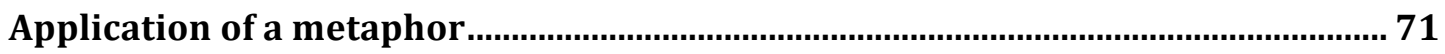

The use of metaphors and implications ………………................................................ 71

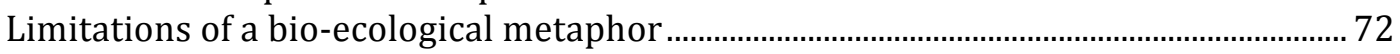

A bio-ecology metaphor: Organizational Ecology …….................................................. 75

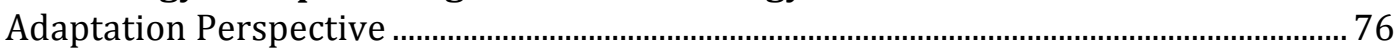

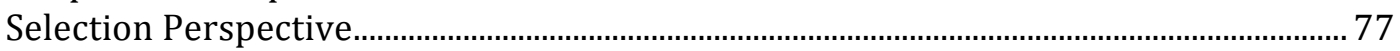

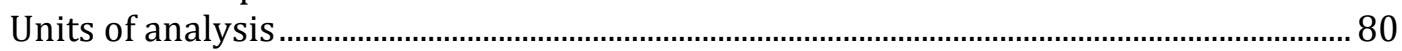

Application of the bio-ecology metaphor …………….......................................................... 83

A bio-ecology metaphor: Open-system approach …….................................................. 96

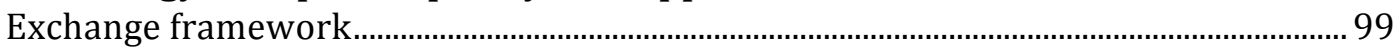

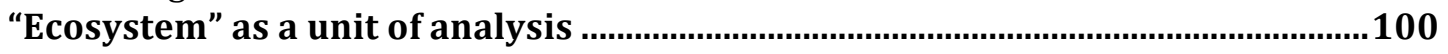


Biological interpretation of ecosystem ................................................................................... 101

Organizational interpretation of ecosystem ................................................................... 102

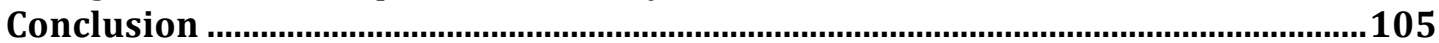

CHAPTER IV: DATA ANALYSIS ON ECOSYSTEM INTERACTIONS AND
INTERRELATIONS
Introduction
Exchange as a form of interaction
$\quad$ Types of exchange.
Exchange as a variable
Interdependence
$\quad$ Diversity
Life and death cycles.ics

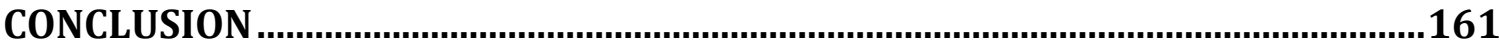

Discussion ...............................................................................................................................161

Limitations and opportunities for research......................................................... 166

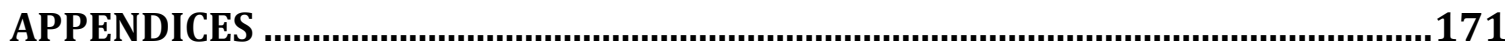

Appendix A: Letter of request to conduct research at Enspiral ................................171

Appendix B: List of interviewees and organizations ..................................................173

Appendix C: Interviewee information sheet ......................................................174

Appendix D: Interview consent form .....................................................................178

Appendix E: Interview guide ...........................................................................................179

Appendix F: Enspiral Ventures list, 2014 .................................................................. 183

REFERENCES 


\section{INTRODUCTION}

In business and management, it is becoming more common to look at entrepreneurial activities as part of bounded ecosystems. This is partly due to a growing interest in using biological metaphors to describe and understand entrepreneurial activities. Ecosystems are made of interrelated entities that are in constant interactions with one another. Rosabeth Moss Kanter, a thought leader in the study of business and change management, wrote an article for the Harvard Business Review titled "Enriching the Ecosystem," and she argues that economic agents are less effective when they operate in isolation (Kanter, 2012a). Kanter (2012a) posits that when the foundational institutions that heavily influence economies - such as universities, entrepreneur and investor communities, supply chains, labor markers, etc. - are networked together, more startups can be launched, more jobs can be created, and more companies can innovate better. When collaboration takes place between those institutions, the business ecosystem they belong to can be enriched. She places emphasis on enhancing the interrelatedness of organizations so that the whole ecosystem can prosper. Kanter (2012b) adopts a biological metaphor to depict what an enriched business ecosystem looks like. When describing an ecosystem, Kanter refers to a garden needing fertile soil, seeds, and ingredients to make things grow. She defines enriching as continued prosperity based on consistent cycle of nutrients through the soil (Kanter, 2012b). 
The use of biological metaphors in the study of organizations and business is not new, and even the concept of ecosystem is already borrowed from biology (Morgan, 1980, 2006, 2011; Patterson, 2004; Kelly, 1966, 1970, 1971a, 1971b, 1971c, 1972a, 1972b; Trickett, 1984; Hawley, 1950, 1986). An ecosystem approach to organizations in relation to their environment is becoming more widely adopted in the business and management world (e.g. Feld, 2012; Hurley, 2009; Isenberg, 2010). There is a more acute interest in using the ecosystem lens when discussing entrepreneurship communities and collaboration amongst them. Even the use of the phrases such as "entrepreneurial ecosystem" or "entrepreneurship ecosystems" is becoming more common within business communities (The Economist, 2014; Forbes Insights, 2011; Isenberg, 2010, 2011; Hurley, 2009; The University of Auckland Business School, n.d.). For example, Silicon Valley, Tel Aviv, Boston, New York, and other technology hubs around the world are widely referred as "entrepreneurial ecosystems" (Kanter, 2012b). Policy makers in certain parts of the world have also taken that further by placing emphasis on supporting and nurturing ecosystems (The Irish Department of Jobs, Enterprise and Innovation, 2014). I share such interest in studying collaboration and interorganizational interactions at an ecosystem level and the application of natural metaphors to understand such interactions.

In this thesis, I explore the use of biological metaphors to study the interactions and interrelations taking place in entrepreneurial ecosystems. Metaphors are widely used to study and understand organizations (Morgan, 
2006; Cornelissen, 2004, 2005; Oswick \& Jones, 2006; Grant \& Oswick, 1996; Miles \& Snow, 1995; Weick, 1989; Walck, 1996). Other metaphors researchers have used include exploring parallels between machines and bureaucratic organizations, brains and learning organizations, cultures and organizations, and organizations and political systems (Cornelissen \& Kafouros, 2008; Morgan, 2006; Grant \& Oswick, 1996; Lackoff, 1993; Lackoff \& Johnson, 1979).

I utilize a qualitative ethnographic research method and a case study strategy to analyze a community of organizations called Enspiral. ${ }^{1}$ Based in Wellington, New Zealand, Enspiral is an ecosystem of entrepreneurs and young startups that have been in existence for less than five years. By adopting a general inductive approach, my research aims to better understand the contexts that allow for organizations to take more collaborative approaches when engaging with one another. Enspiral offers an opportunity to study organizational interactions and interrelations taking place in a highly collaborative way. A leading Silicon Valley entrepreneur points out that the nature of interactions and relationship he sees at Enspiral are way more collaborative than those he sees in entrepreneurial incubators, accelerators, or even teams in large organizations in other parts of the world (B. Monahan, personal communication, February 10, 2014).

In this research, I attempt to model how interactions and interrelations take place within the Enspiral ecosystem, and in doing so I identify the key

\footnotetext{
${ }^{1}$ Enspiral website: www.Enspiral.com
} 
characteristics of the ecosystem that influence the levels of interactions. I do so by creating a parallel between the interrelations and interactions of organisms in biological ecology and interrelations and interactions in the Enspiral ecosystem. One major factor that Morgan (2006) and Carroll (1984) emphasize is that when creating parallels with natural ecology, our conclusions differ significantly based on the primary unit of analysis adopted - other researchers have used different units of analysis when applying bio-ecology metaphors, including organization level, population level, and community level of analysis, each of which I discuss later in this thesis. Morgan (2006) suggests new insights to the ways we understand and manage the world of organizations can emerge when looking at the entire ecology of organizations (not just individual organizations or populations) and how organizations within those larger systems collaborate. I follow Morgan's (2006) suggestion and study the collective Enspiral ecosystem as the focal point of my case study. In doing so, I develop an ecosystem unit of analysis ${ }^{2}$ that can encompass both the groups of organizations within the ecosystem and the systems that facilitate interactions and interrelations. I distinguish an ecosystem unit of analysis from the unit of analysis used by organizational ecologists, and following that I analyze the case study through an ecosystem lens. ${ }^{3}$ Based on data from my research on

\footnotetext{
${ }^{2}$ Here it is important to distinguish the ways the term is used in this thesis. Enspiral is identified as an entrepreneurial ecosystem, and individuals within the community and around Enspiral refer to it as such. This is similar to the way the term 'entrepreneurial ecosystem' is used by management practitioners, as discussed in the earlier pages of this chapter. An ecosystem unit of analysis is a framework that I further develop in this thesis, and that is a lens that allows the study of both organizations in bounded systems and the channels of communications and interactions can be studied. I adopt the ecosystem unit of analysis to study Enspiral.

3 Other units of analysis used in organizational ecology do not place emphasis on the mechanisms of interactions and interrelations. The ecosystem unit of analysis I develop encompasses such mechanisms as well.
} 
Enspiral, I orient my thesis to answering the following question: what characteristics influence the interactions and interrelations within entrepreneurial ecosystems? Before attempting to answer this question, I assess the organizational ecology theoretical framework to understand existing applications of bio-ecology metaphors in the study of organizations. I also examine open-systems approach to help frame my analysis of interactions and relations within ecosystems.

\section{Framing the literature}

\section{Organizational Ecology}

Organizational ecology is one of the main fields of organizational theory research that has attempted to study organizations by adopting a biological metaphor (Morgan, 2006). This field originally derives from human ecology (Hawley, 1950, 1986), and its main focus thus far has been to understand the relationship between organizations and the environment surrounding them. There are various ways that researchers within organizational ecology have drawn parallels between natural organisms and organizations, and their approaches have led to different conclusions regarding the nature of the organization-to-environment relationship. One of the main aspects that steered the divergence in thoughts is the unit of analysis used to study ecology (Carroll, 1984). Various studies have looked at the study of ecology from an individual organization's perspective, a population perspective, and a community perspective (Freeman \& Hannan, 1977; Carroll, 1984). Hawley (1986) is one of the few ecologists who elaborate parts of an ecosystem 
perspective and Morgan (2006) urges researchers to apply such an approach to study organizations. In this thesis I intend to contribute to the wealth of knowledge in ecology by further unraveling that ecosystem unit of analysis.

While organizational ecologists premise that organizations are in constant interaction with one another and the environment around them, the main question that has influenced academic conversations in this field is, "Why are there are so many (or so few) kinds of organizations?" (Hannan \& Freeman, 1977, p. 7, 1989; Carroll, 1984). Organizational ecologists attempt to answer this question by studying the environment's influence on the survival rates of individual organizations and organizational forms. Their main attention has been to assess evolutionary trends of organizations, how they adapt to the changing environments and how organizations are 'selected' through the natural selection process of organizational evolution (Freeman \& Hannan, 1977). The selection approach places emphasis on Darwin's idea of 'survival of the fittest' in natural selection to explicate an organization's relationship with its environment (Hannan \& Freeman, 1977). My research however is less concerned with survival rates. Instead, I use an ecological perspective and explore the patterns through which organizations interact with and interrelate to one another. I posit that one can get a better understanding of the relationship between organizations and their environments by observing the ways organizations are related to one another and interact with each other in bounded systems. 
Gareth Morgan (2006) discusses limitations of earlier ecological studies of organizations. He posits that organizational adaptation and selection "view organizations as existing in a state of tension or struggle with their environment," and "both presume that organizations and environments are separate phenomena" (Morgan, 2006, p. 62). He argues that organizations do not live in isolation and are not self-sufficient, rather "they exist as elements in a complex ecosystem" (Morgan, 2006, p. 62). He proposes the study of patterns of relationships rather than individual organizations:

Many biologists now believe that it is the whole ecosystem that evolves and that the process of evolution can really be understood as only at the level of the total ecology. This has important implications because it suggests that organisms do not evolve by adapting to environmental changes or as a result of these changes selecting the organisms that are to survive. Rather, it suggests that evolution is always evolution of a pattern of relations embracing organisms and their environments. It is the pattern, not just the separate units composing this pattern, that evolves" (pp. 62-63).

Here, Morgan (2006) proposes to study patterns of relations, not just the evolution of organizations. He premises that organizations and their environments are highly intertwined, in constant co-creation, and that each produces the other. When we study organizations at an ecosystem level, we "find that, as in nature, collaboration is often as common as competition," (pp. 63-64). Morgan argues:

An ecological perspective that emphasizes the important of collaboration can make an important contribution to how we understand and manage the world of organizations. Under the influence of interpretations of evolution that emphasize the survival of the fittest, competition is often encouraged as the basic rule of organizational life. Under the influence of more ecological interpretations stressing the "survival of the fitting," the ethic of collaboration receives much more attention" (p. 64). 
My goal is to adopt a bio-ecological metaphor and discuss how characteristics of an ecosystem influence the levels of interactions and interrelations within that ecosystem. While my research goals diverge from ecologists' predominant emphasis on adaptation and selection of organizations and organizational forms, the general organizational ecology framework is applicable to my inquiry.

There is a notable lack of literature that highlights an ecosystem perspective in the organizational ecology field. Morgan $(1980,2006,2011)$ is one of the few authors who emphasizes on the study of relational patterns in ecosystems and calls for more research in this area. Patterson (2004) is another researcher who applies an ecosystem perspective to explore the relationship between competition and cooperation. Patterson (2004) infers that an ecosystem level of analysis allows us to observe both because focusing on specific organizations skews our attention to observe competition. Ergo, I follow Morgan's (2006) suggestion to look at the patterns of relations and study a whole ecosystem. I bring in the organizational ecology frameworks into my thesis but with great caution, often critiquing the approaches and arguments made in this field as Morgan (2006) highlights above. I use an ecological perspective to explore the concept of collaboration as Morgan (2006) calls for additional research in this area. I incorporate open-system theory to further develop an ecosystem approach when studying organizations. Below I 
provide a brief explanation of how an open-system approach is applicable in an ecological study and how I use it to further my arguments in this thesis.

\section{Open-system approach}

An open-system approach builds the principle that organizations are in a relationship with their environment, and that "all systems are characterized by an assemblage or combination of parts whose relations make them interdependent" (Scott \& Davis, 2007, p. 87). An open-system approach is also based on a bio-ecological metaphor and derives from general systems theory that biologist Ludwig von Bertalanffy developed in 1956 (Cook, 1977). The approach is most concerned about understanding the systems that facilitate relations and interactions between organizations and the environment (Bastedo, 2006; Baum \& Rowley, 2002; Katz \& Kahn, 1966). An area of focus in this approach is the continuous exchange between an organization and its environment (Miller, 1989). The materials, energy, people, capital, and information that are exchanged cross organizational boundaries and circulate within the system boundary (Miller, 1989). I adopt the open-system approach to study Enspiral as a bounded system unit that has sub-systems, and one that facilitates interactions and interrelations within it. While the focus of my research remains to study interactions and interrelations within an ecosystem, I briefly explore some ways in which Enspiral interacts with the outside world. I explore the concept of exchange developed by Levine \& White (1961). I use exchange as a variable to study interactions within an ecosystem. 
I incorporate organizational ecology and open-system approach as two useful theoretical frameworks to help understand the data from the Enspiral case study. I cautiously engage with these frameworks and do not confine my core arguments to the perspectives that have been developed through such frameworks. My main arguments and propositions emerge from the data using an inductive approach, and some of those arguments contribute to the furthering of how we apply bio-ecological metaphors and utilize an ecological perspective to understand organizations.

\section{Development of propositions}

I employ an inductive approach to understand and examine the ways bio-ecological metaphors can be applied to study the Enspiral ecosystem. An inductive approach allows for generalizable theories and models to emerge through research, where theory is the outcome of research (Bryman, 2012). I chose an inductive approach to research because it permits unfiltered insights to emerge from the phenomena I observe at Enspiral. Weick (1989) and Morgan (2011) posit that reductionist empirical methods tend to filter out innovative metaphors that can generate useful insights. Weick (1989) further argues, "to build better theory, theorists have to 'think better'" (p. 529), and we must lay foundations of thinking imaginatively to set the stage for theory to emerge. I find an inductive approach facilitates imaginative thinking because it enables data-driven models to emerge instead of fitting existing frameworks to understand phenomena. 
My research aims to answer, what characteristics influence the interactions and interrelatedness within entrepreneurial ecosystems? I approach this question by first examining what form interaction takes when using an ecosystem lens and how they may be studied. The data suggest that interactions take many forms and are constantly happening within the ecosystem; interactions constitute a great degree of what the ecosystem truly is about. To analyze such interactions, I use the lens of exchange because it provides a variable that can encompass most if not all forms of interactions observed in this case study. Exchange is a variable that is used in bio-ecology to understand activities taking place within natural ecosystems (Begon, Townsend \& Harper, 2009). This includes the way plants, animals, birds, and other living and non-living beings in a natural environment are constantly exchanging matter and energy. Water, different forms of nutrients, shelter, and food are examples of what is exchanged. When applied in the Enspiral case study, I look at the exchange of knowledge, skills, resources, energy and emotional support. Since my primary unit of analysis is the ecosystem, I focus on exchange activities within the ecosystem instead of studying exchange as a transaction between two entities.

Using the lens of exchange, I analyze the key characteristics of the ecosystem that influence the level of interactions taking place. Through the inductive analyses approach (Thomas, 2006), I synthesize my observations to identify three main characteristics that influence the levels of exchange activities. Below I outline three propositions: 
1) Ecosystems facilitate interdependence between organizations, and greater degrees of interdependence allow increased level of exchange activities.

2) Diversity within an ecosystem fuels an internal economy, facilitates more innovation, and allows for access to resources, knowledge, and talent, and as such it enables for more exchange activities to take place.

3) Organizational births and deaths in ecosystems augment exchange activities by composting, recycling and/or repurposing knowledge, resources, talent, organizational infrastructures, and different forms of access.

I further develop each of these propositions later in this thesis and provide data to indicate how the characteristics of interdependence, diversity, and birth and death lifecycles influence the interactions and also enhance the interrelations within the Enspiral ecosystem. Figure 1 shows a chart that summarizes these relationships.

Figure 1: Ecosystems and characteristics that influence exchange activities

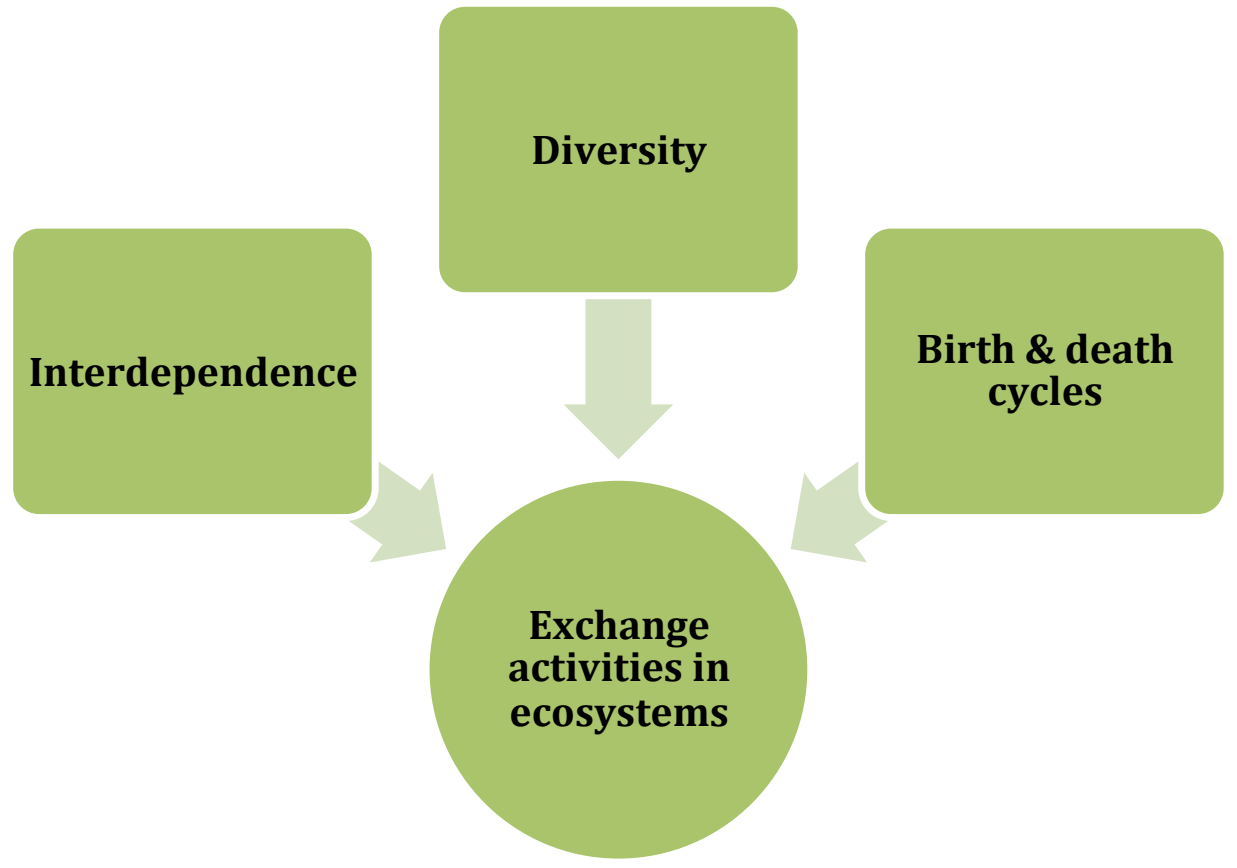




\section{Intended contributions}

There are several ways my research can contribute to our understanding of organizations, both for future academic conversations and for management practitioners.

First, the development and application of an ecosystem lens can influence our understanding and management of organizations. An ecosystem lens zooms out from the focus on organizations and places it on collectives of organizations. It includes the environment as part of the ecosystem rather than an external force that organizations are in struggle with. Such a lens sees beyond the birth, growth, and decline of an organization. It allows us to also observe how organizations can co-exist and create a healthy ecosystem; the attention can shift from how well an individual organization can achieve its goals to how organizations can co-create value for the ecosystem. Changing that lens can alter the emphasis from how to ensure health and prosperity of an organization to how to ensure health and prosperity of the whole ecosystem. It places less attention on the survival of the fittest approach (that of continuous struggle for survival) to nurturing an ecosystem to become more vibrant. An ecosystem lens allows us to observe and better understand the collaborative aspects of organizations (Morgan, 2006; Patterson, 2004; Hawley, 1986). The ecosystem unit of analysis builds on the existing three units (organization, population, and community) within organizational ecology and can contribute to further research in this field. 
By studying exchange activities in ecosystems, the phrase of "the whole is greater than the sum of its parts' becomes relevant because it encapsulates different forms of value that is exchanged but not directly accounted for by individual organizations. We can generate insights on value created through exchange activities in the ecosystem, beyond just the sum of the quantifiable value individual organizations extract from the ecosystem.

Second, by shedding light on the aspects of an entrepreneurial ecosystem that influence the exchange activities, my thesis helps identify focus areas for stakeholders who are attempting to improve health of existing ecosystems or facilitate the formation of new ones. There are city planners, national governments, and entrepreneurial visionaries who are attempting to create entrepreneurial ecosystems around the world. Examples of existing efforts include Enspiral, Grow Wellington, ${ }^{4}$ the Irish Department of Jobs, Enterprise and Innovation, ${ }^{5}$ Downtown Vegas, ${ }^{6}$ Summit, ${ }^{7}$ Start-up Chile, ${ }^{8}$ and Sandbox. ${ }^{9}$ These are some of the multi-million and multi-billion dollar projects that are attempting to engineer a rise for entrepreneurial ecosystems in their specific locations, with the goal of boosting economic activities, facilitating innovation, and becoming global hubs for entrepreneurs. On smaller scales, startup incubators and accelerators all around the world attempt to create healthier entrepreneurial ecosystems by bringing together talented individuals.

\footnotetext{
${ }^{4}$ http://www.growwellington.co.nz

5 http://www.djei.ie

${ }^{6}$ http://downtownproject.com

7 http://www.summit.co

8 http://startupchile.org

${ }^{9}$ https://www.sandbox.is
} 
They provide entrepreneurs with financial, organizational, and social infrastructures aiming to facilitate greater levels of innovation and collaboration. Similar targeted initiatives can benefit from the study of how other ecosystems operate and from insights on factors that influence interactions in those ecosystems.

\section{Thesis roadmap}

I have organized this thesis in a slightly unconventional format, primarily to reflect the inductive approach to my study of Enspiral. I started this research by first understanding the distinctive characteristics observed at Enspiral, and took time to immerse myself in the ecosystem. Therefore, I used aspects of the data I collected to develop frameworks to analyze it with - similar to the way metaphors help generate theory that is then applied in research (Morgan, 2006; McCourt, 1997; Palmer \& Lundberg, 1995). Theoretical frameworks from past research helped make sense of my analyses and locate my work in existing academic conversations, as is true in the nature of inductive research (Thomas, 2006).

In Chapter I, I present the research method used to conduct this research. I discuss how I employed an inductive study approach to this research and the thought process behind it. I explain how I adopt a qualitative micro-ethnographic method and a case study strategy. I describe how I collect data through semi-structured interviews, participant observation, and archival data, all of which help triangulate my data enhancing consistency and accuracy 
in my findings (Yin, 2005). I then articulate the inductive data analyses process I chose to use, including how I coded and categorized transcribed interviews, field notes, and other documentations. I then present the limitations of my method, highlighting biases, and other obstacles to generalizations that can be made based on my findings.

In Chapter II, I set the stage for why and how I focus on the Enspiral case. I describe the Enspiral case study and the distinct characteristics that compelled me to study for this research. Here, I provide a brief account of the founding story. I synthesize the organizational, legal, financial, and social structures that exist at Enspiral and their relevance in the ecosystem.

In Chapter III, I review academic conversations that have applied bioecological metaphors to study organizations. In the beginning of this chapter, I illustrate what metaphors are and how they can be applied to better understand complex phenomena in organizations. In the first section of this chapter, I present discussions from the organizational ecology field. Here, I deliberate the different ways bio-ecological metaphors have been applied to study the organization-to-environment relationships and how varying interpretations of nature have influenced these applications. I emphasize the importance of the unit of analysis used in this field of research, and present the three main units adopted amongst organizational ecologists. I discuss how the main focus in organizational ecology is vitality rates, while my thesis is concerned with patterns of interactions and interrelations. In the second part 
of this chapter, I review literature on open-system theory and the way it is used to study interactions amongst organizations. I further present literature on the exchange framework that I then use to understand interactions and interrelations in complex systems. Lastly, I develop an ecosystem unit of analysis based on research from organizational ecologists and open-system theorists.

In Chapter IV, I analyze the Enspiral case study by adopting an ecosystem unit of analysis. I use exchange as a variable to analyze patterns of interactions and interrelations within the Enspiral ecosystem. I identify the main exchange activities observed through this research, and discuss the characteristics of the ecosystem that influence exchange activities. I highlight how the three characteristics (interdependence, diversity, and birth and death cycles) can augment the levels of exchange activities in the ecosystem.

I conclude the thesis by offering a discussion on how the way we use metaphors can lead to varying conclusions. I distinguish the ecosystem metaphor I use in this thesis from those applied by organizational ecologists. In doing so, I point out the key contributions my thesis can make to academic conversations and to the practice of management. I then suggest additional research to further develop our understanding of entrepreneurial ecosystems. 


\section{Introduction}

I begin this chapter by describing the evolution of my thesis explaining the process through which I chose to study Enspiral. I discuss how I arrived at the research question my thesis attempts to answer. I present the research method I used to collect, analyze, and synthesize data and develop the three propositions I present in this thesis.

I adopted a qualitative micro-ethnographic method and used a case study strategy. I collected data through semi-structured interviews, participant observation, and archival data. I then used a general inductive process of data analyses to develop propositions based on findings. My research design also employed an inductive approach, which I explain in the first part of this chapter. The research method I utilized allowed me to synthesize the rich data I collected during the nine months of research.

\section{Research design}

\section{Inductive process}

I take an inductive approach to the way I design the research, create a focus for a research question, collect and analyze data, and develop propositions based on findings (Bryman, 2012; Bloor, 1978). At the beginning of this research I identified interesting and complex phenomena taking place at 
Enspiral and oriented my research design to help untangle those complexities. My approach to this research and the method I utilized are influenced by the need to capture, analyze, and articulate the complexities of the case in question. I began my research design by asking, what is the best approach to capture the complex characteristics of this startup ecosystem and generate useful insights to researchers and practitioners? This approach influenced my decisions on the research method, research scope, data collection, analysis, and reporting. In the following paragraphs, I provide an account on how and why I chose my research method.

\section{Developing my research method}

I commenced this research after my first exposure to Enspiral in February 2013. During my initial engagements with Enspiral, I started noticing some of the ways the community of startups facilitates highly collaborative interactions. Observing how the founding members frame Enspiral as an experiment, and learning how they intend to design an "organization of the future" made them a fascinating group to research. At the beginning of my research, I began tuning into the ways individuals at Enspiral use ecological metaphors to describe and inform how their ecosystem operates. Such observations helped build a connection between the ecosystem of organizations that Enspiral was developing and the ecological metaphors many at Enspiral refer to. 
Several characteristics of Enspiral stood out as worthy of further academic inquiry. When I first engaged with Enspiral, I noticed a great level of commitment to building an ecosystem of organizations while having those organizations operate as independent businesses. Enspiral members take social concepts such as democracy, citizenship, freedom, and trust and apply them to the way organizations build communities around themselves. During the time of my research, Enspiral was mostly attracting highly entrepreneurial individuals. These people often work on several startups, and come from diverse backgrounds. I became interested in investigating the types of relationships and interactions that are taking place between the startups, and the ways the startups formed an ecosystem that supports them. Their approach to collaboration and why they value it while operating in the business world further motivated me to study Enspiral. The pace at which individuals change their roles, the regular ways startups pivot from their original models, and the continuous evolution of the organizational structures within Enspiral made it a fascinating case to study. Enspiral also has very little hierarchical management. It is experimenting with different ways to create distributed ownership and decision-making models to operate the ecosystem. All these points and more made Enspiral an interesting case to study (Stake, 2000, 2005, 2008; Yin, 1984).

What I soon realized is that it was hard to take one of these concepts and study them in isolation. To untangle the complexities of concepts such as collaboration, cooperation, and formations of ecosystems, it became necessary 
to study them all together and also to look at the ways those concepts relate to each another. It became clear that beginning an academic inquiry with a narrow lens was not going to do justice to the ideas and lessons that could potentially emerge from studying Enspiral. I decided to adopt a qualitative empirical research method (Bryman, 2012) to uncover interesting and complex phenomena when organizations collectively operate as an ecosystem. Such a method allowed me to do an in-depth analysis of Enspiral. It enabled me to understand the complex relationships and interactions between the different organizations that exist within Enspiral, understand the internal and external forces in play, and understand the ecosystem's development over time.

\section{Micro-ethnography}

I adopted a qualitative micro-ethnography research method (Wolcott, 1990). I embedded myself into the Enspiral ecosystem as a participant-asobserver in an attempt to collect rich data (Bryman, 2012). This was because the nature of Enspiral as a non-hierarchical and continuously evolving ecosystem made it rather difficult to study from outside. For example, there isn't a point person who manages the activities at Enspiral who could tell me what was happening in all parts of the ecosystem at a given point. Some individuals were able to give me overviews of major activities that were going on at specific times, or I could get historical narratives on certain aspects of the ecosystem. But to understand the relationships between different organizations, to conceptualize what Enspiral means and the value it adds to the startups that participate in it, I had to spend significant amount of time 
speaking to the different teams within the ecosystem. Even then, when I asked, "What is Enspiral, and what does it mean to you?" the most common answer I received from Enspiral participants is along the line: "It depends who you are talking to, and the answer you will get will be different each time you ask that question." Every startup and entrepreneur that is part of the Enspiral has a unique experience and relationship with the ecosystem, and that relationship evolves over time - this seems implicitly expected in the ecosystem. Therefore, to capture the nature of relationships and interactions different entities had with the ecosystem, adopting a qualitative research method, becoming a participant and observing those interactions from the inside was ideal (Jorgensen, 1989).

Furthermore, Enspiral operates in an organic and dynamic way. Few individuals have a large sway over the whole ecosystem and there is little centralization of power and control. There is continuous flow of individuals in and out of Enspiral, the focus of energy within the ecosystem changes constantly, and individual organizations are at different parts of their lifecycles. New initiatives are being created and others do fade away in short periods of time. The Enspiral retreats that are held every six months tend to be quite different from each other, with new faces and different focus and areas that draw the ecosystem's energy. Therefore, in order to achieve a greater level of depth in my study and analysis of the whole ecosystem, it became necessary to embed myself within the ecosystem, become part of it, and experience it as a participant. As a result, I pursued an ethnographic research method. I 
immersed myself within the ecosystem, became part of Enspiral and started participating in online conversations, working from the shared office, joining work-related and social activities and events, and at times participating in meetings about aspects that affected the Enspiral ecosystem.

I chose a micro-ethnography approach (Wolcott, 1990). I spent approximately nine months doing ethnographic research. Nine months seemed relatively long within the Enspiral context because the Enspiral ecosystem had been around for just over 3 years when I started this research. The set of activities and phenomena I was interested in were quite diverse so I focused my study on only a few aspects of the ecosystem during the time of my research, namely organizational interactions and interrelations. Focusing on particular phenomena taking place in this case study qualified my research approach as micro-ethnography (Wolcott, 1990). In addition, the time I was able to spend at Enspiral was limited and my integration into the team was partial. Unlike many other entrepreneurs I could not be a full-time entrepreneur working five or more days a week from the Enspiral office. I wasn't able to commit full-time to one of the Enspiral startups. I worked on my own projects that occasionally allowed me to engage professionally with various individuals and companies within the ecosystem but this was a rare. One such example is when I was looking to hire a team to build a website for a personal project I engaged a few contracting companies at Enspiral that do web design and development. While I did not end up contracting any of the Enspiral companies, it was one of the few experiences when I engaged with the 
ecosystem through a work context. Therefore, a micro-ethnography approach was most suitable for this research.

Through my research approach, I took the role of participant-asobserver (Bryman, 2012). This role entails participating in a group's main activities but not as a full member (Bryman, 2012). Members of Enspiral knew my role as a researcher while I infiltrated the social setting of the ecosystem. I was treated as other entrepreneurs were treated within the ecosystem. I was continuously invited to events and social gatherings, asked to participate in activities, and given privileges that others had.

At the beginning of my research, I sought permission to conduct participant observation from the founder and board member at Enspiral. I provided a formal letter to be circulated to the entire community asking for permission to conduct this research, and explicitly stating that I would be doing participant observation (See Appendix A for the letter submitted to Enspiral) Following approval, it was not challenging to physically embed myself in the ecosystem because the Enspiral shared office rents desk space to entrepreneurs and individuals looking to work in such a setting. I rented a temporary desk at the Enspiral office and worked there two to three days a week alongside various other startups. I also used the conference room facilities to conduct most of my interviews. 
Embedding myself into the communication structures was not challenging either because of the openness and welcoming approach of the community. I was quickly added to the Yammer ${ }^{10}$ closed group where over 100 entrepreneurs in the ecosystem participated in different forms of conversations. I was also invited to the Loomio ${ }^{11}$ group for the open network once I rented a desk. I discuss more on how I collected data as an observer in the data collection section.

There are important ethical considerations when conducting ethnographic research (Tedlock, 1991). While I operated as an overt participant observer (Bryman, 2012) and individuals involved recognized that I was researching Enspiral, they didn't necessarily identify me as a researcher first in every interaction we had. The trust and relationships I built during the time I spent at Enspiral and the way I integrated within the group quickly made me more of an 'insider.' Enspiral entrepreneurs considered me one of them. They were not necessarily filtering all the information they shared with me with the assumption that everything I learned could potentially be publicized in my research. For example, some individuals I had established a level of trust and good rapport with came to me and shared privately some of their challenges, frustrations, interpersonal conflicts, and other business activities they were dealing with. The approach I took here was to uphold the trust I established with various individuals and not compromise it. The details of

\footnotetext{
${ }^{10}$ www.yammer.com

${ }^{11}$ Loomio (www.loomio.org) is a company established within the Enspiral ecosystem. It is a web application that allows people to make decisions collaboratively. It emerged from the Wellington Occupy movement, and it is now a product that organizations and different types of companies can use.
} 
many of the private conversations were relevant only in those specific contexts, but the meta observations on how individuals and their startups interacted with one another, the way individuals handled conflict, the form of relationships they established and ways those relationships changed were all relevant to my research. My approach to such instances was to take insights from what I was learning as a participant observer and create space to discuss some of those issues during the interviews I conducted. I decided what specific examples to bring up during interviews and which ones to speak about more

generally. I made those decisions on a case-by-case basis with the goal of maintaining trust and not compromising the confidentiality of research subjects. I then used data from interviews directly in this thesis. Building and maintaining trust was critical to ensure that I continued to be an 'insider' and get deeper insights into how interactions and interrelations took place at Enspiral.

\section{Case study strategy}

A case study strategy was ideal for my micro-ethnographic research because it allowed me to conduct a holistic study of a bounded ecosystem (Merriam, 1998). Using this strategy, I was able to extract rich and significant insights into behaviors and events observed at Enspiral (Yin, 1984). Those insights may not necessarily be generalized to other situations, but can increase our understanding of particular phenomena (Yin, 1994, 1984; Stake, 1994, 1995). An empirical inquiry that utilizes the case study strategy investigates a "contemporary phenomenon in depth and within its real-life context, especially 
when the boundaries between phenomenon and context are not clearly evident" (Yin 1999, p. 18). Such a strategy allowed me to investigate the types of relationships and interactions within Enspiral and in doing so I was able to place the concepts I was studying in their appropriate contexts.

The nature of my inquiry made it necessary to take a holistic approach that allowed for a comprehensive understanding of the types of interactions and interrelations in play within an organizational ecosystem. A case study strategy allowed me to take a holistic view and explain complex situations (Merriam, 1998). A study of one case offered a level of depth in understanding and analyzing the various phenomena that were taking place, many of which are interconnected. As Stake (1994) articulates, "the purpose of case study is not to represent the world, but to represent the case. [...] the utility of case research to practitioners and policy makers is in its extension of experience" (p. 245). This approach provided a method to generate insights from complex interrelated phenomena. Findings from my work may be applied to other case studies in future research.

\section{Unit of analysis}

After deciding that a case study strategy was the most appropriate for this research, I elected to study the whole Enspiral ecosystem as my primary unit of analysis. I discuss how I develop and apply this unit of analysis at the end of Chapter III. While I was learning the ins and outs of the Enspiral ecosystem, what stood out the most were not necessarily the individual startup 
organizations but rather how those startups interact and relate to one another while existing within a bounded ecosystem. Studying Enspiral as a whole meant that I had to understand the individual startups and the entrepreneurs behind those startups that make up the whole ecosystem. However my inquiry focuses on how those players interact with everything else going on at Enspiral and the ecosystem as a whole. This was an act of demarcating a boundary of what I was going to study and what I was not going to study (Merriam, 1998).

In summary, a qualitative micro-ethnographic research method permitted a holistic study of the complex phenomena I found fascinating about Enspiral (Bryman, 2012; Hammersley \& Atkinson, 2007; Tedlock, 1991). This method enabled me to circumvent various challenges I would have faced studying Enspiral as an outsider and to overcome the data limitations I might have experienced while attempting to gain a holistic understanding of the whole ecosystem. A case study strategy was ideal to focus my research on a bounded system and study it as a single unit (Merriam, 1998). Below, I discuss the methods I employed to collect and analyze data from this research.

\section{Data collection}

I collected data using different methods, with the intention to triangulate data and search for consistency and cohesiveness in the data I was gathering (Yin, 2005; Denzin, 1970; Webb et al., 1966). By using more than one source of data to study social phenomena, I was able to cross-reference the data to maintain a chain of evidence, fill gaps in my data, compare and contrast 
different accounts, and study Enspiral from different angles. The triangulation approach of collecting data permitted me to use multiple sources of evidence (Yin, 1984). Ergo, the three ways I collected data are semi-structured interviews, participant observation, and archival data. I discuss each of them below.

\section{Interviews}

I chose the interview method as one of the primary means of data collection because it allowed Enspiral members to share undocumented information about Enspiral as an ecosystem, how it operates, and their individual and startup involvement (Rubin \& Rubin, 2012; O'Leary, 2010). Moreover, such a method permitted the entrepreneurs to provide their accounts about the nature of their relationship with Enspiral, the rationale behind their startups' involvement, their dynamics when engaging with other organizations, and their general reflections on the whole ecosystem (Bryman, 2012).

Semi-structured interviews allowed for more open-ended questions to be asked, and for conversations to flow naturally between the interviewees and myself (O'Leary, 2010; Wengraf, 2001). This was well suited to the inductive approach I employed. Semi-structured interviews also provided a less intimidating setting for the interviewees to engage with my research $\left(\mathrm{O}^{\prime}\right.$ Leary, 2010). This was important because those participating in Enspiral treated me like one of them (Bryman, 2012) and it was necessary to maintain good rapport 
and remain an 'insider' to retain trust with all research subjects. This trust made it even more possible to gather richer data. Semi-structured interviews also permitted interviewees to point out issues not solicited from the questions I posed (Bryman, 2012). This was important because it allowed different phenomena that I wasn't actively searching for to emerge.

I conducted 21 semi-structured interviews with 20 individuals, 18 of whom were from Enspiral. This was around 20\% of all the entrepreneurs in the entire Enspiral ecosystem during the time of the research, comprising core members, collaborators, and friends. The Enspiral ecosystem had 33 core members (at the time this research was conducted) who serve as stewards of the ecosystem, and out of the 20 I interviewed, 15 of them were Enspiral core members. The two non-Enspiral based interviewees were individuals from external governmental and non-governmental organizations that offered a different perspective on the way Enspiral operates. (See Appendix B for a list of all interviewees and organizations they represented). These interviews took place during a five-month period of time. The time gap gave me time to digest and analyze each interview, compare it with field notes from participant observations, and develop key themes from the phenomena being observed.

Each interview lasted anywhere between 60 and 120 minutes. I interviewed the founder of Enspiral twice, where one interview took place at the beginning of my research and the other took place close to end of my interview cycle. Each interviewee was given an information sheet (See 
Appendix C) and asked to sign a consent form (See Appendix D). Interviewees had the option to withdraw from the research anytime up until October 30, 2013. No interviewee withdrew. All interviews were recorded and transcribed verbatim.

\section{Recruiting interviewees}

I utilized purposeful sampling when choosing the individuals to interview. Interviewees were recruited to represent a cross-section of perspectives (Bryman, 2012). I made the selection based on levels of involvement, length of involvement, representation of organizations, and on the potential diversity of insights they could offer into how interactions take place within the ecosystem. I tried to maximize for diversity of perspectives from interview data in order to build a more comprehensive case description (Bryman, 2012). Spending about a month as a participant observer and getting to know the various individuals involved with Enspiral, embedding myself in the community, and participating in online conversations helped me develop an initial list of potential interview recruits. I was also lucky that right when I started my research, Enspiral was holding its bi-annual retreat, where about 25 individuals spent three days talking about the state of the ecosystem, challenges they were facing, areas they saw the ecosystem moving towards, and undertaking a 360-degree overview of the health of Enspiral. Attending this retreat allowed me to quickly immerse myself into the community, observe the different perspectives, and develop a list of people to interview. I also recruited interviewees based on other interviewees' recommendations. For 
example, when I asked about the online collaborative budgeting system, several interviewees suggested I speak to the person who was involved in designing it. Or when interviewees provided their perspective on a specific phenomenon such as competition amongst Enspiral companies, many interviewees recommended that I also speak to a list of specific individuals to get opposing perspectives.

There is an inherent bias in both recruitment strategies that is worth acknowledging. The first approach heavily relied on my discretion and understanding of individuals and their potential contributions to my thesis, while the latter approach relied on the interviewees' perspectives, their knowledge of other individuals within the ecosystem, and also their own biases (O’Leary, 2010). However, during the time I studied Enspiral, I interacted with more than $90 \%$ of the entire network at different capacities. In each conversation I had with them, I assessed the possibility of recruiting them for an interview. Luckily no one turned down an interview request. While I accept that personal biases are present in the recruitment process, I utilized a purposeful sampling process to represent as much of the diversity that existed within the Enspiral ecosystem as possible (O'Leary, 2010). As such, I reduced the chances of having my findings heavily skewed by a small portion of the ecosystem. 


\section{Interview guide}

A general interview guide was used to obtain responses to certain issues from all interviewees. Questions were also tailored to extract useful information from each individual according to his/her role and involvement in the ecosystem (Bryman, 2012; O'Leary, 2010). (Appendix E includes a general interview protocol used in this research). Each interview was slightly different from the others due to the fact that interviewees were recruited to maximize diversity of perspective. However, all interviews shared a similarity in the way they were structured.

My interview guide had three main parts to it. The first part focused on the background of the individual being interviewed. This aimed to understand why and how that interviewee became involved with Enspiral. This was important because the organizations that make up the Enspiral ecosystem heavily depend on the individuals behind them. Being an ecosystem of startups that are less than five years old, and due to the fact that each organization's team range between one and nine full-time team members, individuals have a great impact on the ways organizations interact with one another. Therefore, it was important to understand the people behind the organizations and the whole ecosystem.

The second part of the interview focused on the organization-toecosystem relationship. It attempted to capture the way the interviewee's 
organization participated in the ecosystem, interacted with other organizations, and benefited from being part of Enspiral.

The third part focused on one or two specific themes relating to the way interactions take place at Enspiral. The themes I focused on varied in each interview. I chose the themes to discuss with an interviewee based on their previous experience with that theme, formal/informal level of involvement with supporting the ecosystem in direct relation to that theme, or when they had their own perspective on how that theme impacted the whole ecosystem. For example, some of the themes discussed include how collaboration takes place between organizations, how organizations balance between meeting their own needs and meeting the needs of the ecosystem, how and why specific communication infrastructures were being built, instances of competition between Enspiral companies, how the decline and death of organizations takes place within Enspiral, the significance of ecological metaphors to Enspiral, and how non-hierarchical management model is implemented in the ecosystem.

Many of the interview questions were purposely kept open-ended (Bryman, 2012) and allowed the interviewees to focus on aspects of their relationship with the ecosystem that were most relevant and important to them. Yet, I had pointed questions that focused on specific issues or examples (Bryman, 2012). I also provided an opportunity for interviewees to share any information and experiences that I did not ask them about. This allowed for interesting and unanticipated insights to emerge in unplanned manners. 
In summary, semi-structured interviewed provided an avenue to collect rich data in a way that I was able to examine Enspiral more holistically. Purposeful sampling process and a semi-structured and flexible interview guide allowed me to collect diverse sets of data and get a more comprehensive understanding of how interactions take place within Enspiral (O'Leary, 2010). Below I discuss how I utilized participant observation as another primary source of data.

\section{Participant observation}

In the above sections, I touched upon how I embedded myself as a participant and 'insider' within the Enspiral ecosystem, discussed the benefits and even the necessity of such an approach, and how micro-ethnography was an important aspect of my research design (Wolcott, 1990). Below, I briefly describe some of the specifics on how I conducted participant observation and collected data (Jorgensen, 1989). I adopted a participant observation method of data collection through the following activities:

- I physically situated myself in the main shared office space at Enspiral,

- I participated in and observed online communications within the ecosystem,

- I joined in conversations and meetings about the well-being of the Enspiral ecosystem and individual organizations, and

- I attended Enspiral social and work-related events during the time of my research. 
I rented a desk at the Enspiral shared office and on average I spent 2-3 days a week there conducting participant observation from the beginning of June 2013 until the end of February 2014. I intentionally interacted with several individuals working from that office each day I went to the Enspiral office, catching up with them on the projects they were working on, ideas and concepts they were excited about, and challenges they were facing. Being present in the office and maintaining physical proximity over the nine months allowed me to observe changes that were taking place, I was able to understand the different types of roles individuals played, and witness interactions between individuals from different organizations including noticing who spends more time with who. As such, I got a more holistic view of the way Enspiral operates.

A large part of the interactions and communications within Enspiral takes place through the online platforms. Part of my participant observation has involved following many of the online communications. I observed general conversations that took place in the Yammer and Google +12 closed groups. I also followed discussions on Loomio that resulted in collaborative decisions on areas that impact the entire ecosystem. These tools provided a platform for participants in the ecosystem to cross-pollinate their ideas, discuss issues that influence their activities, and make decisions that affect the ecosystem. Having

12 https://plus.google.com 
access to these tools offered very useful data that I collected and stored for further analysis.

I had opportunities to participate in and observe various types of conversations members of Enspiral held to discuss matters that impacted the entire ecosystem. While many of these conversations took place online through their closed platforms, attending in-person meetings provided a greater level of depth on the conversations and issues that were of concern in those particular times. The types of conversations I observed include fundraising and planning for new office space, work-related contracts, strategies to raise investments for various ventures, discussions on the state of the Enspiral network and what it means to those who are part of it, and various new initiatives that were being incubated within the group. In addition I had dozens of one-on-one meetings with people from the different startups to discuss projects and initiatives they were working on, challenges they were facing, strategies they were developing, and teams they were building. These conversations offered even greater levels of depth that helped me understand the ins and outs of the different startups and the way they relate to the entire ecosystem.

I also had opportunities to attend and observe different types of events that were organized under the Enspiral name. Some of these events were open to the public, and they allowed me to observe how outside individuals engaged with the ecosystem and viewed. Attending those events also allowed me to witness the ways in which organizations and individuals from Enspiral identify 
themselves with the ecosystem. Some of these events include new product launch parties, startup anniversary celebrations, networking events Enspiral hosts on a regular basis, presentations certain Enspiral companies were making to government officials and industry players, and large conferences organized by Enspiral companies. These events had anywhere from 30 to 400 participants, and provided a wide range of contexts in which I could observe Enspiral organizations interfacing with the outside world. I also attended more private events, including bi-annual retreats, regular dinner parties, group expeditions, and story sharing circles. These private events allowed me to know Enspiral members more at an individual level, establish greater levels of trust with them, and observe how they interact in more social settings. It was fascinating to observe how often work-related conversations were taking place in social settings. I noticed how in such situations, individuals were more open to speak their minds and be a lot more honest. In situations when the line between pure participant and researcher blurred, I chose to maintain the participant hat and maintain the trust established between the research subjects and myself.

I kept field notes to document the phenomena I was observing as a participant observer. The purpose of the field notes was to capture insights and document specific experiences that highlighted aspects of Enspiral that may be relevant to my research. During my experience as a participant observer, I noticed many interesting phenomena taking place, but considering the focus of my research I did not necessarily document everything that I was 
observing. Since I spaced out my interviews over a five-month period of time, I was able to direct various interview conversations based on phenomena I was observing as a participant. That allowed for greater triangulation of the data I collected. Most of the field notes I maintained were in the form of diagrams, mind-maps and other forms of visual representation that helped articulate and draw links between the key phenomena I was observing. Considering the vast amount of information I was absorbing on a regular basis as a participant observer, these forms of note taking allowed me to synthesize key themes and continuously build on them.

In summary, participant observation was one of the primary forms of data collection along with in-depth and semi-structured interviews. These two approaches were complimentary and provided me a wealth of data to analyze and develop a model on the forms of interactions and interrelations that exist within the Enspiral ecosystem. Below, I discuss the third approach I employed to collect data.

\section{Archival data}

When I started my study I learned that there was limited documentation that was taking place within the Enspiral ecosystem and getting access to that documentation was challenging. There were few official contracts, formal agreements, memos, work descriptions, reports, minutes from meetings, and other documents that were readily available to me in a centralized place. Some 
archival data (Berg \& Lune, 2004) however became quite useful in this research.

The documents that I had access to were useful for fact checking, but were less relevant when trying to understand the ways organizations interact with one another and the rest of the ecosystem. Beyond such formal documents, the historical records of the communications and discussions on Yammer and Loomio were very useful when cross-referencing the information I was getting through interviews and observation. Therefore, archival data complimented the wealth of data I was collecting through interviews and observation (Bryman, 2012; Berg \& Lune, 2004). The three methods enabled me to study Enspiral from different angles, capture useful insights, and develop a set of propositions (Yin, 2005). In the section below, I discuss how I analyzed my data.

\section{Data analyses}

\section{Inductive analysis}

I chose a general inductive approach as my primary method to analyze data from this research. Thomas (2006) explains:

The primary purpose of the inductive approach is to allow research findings to emerge from the frequent, dominant or significant themes inherent in raw data, without the restraints imposed by structured methodologies. Key themes are often obscured, reframed or left invisible because of the preconceptions in the data collection and data analysis procedures imposed by 
deductive data analysis such as those used in experimental and hypothesis testing research. (p. 238)

A general inductive approach is one that is not constricted by traditional approaches such as grounded theory (Strauss \& Corbin, 1994), phenomenology (e.g., van Manen, 1990), discourse analysis (e.g., Potter \& Wetherall, 1994) and narrative analysis (e.g., Leiblich, 1998). Instead, an inductive approach can be generic (Thomas, 2006) and is applied in much qualitative data analyses in its generic form (Bryman \& Burgess, 1994; Dey, 1993).

A general inductive approach to analysis was most appropriate because I was not proving/disproving existing theories or arguments, but rather aiming to develop a set of propositions that identify the main characteristics of ecosystems influencing the levels of interactions and relations taking place within them (Thomas, 2006; Znaniecki, 1934; Robinson, 1951). Such an approach ensured that obscure themes were not left invisible, and it allowed for concepts to emerge from the raw data without limiting my inquiry to existing conceptualizations (Angell, 1954). Thomas (2006) lists the goal of a general inductive approach in the following way:

1. To condense extensive and varied raw text data into a brief, summary format.

2. To establish clear links between the research objectives and the summary findings derived from the raw data and to ensure these links are both transparent (able to be demonstrated to others) and defensible (justifiable given the objectives of the research).

3. To develop a model or theory about the underlying structure of experiences or processes which are evident in the text (raw data). (p. 238) 


\section{Inductive coding process}

Once I had compiled 21 transcribed interviews, a set of field notes from observations, and some archival documents, I used a systematic procedure of inductive coding as outlined by Dey (1993) and Thomas (2006). Below is the process I adopted (also see Figure 2 for a table that further clarifies this process):

- I developed an initial approach to segment data from notes taken during interviews and participant observation. The broad segments that I created at this stage were:

○ explanations for why individuals and organizations participate in Enspiral,

$\circ$ how organizations co-exist and interact with one another within a bounded ecosystem,

○ what activities are taking place within Enspiral, and

$\circ$ what internal and external forces influence the continued existence of Enspiral.

- In the second phase I read the transcribed interviews, field notes, and archival documents. While reading this data I highlighted quotes, certain themes that were developing patterns, and insights that I found relevant to my research objective. I placed these into the broad segments that I had created earlier.

- I created multiple categories within each segment and arranged data into those categories. For example, for the "why join Enspiral" segment, 
I separated the data into push forces and pull forces sub-segments. For the pull forces sub-segment, earlier categories I created include Enspiral offered "freedom", a community of trust, diverse network, etc.

- I sketched dozens of mind-maps to organize and visualize the many categories that emerged from data. Mind-maps enabled me to experiment with ways to identify interesting patterns by grouping and ungrouping various categories, by creating new categories and collapsing others, and by experimenting with building relationships with different categories. I developed frames of associations between the categories, built relationships based on themes, and collapsed and consolidated themes that belonged together. Whenever I modified categories, I went back to the data that I had placed under each category and reorganized them accordingly. That data was in the form of quotes, notes, and in depth descriptions.

- I focused on the most important themes based on the direction of my research objectives, and developed frames of associations between them, including cause and effect associations. I formulated relationships between them, and brought in relevant categories that were left out during the process. I rearticulated categories that encompassed multiple associated themes.

- I developed a model based on four encompassing categories and created sub-themes that contributed to the understanding of those categories. The model I built looks at how interactions take place within the 
Enspiral ecosystem, and identifies three main characteristics that influence the level of interactions.

Figure 2: The coding process in inductive analysis

\begin{tabular}{|c|c|c|c|c|}
\hline $\begin{array}{c}\text { Initial read } \\
\text { through text } \\
\text { data }\end{array}$ & $\begin{array}{c}\text { Identify specific } \\
\text { segments of } \\
\text { information }\end{array}$ & $\begin{array}{c}\text { Label the } \\
\text { segments of } \\
\text { information to } \\
\text { create categories }\end{array}$ & $\begin{array}{c}\text { Reduce overlap } \\
\text { and redundancy } \\
\text { among the } \\
\text { categories }\end{array}$ & $\begin{array}{c}\text { Create a model } \\
\text { incorporating } \\
\text { most important } \\
\text { categories }\end{array}$ \\
\hline $\begin{array}{c}\text { Many pages of } \\
\text { text }\end{array}$ & $\begin{array}{c}\text { Many segments of } \\
\text { text }\end{array}$ & $30-40$ categories & $\begin{array}{c}15-20 \\
\text { categories }\end{array}$ & 3-8 categories \\
\hline
\end{tabular}

Thomas, 2003, Table 1, p. 6. Adapted from Creswell, 2002, Figure 9.4, p. 266.

The inductive coding process set few limits on concepts that could emerge from the raw data and it allowed me to ask what, when, where, why, and how as I identified concepts and attempted to establish relationships between them. It allowed pattern matching (Yin, 1984) where I identified patterns and developed explanations of these patterns using data.

When presenting the inductive coding approach I adopted, it is important to note where and how my literature review influenced the analysis process. From the beginning of the research, I was actively searching for different theoretical frameworks that can help explain the various phenomena I was observing at Enspiral. The majority of the segmentation and categorization processes took place independently of existing theoretical frameworks. Various literature sources I looked at did inform some of the thinking process when developing mind-maps and frames of associations 
between the themes I was working with. For example, literature on ecological metaphors influenced my thinking on ways I organized some categories and placed them together in biological terms. Theoretical frameworks from past research did come in to the equation once I had decided on the majority of the main categories and built frames of associations between them. At this stage, theoretical frameworks such as organizational ecology and open-system theory helped make sense of the ways the categories were framed, the types of thematic relationships that developed through the data analyses process, and the model that emerged from the association between the key categories. As such, the primary mode of analysis was the categorization of the raw data and the recognition of patterns and frameworks that captured the main themes. External theoretical frameworks were applied in making sense of the findings and reporting those findings.

\section{Research limitations}

There are several limitations in my research design and methodology. First, it is difficult to generalize findings from this research due to the fact that I am only using one case study to develop arguments on how we can better understand organizations (Stake, 1994). While the case study method is considered a strong strategy for research in the qualitative paradigm, its findings can rarely be generalized because of how the scope of the case study is bounded (Yin, 1981, 1984, 1994, 1999, 2005).

Case studies can however "contribute uniquely to our knowledge of 
individual, organizational, social, and political phenomena" (Yin, 1984, p. 14). The key findings from this research condense into propositions that can be tested in future research (Thomas, 2006). The propositions I develop may be furthered through a comparison with other case studies.

Second, the issue of subjectivity also arises when conducting qualitative research when employing an ethnographic method and using a general inductive approach to data analyses (O’Leary, 2010; Tedlock, 1991). My preexisting assumptions, biases, and ways I ask the questions impact the findings presented in this research (Thomas, 2006). Therefore, objectivity is not assumed. Tolich \& Davidson (1999) posit that when utilizing a qualitative case study method, "where you end up depends in a large measure on where you start" (p. 42). As a researcher, I do not divorce myself from the case study. The ethnographic method I employed embedded me deep in the ecosystem until I became an 'insider.' I assumed the role of identifying "coherence and sequence" of data (Stake 2005, p. 444) and formulate a model that best represents the patterns of experiences I studied. By immersing myself in the Enspiral community as a researcher I took the role of an interpreter (Stake $1995,2005,2008)$. As a researcher employing a qualitative case study method I continuously interpret what I observe through my ethnographic research, including the synchronization or lack thereof between the data I collect in this study. Also, much of the inductive analyses approach is highly influenced by the researcher, from how I interpret and code the raw data to the ways I categorize themes and develop associations (Thomas, 2006). As a matter of 
fact, Thomas (2006) posits that when utilizing an inductive analyses approach, it is very likely that another researcher who looks at the same data may end up producing different findings from the ones discussed in this thesis.

To augment the credibility of my findings, I performed stakeholder checks (Thomas, 2006) seeking feedback on the accuracy of the data I was using. The stakeholders I spoke to are mostly individuals within the Enspiral ecosystem. I took a number of approaches to accuracy checking. I had informal conversations with active participants in the ecosystem. I conducted a followup interview with the founder of Enspiral close to the end of my research to discuss some of the ideas that were emerging during my thesis. I also sought feedback on some of the findings from participants in the ecosystem and from individuals not affiliated with Enspiral but actively engaged. Due to the scope of my research, I was unable to employ an independent coder to go through the data and generate categories in order to compare those with mine.

Finally, while the methods I employ allowed me to take a more holistic view of the case study in question, it is not a completely holistic study of Enspiral. My research studied Enspiral only during a specified period of time, where I spent a couple of days a week in the shared office space, and interviewed a portion of the entrepreneurs who represent a selection of startups that participate. As a participant observer, I primarily focused on the part of the ecosystem that was physically present in Wellington, while the network spans organizations and individuals around the world. I was able to 
interact with many of these non-resident members through the online platform, but didn't have the level of regularity as the ways I interacted with those present in Wellington. I did not go to the Enspiral office every day and didn't get to engage with every single startup. My research also focuses on certain areas of the ecosystem and many others are intentionally and unintentionally left out due to the scope of my research. Because they are left out doesn't necessarily mean they have zero influence over the focus areas I discuss in this research. One of the main points made earlier in this thesis is how different observed phenomena relate to one another at different levels. However, I do not attempt to provide a comprehensive account, but rather take a selective approach in developing a case description and articulating findings.

\section{Conclusion}

The qualitative ethnographic method and a case study strategy I employed in this research enabled me to analyze complex phenomena in play when looking at Enspiral through an ecosystem lens. Such a method was appropriate to capture rich data from different angles and facilitate a holistic and comprehensive study of Enspiral. The general inductive approach to data analyses and the systematic coding process I utilized allowed for interesting themes and patterns to emerge from the raw data. As the main outcome of the research I develop propositions, and this thesis encapsulates the key findings. I propose a theoretical framework that can further shed light on the aspects of an organizational ecosystem that influence the levels of interactions and interrelations taking place within it. 


\section{Founding story}

Enspiral was first conceived in 2009 by Joshua Vial, an entrepreneur/programmer based in Wellington, New Zealand (J. Vial, personal communication, June 6,2013$)$. He was driven by a desire to contribute to solutions for large global issues, including poverty, climate change, education, water, and many other social and ecological issues. He quit his job and began doing high paying web development contract work two days a week so he could free up more time to work on things he was passionate about. He established Enspiral so that other people motivated by similar goals could also do high paid contract work for part of their time and use the rest of their time to work on "stuff that matters." Joshua believes that the fundamental challenges the world faces are obvious:

We do not need any new technology or new processes. There are bits and pieces to figure out, but fundamentally we know how to fix them, we just do not have enough people working on them and there is not enough human energy going into the biggest issues of our time. Enspiral is just helping turn that human energy into a river. That is the fundamental drive and I think that is still there today and I think the tag line that I most gel with for Enspiral is help people work on stuff that matters. That is the purpose of the network and we do not care what you work on, we do not care how you work on it, follow your skills, your passions, your opportunities, just spend your life doing something that makes a difference and that is how we started. (J. Vial, personal communication, June 6, 2013). 
In the early days of Enspiral, individuals were leaving salaried jobs, and Enspiral was helping them find contract work so that they could become financially self-sufficient. Most were programmers, and the agreement was that they would contribute $20 \%$ of their contract revenue to Enspiral. That money was used to cover administration expenses to run the network and cover overheads for the Business Development team that helped source contract jobs.

However between December 2009 and March 2010, as the group of people involved in Enspiral grew in numbers, ${ }^{13}$ they were prototyping what Enspiral could become. In 2010 and 2011 Enspiral began evolving into a place to experiment and do continuous research and development with the goal of creating new organizational models. Their intention became to model a "company of the future" as Joshua Vial put it, and to develop:

"a really different way of working, distributing work forces, networks, using [their] I.T. skills to organize substantially differently... decentralizing power throughout the organization so that individuals have money and control to run their own shows, but still providing enough organizing so that people can co-ordinate and facilitate discussion and collaboration."

Enspiral instituted non-hierarchical models of running the community where they aimed for a self-managing and self-supporting ecosystem. They began experimenting, making decisions collaboratively and building software tools and organizational processes to make collaboration easier and cheaper. Furthermore, Enspiral evolved from being a place where people came to find

${ }^{13}$ There were about 20 individuals involved with Enspiral by end of 2010 . 
work to a community where its network started becoming a strong value proposition. It offered a community of smart and talented people who wanted to build things together. New ventures and startups started emerging from within the community. Enspiral Accounting, Enspiral Legal, BuckyBox, Chalkle, and Loomio were some of the earlier startups that were founded within the ecosystem (see Appendix F for a list of all companies that are part of Enspiral). According to another member:

Enspiral was described as the nexus of these very bold revolutionary ideas that you could have an organization with no hierarchy, where everyone was very self-determined and self-motivating, that you could do work that was both meaningful and impactful and scalable and fundamentally change the way society operates.

2011 was a year when Enspiral built key infrastructures to get closer to that nexus.

\section{Legal structure}

Enspiral was a Limited Liability Company (LLC) that was owned by Joshua Vial until 2011 when it changed into a foundation structure (though it continued to legally operate as an LLC). Enspiral Foundation, as it became known, has a constitution similar to that of a charitable organization. The foundation created an Enspiral membership, where individuals who were at the core of the community and showed commitment to serving as stewards were voted in to be members. Each Enspiral member is a shareholder of the foundation with voting rights but receives no financial return, even in times of liquidation. The Enspiral board is voted in by members and oversees the 
foundation's activities. The board and members of Enspiral collectively make decisions on things that affect the whole ecosystem. According to Alex Hannant, Director of Hikurangi Foundation, Enspiral was creating "a new version of something old; [...] the cooperative movement has been reinterpreted" (A. Hannant, personal communication, June 10, 2013).

\section{Organizational structure}

The Enspiral Foundation is the main entity responsible for the health and well being of the ecosystem and Enspiral Spaces is the company that runs and manages the shared office space. Startups, companies, and individual contractors maintain a level of organizational independence from Enspiral. Certain organizations use the Enspiral brand (e.g. Enspiral Legal, Enspiral Accounting) where they serve companies in and out of the Enspiral ecosystem. Moreover, individuals from the ecosystem assume different types of part-time roles and positions with the Foundation. There are also individuals who participate in different organizations and ventures within the ecosystem. If an organization wishes to be part of Enspiral, they need to be voted in by the membership. However, almost anyone can rent a desk at the Enspiral office, as that is not necessarily a form of formal engagement with the Enspiral network. Renting companies are considered part of the ecosystem but do not operate under the Enspiral umbrella nor contribute a percentage of their income to the Foundation. 


\section{Financial structure}

Startups and companies that operate under the Enspiral umbrella alongside with individuals who work as contractors contribute a percentage of their revenue to the Enspiral Foundation. Members of the ecosystem participate in collaborative budgeting to allocate those resources to serve the needs of the ecosystem. Furthermore, internal billing and accounting systems allow organizations and individuals to make financial transactions with one another easily and in a way that is tax efficient. In addition, a number of companies offer their services at discounted prices to other Enspiral based organizations, and at times for free to the Foundation. For example, until February 2014, the Enspiral ecosystem used the Loomio collaborative decisionmaking tool at no cost.

\section{Social structure}

Socially, the ecosystem is categorized into three concentric circles: members, contributors, and friends. Members own and run the Foundation, have voting rights, and are at the core of the inner circle. After them, there are contributors, who are individuals who have business engagement with Enspiral, either as members of any of the Enspiral companies or individual contractors. They have a non-binding vote, contribute part of their income to the foundation (directly as contractors or indirectly through their ventures), and participate in collective decision-making and budgeting. The social boundary between members and contributors is blurry and it is an area that the foundation is still working to clarify. The distinction is that members make 
a formal commitment to be stewards of the ecosystem, while contributors can be as committed but are not officially recognized as members. Friends are individuals who participate in the ecosystem but not necessarily through formal and continuous business engagement within Enspiral. Individuals and companies that rent office space for example are considered friends. ${ }^{14}$ Most people who get introduced to Enspiral and continue to engage with the ecosystem are considered friends, introduced to everyone else at Enspiral, added to the private Google+ group, and welcomed socially into the ecosystem.

Enspiral retreats held every six months are important aspects of the social infrastructure. According to Joshua, these retreats "build culture, get people together, and really help build deep bonds between people." They have been held since the founding of Enspiral and individuals use retreats to mark specific times and phases in the history of the ecosystem.

\section{Why study Enspiral?}

When I first came across Enspiral, I noticed quite distinct characteristics and features that I found interesting. A friend of Enspiral describes Enspiral as "a new form... It's an emergent form that is moving and dynamic" (A. Hannant, personal communication, June 10, 2013). Hannant further points out "there is no other organization like Enspiral in the country, so it's kind of unique selfevident in that way."

\footnotetext{
${ }^{14}$ As a researcher and participant observer, I fall in the friends category.
} 
Enspiral creates a sense of shared identity. It is a community of entrepreneurs and enterprises that have shared values and a sense of commitment to making a positive difference in the world. I observed how these values created a shared sense of identity. "It's a place you become your own entrepreneur" (A. Hannant, personal communication, June 10, 2013). Enspiral does not build any of the startups. It provides the ground for new ventures to emerge. Enspiral has its own established infrastructures and mechanisms through which members of the community can interact and interrelate with one another. These are the characteristics that are found in organizational ecosystems (more on this is discussed later on in the literature and findings sections). Importantly, Enspiral is also small enough that it could be studied. For example, studying the Silicon Valley entrepreneurial ecosystem would have been much more methodologically challenging to study because of its increased complexity and geographic spread.

The way Enspiral members apply biological metaphors in the ways they understand and build organizations also motivated me to research this case. Members regularly reference how gardens work, how ecosystems can be seen as one, and how all living beings are interconnected when describing how Enspiral operates. Such parallels motivated my interest to apply a bioecological metaphor to study Enspiral.

Furthermore, Joshua Vial, the founder of Enspiral, intended it to be an experiment. One of the aims behind establishing such an ecosystem was to 
create a place of research and development to create new models of working, interacting, and collaborating across individuals and industries. Such active testing of new ideas of facilitating interactions and interrelations in an ecosystem made it attractive.

Moreover, certain aspects of Enspiral challenged some of my preconceived understanding of how organizations interact with one another. For example, the high level of trust between individuals and across different organizations I observed stood out as being quite distinctive. Rather than create too many structures of control, they pursued more organic and dynamic approaches to operating an ecosystem. I also found the non-hierarchical form of governance where the collective made decisions together on aspects that influence the whole ecosystem a fascinating characteristic to study.

In addition, the dynamic between how individuals furthered their own startup goals and also committed to seeing Enspiral thrive is an aspect that captured my interest. Will Lau, co-founder and CEO of BuckyBox, ${ }^{15}$ states:

As I look at success for BuckyBox, what is kind of distinct is that [when] Bucky Box achieves its mission, Enspiral achieves its mission too. If we achieve our mission the Enspiral is getting a big win out of that because that is the mission of Enspiral. (W. Lau, personal communication, July, 17, 2013).

\footnotetext{
15 BuckyBox is a software company founded by Enspiral members, and it offers a farm produce inventory management tool.
} 
Such active ties that entrepreneurs built between their startups, the ecosystem, and how these ties may be applied on a day-to-day basis warranted further research.

Finally, the approach to collaboration and competition that I noticed at Enspiral is quite distinct. From first interactions with that community, it was evident that they considered collaboration to be the norm, and competitiveness an exception. There was a narrative of 'we are naturally inclined to collaborate' that I observed and found relevant to the research of organizational interactions and interrelations.

All of these aspects and characteristics of Enspiral motivated me to make it my primary case study. In the following chapters, I examine theoretical frameworks that can help understand and uncover certain insights from this study, and then I present findings from the inductive process of analysis. 


\section{Introduction}

I begin this chapter by discussing the use and applications of metaphors. My attention in this thesis is bio-ecological metaphors, and in this chapter I highlight ways they are applied to better understand organizations.

In the first part of this chapter I discuss how organization ecologists use bio-ecological metaphors to understand the relationship between organizations and their environments (Hawley, 1950; Trist, 1977; Hannan \& Freeman, 1977; Carroll, 1984). Such applications have led to different perspectives regarding that relationship. One perspective suggests that organizations are highly adaptive and respond to changes in their environment, while another perspective posits that organizations are highly inertial and are subject to the natural selection process.

Next, I further expand on how different units of analysis are adopted and their implications. I distinguish organizational, population, and community levels of analysis. I place great importance on the unit of analysis because it determines the subject of the conversation and the types of questions that are asked. 
I then discuss how different applications of bio-ecological metaphors have varying interpretations of the way nature behaves. I explain how and why I focus on the interpretations of nature that show the interconnections and interdependence between all living and non-living beings, including an interpretation that shows the existence of both competition and cooperation. I underscore that throughout the different applications of bio-ecology, the adoptions of different units of analysis, and the interpretations of nature, organizational ecologists are mostly focused on survival rates of organizations and their evolutionary trends. My research deviates from this path as it focuses on the interactive and relational aspects existing in ecosystems.

In the second part of this chapter, I analyze how the open-system approach applies bio-ecology metaphors to understand the systems that facilitate interactions and interrelations amongst organizations. I describe how a systems perspective studies organizations as a web of complex relations (Baum \& Rowley, 2002; Scott, 1998), and highlight this perspective's emphasis on diversity of systems. I review the exchange framework that systems theorists have developed to understand interactions within complex systems. The exchange framework helps me incorporate overall exchange activities in the case I am studying, instead of just transactional exchange between individual entities (Levine \& White, 1961).

Building on some insights from organizational ecology and the opensystem approach, I develop an ecosystem unit of analysis. I apply a bio-ecology 
metaphor to study interactions and interrelations in ecosystems. I do so with an emphasis on the study of patterns of interactions and interrelations that biologists (Begon et al., 2009; Miller, 1975) and social scientists (Morgan, 2006; Patterson, 2004) suggest, rather than study vitality rates that most organizational ecologists focus on (e.g. Freeman \& Hannan, 1977, 1989; Carroll, 1984; Amburgey \& Rao, 1996; Singh \& Lumsden, 1990). By using an ecosystem lens, my research looks at both the living (organizations) and non-living (channels of interactions) aspects of ecosystems.

\section{Application of a metaphor}

\section{The use of metaphors and implications}

Lackoff (1993) argues that a metaphor is "a cross-domain mapping in the conceptual system (p. 203), where it helps us map entities, structures, and relations from one domain onto a different domain (Cornelissen \& Kafouros, 2008). Palmer and Lundberg (1995) posit that metaphors can be cognitive lenses used to make sense of organizations. We use metaphors to see organizations in a new way (Grant \& Oswick, 1996), where metaphors open up creative possibilities and are important in theory construction (McCourt, 1997).

Morgan (2006) states that, "all theory is metaphor" (p. 5). He acknowledges that theories we develop about organizations help generate valuable insights when looking through the theoretical lens we have created. "We use metaphor whenever we attempt to understand one element of 
experience in terms of another" (Morgan, 2006, p. 4). A metaphor helps us assert that A is or is not like B. (Lackoff, 1993). It invites us to see the similarities between the two, but also ignores their differences (Morgan, 2006). As such, it distorts perspectives that emerge when metaphors are utilized. While a metaphor is "a way of seeing and thinking" it can also be "a way of not seeing" (Morgan, 2006, pp. 4-5). As such, any theory "is incomplete, biased, and potentially misleading" (p. 4).

Metaphors have been used to study and understand organizations (Cornelissen, 2004, 2005; Coffman \& Eblen, 1987; Morgan, 1980), and an organismic metaphor is a popular one that I adopt in this thesis (Walck, 1996). I utilize a bio-ecological metaphor where I study organizations as if they were organisms inhabiting and participating in living systems (Trickett, 1984; Trickett \& Todd, 1972; Kelly, 1972a, 1972b, 1966). In doing so, I recognize that no single theory will give us a perfect and all-purpose view on the study of organizations (Morgan, 2006). However, the ecological and ecosystem lens can provide a fresh perspective into how we see and understand communities of organizations.

\section{Limitations of a bio-ecological metaphor}

There are several limitations when applying bio-ecological metaphors in the study of organizations. Parallels drawn between nature and organizations come with blind spots, and I present some of the key ones below. 
A direct comparison between key elements of the natural world with organizations may be problematic. If one takes the position that the natural world is real, objective, and pertaining material properties that are visible and touchable (Begon et al., 2009; Trickett, 1984), organizations seem to be more social constructs (Morgan, 2006). While organizations have physical properties, the aspects that are studied and discussed most about organizations are socially created. Morgan (2006) posits that the environments of organizations are created by human creativity and social activities. WeaverHightower (2008) studies the application of ecology metaphor in policy, and argues that what is created, constructed, and manipulated by humans may not always be comparable to the organic aspects of nature. Therefore, natural ecology and man-made organizations may be seen to be operating in different domains, and parallels between the two ought to be created with caution.

Moreover, there are certain inherent differences between how we understand the way nature operates and how organizations behave as things that are influenced by individuals. Morgan (2006) contends that when studying natural ecology, a level of "functional unity" is assumed (p. 68). A functional unity is when each organism is highly interdependent and works for all other organisms. Morgan (2006) finds such a level of harmony to be more of an exception than a norm within organizations. As such, studying organizations through an ecological lens can generate new insights, but the differences between nature and organizations can also limit how far we can draw parallels between them. 
These blind spots can create valid limitations and may construe the application of the bio-ecological metaphor. Yet, I believe there is another critical blind spot that Morgan (2006) and other similar researches I've reviewed have not explicitly articulated. A major limitation of a bio-ecological metaphor is that we do not yet fully-understand the intricate complexities of nature and the way it works, and may never will. All we claim to understand is based on observations, scientific research, and thousands of years of inquiry to even conceptualize how the natural world behaves. While we attempt to make generalizations based on recurring events, or observe interactions between organisms to draw cause-effect inferences, humans are far from developing predictive theories that use an ecological lens. Biologists further claim that the best we can do with ecological study is attempt to understand and possibly explain the working of natural systems (Begon et al., 2009), and that fundamentally "ecology was not and is not a predictive science" (McIntosh, 1986, p. 2). While we can develop greater levels of certainty of what we observe in nature by utilizing a scientific approach of inquiry, we are still attempting to comprehend the complexities of ecology and its ecosystems. What we claim to understand is observed primarily by our five senses, and yet humans can't even hear a dog whistle.

Therefore, I believe that our lack of comprehensive understandings of natural ecology is a limitation that needs great awareness when creating parallels between organisms and organizations. Our observations may suggest 
that there is a great degree of functional unity in natural ecologies. Our eyes may observe the physical properties of natural ecosystems that are visible and touchable but may have not identified all their non-physical properties. Ergo, I posit that having an awareness of our limitations can help orient our attention towards discovery of overlaps and uncovering of new ways to understand organizations, rather than falling in the trap of ideology creation as Morgan (2006) warns or prescribing normative narratives of how organizations should behave.

With some understanding of applications and limitation of bioecological metaphors, below I discuss one of the main applications of such a metaphor in the study of organizations.

\section{A bio-ecology metaphor: Organizational Ecology}

The ecology literature claims that organizations cannot be studied in a vacuum, but rather according to their interactions with the surrounding environment. An ecology of organizations looks at how changes that take place within the environment affect organizations and their structures (Hawley, 1968; Hannan \& Freeman, 1977; Aldrich, 1979). Much research has been done to develop organizational ecology as a field of study, going as far back to 1950 where Amos Hawley highlighted parallels between bio-ecology and human ecology. This field of research has evolved over the past few decades, with varying spurs of interest from a diverse group of researchers influencing its direction. In this section, I examine the way organizational ecologists apply a 
bio-ecology metaphor to study organizations, and I discuss how some of the influential researchers' inquiry evolved overtime. I deliberate how different interpretations of nature have influenced the way researchers in this field have theorized about organizations. I further elaborate on how the unit of analysis is a major consideration in this field of research and discuss the relevant implications.

Below I discuss two perspectives in organizational ecology: the adaptation and selection perspectives. The primary difference between these two is in the way they characterize the organization-to-environment relationship. They also infer different interpretations of natural ecology. Adaptationists consider organizations existing in congruence with their environment, while selectionists see organizations in constant struggle with their environment. The unit of analysis used in each varies as well, influencing the types of argument made.

\section{Adaptation Perspective}

The adaptation approach to ecology looks at organizations in their environmental contexts where organizations depend on external sources for sustenance (Kasarda \& Bidwell, 1984). It is assumed that organizations are highly adaptive and change over time in response to changes in their environments (Hawley, 1950; Carroll, 1984). Structural constraints and pressures determine changes in organizational structures. 
Hawley argues that organizations change in response to internal and external stimuli (1950). He utilizes Darwin's metaphor "web of life" to highlight the interdependence of living and non-living beings, interdependence is seen as the circulation of matter (1950). He argues, "ecology [...] is a study of the morphology of collective life" (1950, p. 67). He posits that every form of life is bound to the conditions of its environment, and populations of organisms form bounded ecosystems that work towards an equilibrium (1986). His work has been categorized along with the developmental approach to evolution (Carroll, 1984), and developmental researchers adopt an organizational level of analysis where the organization is the focal point. As such, the whole environment is considered from the perspective of the organization.

The adaptation perspective applies a bio-ecological metaphor by emphasizing the organic and more congruent relationship between organizations and their environments. It proposes that organizations are looking to find their 'fit' in their changing environments (Morgan, 2006), and that the primary activity that influences adaptation is changes in the environment.

\section{Selection Perspective}

Selectionists take a different approach to explaining the relationship between organizations and their environment. Hannan and Freeman (1977) popularized the selection perspective. They argue that the dominant mechanism for social change is natural selection, governed by competition and 
environmental constraints (Hannan \& Freeman, 1977, 1979). Unlike the adaptationists, Hannan \& Freeman (1977) claim that organizations are not primarily adaptive, but largely inertial. Their main argument is that social and environmental conditions are the best indicators on the evolution of populations. Hannan \& Freeman (1977) posit that these conditions influence the rates at which new organizations are created, the rates at which existing organizations die out, and the rates at which organizations change form.

Hannan and Freeman $(1977,1984,1989)$ developed a population unit of analysis, and they were primarily preoccupied with examining the changes within populations of organizations. They studied the external factors that are influencing and/or dictating those changes.

Furthermore, Hannan and Freeman $(1977,1989)$ adopt an evolutionary approach to understand organizations, and they emphasize that the selection process is the primary determinant of an organization's mortality. In doing so, they infer net mortality because weaker organizations are continuously dying due to selection, and only the fittest continue to survive (Carroll, 1984). A fundamental argument they make is that organizational mortality is a major force that drives natural selection (Hannan \& Freeman, 1977), and their contributions focus on how organizations can overcome inertia to change and adapt when faced with changes in their environments. 
Using Stinchcombe's (1965) argument that an organization's 'mortality' rate declines as it ages, Hannan and Freeman (1989) argue that older organizations have higher inertia. ${ }^{16}$ They state that newer organizations are extensions of the wills of individuals and do not have lives of their own (Hannan \& Freeman, 1989). Newer organizations can change their strategies and structures in response to environmental changes almost as quickly as the individuals who control them. But older organizations, having attained external legitimation, have institutionalized dense webs of exchange internally and with external sources, and have established reliability and accountability ${ }^{17}$ (Hannan \& Freeman, 1989). Such organizations are well established within the environment and do not change easily. Hence, Hannan and Freeman (1989) argue that the age of an organization affects the rate of organizational change in response to environmental changes.

Hannan and Freeman's $(1977,1989)$ work placed more emphasis on probabilistic evolution. Probabilistic evolution is when an organizations' ability to adapt has greater effect on its survival during the selection process, while environmental determinism is when organizations have very little control over environmental conditions of influence (Carroll, 1984). Yet, change happens because of natural selection, a condition based on environmental forces (Hannan \& Freeman, 1977; Aldrich 1976, 1979; Kaufman, 1976).

\footnotetext{
16 Organizational ecologists apply natural concepts of birth, death, and mortality rates when studying organizations. Here, Stinchcombe (1965) is referring to the natural decline and extinction of an organization.

17 Reliability of organizations is the consistency through which organizations produce collective products at a given quality. Accountability of organizations refers to their ability to account their actions consistently and in a rational manner through procedures and rules.
} 
Because organizations are inertial, only those who overcome that inertia are able to adapt and survive during selection. Or in other words, the most competitive organizations in a given population tend to be the survivors within their group.

Selectionists are generally criticized for offering a one-sided view of the evolutionary process (Morgan, 2006). They over-emphasize resource scarcity and competition as main drivers in evolution (Patterson, 2004), and underplay the notion that new resources can be abundant when there are organizations creating new value (Morgan, 2006). Part of the overemphasis on competition is due to the unit of analysis adopted, because it positions the inquiry on learning which of the similar organizations in a specific population are more likely to adapt. Part may also be influenced by the way a bio-ecology metaphor is applied. Here, I discuss the distinction in the unit of analysis more in depth, and following that I examine the ways a bio-ecological metaphor is used in this field.

\section{Units of analysis}

When applying a bio-ecological metaphor, the choice of the unit of analysis is important because it influences the what and how questions that are asked. It determines what we study, and how we understand other elements in relations to it. If we study an organization, we inquire about the environment around it in relation to the organization. The unit of analysis also determines the types of phenomena that we are most likely to encounter. Certain units of 
analysis are more likely to shed light on specific phenomena than others. They influence what we emphasize on and what we don't.

Carroll (1984) explains the distinctions between the three main levels of analysis utilized in organizational ecology: individual level, population level, and community level. An individual level of analysis is the study of "demographic events and life-cycle processes across individual organizations" that primarily uses an adaptation approach (Carroll, 1984, p. 72). This approach, as discussed above, considers an organization in the context of its environment. A population level analysis looks at population growth, decline, and interactions between multiple populations (Carroll, 1984). A population is composed of individual organizations that have a unitary character, where "members of the population have a common standing with respect to the processes of interest" and have similar environmental dependencies (Hannan \& Freeman, 1989, p. 45). Carroll introduces a community level of analysis, which looks at the collection of populations and is most concerned with the “emergence and disappearance of organizational forms” (Carroll, 1984, p. 73).

Carroll places the development of organizational ecology in a broader theoretical perspective, including tracing the origins of organizational ecology to human ecology (Hawley, 1950, 1968). In doing so, Carroll (1984) emphasizes the need for more research in organizational ecology at the community level. Here, he highlights that the focus is on understanding more 
how populations of new organizational forms rise or fall instead of simply looking at changes of organizational species within populations.

Carroll (1984) introduces a macro-evolutionary approach to the study of organizational ecology. This approach examines how communities of organizations change over time. In contrast to developmental or population ecology, it utilizes a community level of analysis. However, similar to developmental ecologists and peeling away from population ecologists, Carroll (1984) places greater emphasis on deterministic evolutionary sequences. But by utilizing a community level analysis, the macro-evolutionary approach encompasses organizational selection (while the developmental approach doesn't) and therefore allowing for large-scale changes in communities of organizations to be examined. Carroll (1984) is less preoccupied with rates of organizational reproduction and survival (population ecology) but rather changes in organizational forms over time - Stanley (1979) differentiates natural selection from species or form selection. Carroll (1984) finds the work of Hannan and Freeman (1977) problematic because this approach assumes net mortality (there are more deaths than births), while he argues it is not the case. One of the fundamental assumptions that guides Carroll's argument against population ecology is that "formal organizations can in theory be immortal" (Carroll 1984, p. 74). Therefore, the community level of analysis further develops the selection perspective while incorporating certain interpretations from adaptationists. 
The three units of analysis discussed above continue to dominate research in the organizational ecology field (Ruef, 2000). Understanding the distinctions between them is important as it impacts what the subject of conversation is. At the organization level, seeing the environment in relation to the organization in question puts the continued existence of the organization at the core of the conversation. At the population level, the main focus is the survival of the fittest organization amongst a population of its liking. At the community level, the emphasis is on the emergence and extinctions of whole populations. The way the inquiries frame their unit analysis influences the questions they ask. Each of these approaches to studying organization-toenvironment relationship may be influenced by the ways that the researchers adopt a bio-ecology metaphor. Below, I discuss some of the different ways bioecology metaphors are applied, and the levels of emphasis that is given to them in the study of organizational ecology.

\section{Application of the bio-ecology metaphor}

\section{Origins of bio-ecology}

The word ecology is derived from the Greek, oikos, meaning "home" (Begon et al., 2009), or a "house or a place to live in" (Hawley, 1950, p. 3). Biologist Ernest Haeckel first introduced the word ecology in 1869, and he describes it as the study of the interactions between organisms and their environment. "It is based upon the perception of the world of life as a system of dynamic interdependencies" (Hawley, 1950, p. 3). However, such a definition is rather broad, and Hawley introduces a bit more refined definition of ecology. 
In 1950, he develops a working definition of ecology as "a study of the morphology of collective life in both its static and its dynamic aspects. It attempts to determine the nature of community structure in general, the types of communities that appear in different habitats, and the specific sequence of change in community development" (Hawley 1950, p. 67). He proposes that the ecological enquiry is the community, "the form and development of which are studied with particular reference to the limiting and supporting factors of the environment" (p. 67). Through such a definition, Hawley maintains a level of comprehensiveness and holism to ecology, while refining the various forces in play within ecology.

Hawley's definition of ecology emphasizes the aggregate and not the individual, as the main unit of analysis. He also assumes that the collective life has different forms - static and dynamic - and that collective life exists in continuous interaction with the environment. That environment has characteristics that can limit or support the form and development of the collective life. In this research, I adopt his definition of ecology as it provides greater elaboration on the interaction with the environment than the definition offered by Haeckel. That definition also places an emphasis on the "collective life" which I further explore later in this chapter. Hawley's definition is influenced by Darwin's description of how natural systems work. Below I discuss the Darwinian narrative of natural ecology and how Hawley applied it in crafting a bio-ecological metaphor. 


\section{"Web of life"}

Hawley refers to Darwin's metaphor "web of life" to describe the interrelatedness of all life on the basis of a struggle for existence (Hawley, 1950). Darwin's metaphor was highly influential in defining modern ecology and was the foundation of his theories on human life he wrote about in his book Origin of Species published in 1859. Struggle for existence refers to an organism's relationships with both inorganic and organic elements of the environment, and it includes meanings of competition amongst all forms of life and cooperation that developed amongst organisms (Hawley, 1950). According to Darwin, the web develops as a form of order when the organisms become adjusted to one another and to their physical environment (Hawley, 1950). Furthermore, the environment includes all factors that are external to the organism and influence its behavior. As such, the environment has organic and inorganic elements that affect and are affected by the presence of an organism in it (Hawley, 1950). Darwin's proposition highly influenced Hawley's understanding of ecology, and it serves as a foundation to Hawley's theory on adaptation, cooperation, and competition.

According to Hawley (1950), it is part of life that organisms adapt to the external conditions - it is the environment that provides the materials for the organism's existence but also impede and limit expansion. Survival is a problem for the organism to deal with, and not the environment (Hawley, 1950). Researchers in the life sciences also claim "a population will grow (or decline) exponentially as long as the environment experienced by all 
individuals in the population remains constant"(Turchin, 2001, p. 18). Such an understanding of population follows the work of Malthus (1973) on the exponential law of population growth. Therefore, the adaptation process is "nothing more than striving to establish a working relationship" of an organism with its environment, including its fellow organisms (Hawley, 1950, p. 18). Adaptation occurs at an individual level, either when the genes of an organism develop or change to ensure survival. It also happens when different environments, or somatically become more "plastic" and versatile to variations in the environment (Hawley, 1950, p. 21). This is a point of view that is utilized and further developed by organizational ecologists when discussing organizational adaptation (Hannan \& Freeman, 1977; Carroll, 1989).

Adaptation can also occur at a collective level. Living organisms are inevitably dependent on one another and have the capability to gravitate towards adaptation as a collective unit (Hawley, 1950). Other organizational ecologists further explore the notion of collective adaptation. Astley and Fombrun (1983) elucidate how organizations can collectively and voluntarily adapt to changes in their environment. They argue that organizations can strategically respond to changes in the environment through "overarching inter-organizational collectivity" (Astley \& Fombrun, 1983, p. 577). ${ }^{18}$ According to Astley and Fombrun (1983) and also Aldrich (1979), inter-

\footnotetext{
18 Strategic choice is a phrase used by John Child (1972) to discuss how organizations can exercise a level of autonomy and have considerable latitude in making choices while constrained by environments. Child's (1972) analysis however is at the individual organization level. Prior studies utilized the strategic choice concept primarily within the developmental approach framework, or specifically in studies at the organization level and not the population level.
} 
organizational relations arise from interdependence between organizations. Therefore, Astley and Fombrun (1983) argue that organizations can exercise "proactive choice at the collective level" and respond to environmental conditions due to high interdependence in the corporate environment (Astley \& Fombrun, 1983, p. 577). ${ }^{19}$ Hawley places distinctive emphasis on communal adaptation as a foundational block for the study of ecology because it helps understand how cooperative and organized communities of organisms form and develop. More on the communal life of organisms is discussed below.

Darwin illustrates networks of vital linkages between organisms through the "web of life" and highlights the intricate interdependences (Hawley, 1950). The interdependence is defined by exchange between organisms, including the circulation of matter. An example of the interdependencies can be explained briefly through the basic relationship between plants and animals. Plants require carbon to manufacture their own food, so they absorb carbon dioxide from the atmosphere. Animals need oxygen to survive, and in return they give off carbon dioxide to the atmosphere. Darwin and Hawley propose that organisms are "custodians" of chemicals that are generally essential to life - carbon, oxygen, nitrogen, hydrogen, phosphorus, calcium, iron, sulphur, and others - and they transmit these chemicals from

\footnotetext{
${ }^{19}$ Here, Astley is not ascribing to the developmental approach that suggests organizations are highly adaptable, or the selection approach that emphasizes on environmental forces to determine the face of organizations. Rather, he develops inter-organizational analysis to emphasize collective and proactive forms of organizational adaptation to the environment (Astley \& Fombrun, 1983). He combines population level analysis with community level analysis while avoiding the selection aspect that exists in population ecology. A community level of analysis is defined as a collection of populations and is concerned with the study of emergence and disappearance of organization forms (Carroll 1984, Roughgarden, 1979).
} 
body to body through waste, chains of food relationships, and decomposition. Bacteria help break down decomposed life and free the vital chemicals for plants to absorb and put back in the cycle. Furthermore, plants utilize photosynthesis to transform inorganic material into compounds that animals require. The interdependencies between organisms get a lot more complex, especially when looking at the web between all organisms and not just plants versus animals. Hawley (1950) adopts two types of relationships between organisms that bio-ecologists have articulated: symbiosis and commensalism. He utilizes these two concepts to explore cooperation and competition within the web of life.

Symbiosis denotes a "mutual dependence between unlike organisms" (Hawley, 1950 p. 36), including all forms of living together. With the basis that organisms make dissimilar demands on their environments, they may supplement the efforts of one another. Hawley applies this concept to the way certain species produce a surplus population for the maintenance of a predator species, and as such they are in a vital cooperation, "contributing to and facilitating the circulation of life-giving matter" (Hawley, 1950, p. 37). This forms a biological basis of cooperation between organisms. Astley and Fombrun (1983) also utilize symbiotic relationships to explain how organizations from different groups or populations supplement the efforts of one another and thus become mutually interdependent. Astley and Fombrun (1983, p. 578) refer to symbiosis to further develop the phenomenon of "collective adaptation" or "communal adaptation." 
Commensalism literally means, "eating from the same table" (Hawley, 1950, p. 39), and it denotes the relatedness of organisms on the basis of their likeness as well as their differences. Such relationship is defined by the similar demands organisms make of the environment, and commensalism is primarily expressed through competition. Competition takes place when the organisms' demands exceed the resources available to them, including demands for food and living space. Competition could be indirect and subtle as well. Hawley describes how organisms with similar requirements often join forces and collaborate because they are more likely to maintain favorable conditions than by themselves - "an aggregate acting in concert can accomplish what a lone individual cannot" (Hawley, 1950, p. 40).

Both dimensions of commensalism and symbiosis have been used in the past to classify groups of organizations (including by Astley \& Fombrun, 1983; MacMillan, 1978; Phillips, 1960), but Astley and Fombrun's (1983) discussion of collective adaptation is most relevant to this thesis. Within the commensalism dimension, there is emphasis on high interdependence between similar organizations that exist in competitive and cooperative interactions (Astley \& Fombrun, 1983). An "agglomerate collective" is a "cluster of organizations of the same species that compete for a limited supply of resources" but do not associate to cohere their respective actions or unify their organizational forms (Astley \& Fombrun, 1983, p. 580). Astley and Fombrun (1983) further emphasize that agglomerate collectives can opportunistically 
engage in voluntary and self-governing action. They can do this through "proactive strategies precisely because they occupy the same niche and share a common fate" as they co-exist in a highly competitive environment (Astley \& Fombrun,1983, p. 582).

As discussed in previous paragraphs, by studying bio-ecology through Darwin's "web of life" lens, theorists such as Hawley have surfaced key characteristics of ecology - an ecology that also includes humans along side with other forms of life on earth - in paving the way for further application in the study of organizations. Darwin remains a leading authority of how we understand life broadly, and his theory of how life behaves and changes continues to influence research within organizational ecology. A major part of the organizational ecology literature utilizes his work on ecology, adaptation, and selection as its basis for theorizing the behavior of people and organizations. Compared to most of the influential voices in the organizational ecology literature that I have looked at doing this research (e.g. Hannan \& Freeman, 1977, 1989; Carroll, 1984; Singh, 1990; Singh \& Lumsden, 1990; Baum \& Amburgey, 2000; Audia \& Freeman, 2006), Hawley is one of the few who has provided highly comprehensive understandings and analysis of Darwin's theories, and adopted them to human and organizational ecology. Understanding the origins of ecological studies, including definitions, is of great importance because it allows us to examine how bio-ecological metaphors have been used within organizational ecology. However, the levels of emphasis on the metaphor itself have varied across different researchers in the field. Below, 
I present some of the ways that bio-ecological metaphors have been applied in organizational ecology.

\section{Varying applications of bio-ecology metaphors}

There are different ways researchers in organizational ecology have utilized bio-ecology metaphors to study organizations. The significance of the metaphor in inquiry varies depending on the inquirer. Astley and Fombrun (1983) articulate relationship between the metaphor and organizational ecology in quite a concise way, quoted below:

To what extent is the use of biological analogy valid in explaining social phenomena? of course, the obvious answer is that social life is likely to be similar to biological life in some respects but not in others. Thus, it is unwise to apply, indiscriminately biological laws to social life without first guarding one's conclusions with a great deal of circumspection. On the other hand, this should not prevent one from drawing upon the rich source of principles that biology has generated; its body of theory certainly is more developed than that of organizational science and is capable of offering valuable insights. (Astley and Fombrun (1983, p. 578)

Astley and Fombrun (1983) conclude that application of a bio-ecological metaphors surfaces ideas and theories that can "sensitize management professionals to theoretical problems or empirical variabilities that might otherwise go unnoticed" (p. 578).

Singh \& Lumsden (1990) develop a comprehensive review of organizational ecology research carried out up until 1990, and they discuss how researchers in the field have applied this metaphor. Looking at the 
overlaps of previous research, they point out that the underlying idea of organizational ecology is that "under specific conditions, processes of change in organizational populations parallel processes of change in biotic populations" (p. 162). Their proposition is that research in organizational ecology is focused on investigating parallels between ecological processes within biology and processes in organizations. It is about drawing a parallel to "illuminate organizational processes of interest" and less about the "use of biological metaphors to study organizations" (Singh \& Lumsden, 1990, p. 162). This is important because Singh and Lumsden (1990) are positioning bio-ecological metaphors as sources for ideas in the way we understand organizations, not as a framework that we use to explain and even suggest how organizations behave.

As Morgan (2006) explains, we use metaphors to help explain relationships and develop theories. This is opposed to developing theories and perspectives based on metaphors. Metaphors help illuminate certain aspects of what we're trying to study. As such, bio-ecological metaphors can be used in varying ways and from different angles in order to develop arguments and propositions about organizations. It is possible for organizational ecologists to focus on different aspects of bio-ecology in order to shine light on ideas and perspectives they wish to communicate. For example, some of Hawley's work places greater emphasis on the adaptation process in natural systems, while Hannan and Freeman (1977) focus on natural selection. Both theorists adopt and interpret Darwin's work: Hawley (1950) focuses on the 'web of life' 
metaphor while Freeman and Hannan emphasize on natural selection metaphor.

Furthermore, having different units of analysis allows for varying applications of metaphors that highlight specific parallels with bio-ecology. For example, Singh and Lumsden's (1990) statement above assumes that organizational ecology is primarily concerned with the study of organizational populations. Other organizational ecologists have taken a similar approach as well (e.g. Péli, Bruggeman, Masuch \& Nualláin, 1994; Van Witteloostujin \& Boone, 2006).

Moreover, in the application of a bio-ecological metaphor, the level of influence an environment has on organizations has varied. Organizational ecologists have developed two models that explain how much influence the environment has on organizations: one is a deterministic model and the other one is a probabilistic one. I discuss each of them below and the implications of their applications.

Environmental determinism vs. probabilistic determinism

Environmental determinism posits that human behavior on earth is determined by environmental limitations (Hawley, 1950, 1968). Earlier works on ecology emphasizes that changes in the environment lead to changes in organizations, and evolutionary processes lead to progress (Carroll, 1984). This perspective aims to understand the relationship an organization has with 
its environment and explores how evolutionary processes lead to equilibrium in that relationship (Hawley, 1968). The organization-to-environment relationship is a negotiated one, and the organization part of the environment as much as the environment part of the organization (Hawley, 1950,1968).

Probabilistic determinism considers evolutionary process as more probabilistic rather than as a negotiated relationship between organizations and their environment (Hannan \& Freeman, 1977; Carroll, 1984). This model's emphasis is on organizations' ability to overcome inertia to change. The conversations are on how organizations can influence which end of the stick they will take during the selection process and how they can somehow exempt themselves from mortality (Carroll, 1984). A probabilistic view does not equate evolution as progress, but rather change over time. It posits that organizations are in a struggle with the environment, and only those that are able to change continue to exist. As such, a probabilistic approach to evolution utilizes the concept of strategic choice in presenting the idea that some organizations can exercise strategic choice and control their own outcome (Child, 1972; Aldrich, 1979; Astley \& Van de Ven, 1983; Bourgeois, 1984; Hrebiniak \& Joyce, 1985).

According to some organizational ecologists, selection also happens when administrative and cultural mechanisms regulate the allocation of attention and resources to different areas of strategic initiative (Burgelman, 1991). It is individuals who rise up the ranks at an organizational level who 
influence the strategic choices the organization makes, thus affecting the survival of the organization (Burgelman 1991). Others argue that organizations are both creators and prisoners of their environments (Miles \& Cameron, 1982). Some attribute an organization's size to its ability to influence its own lifespan. The larger and more powerful organizations are able to exert more influence on their environments, argues Scott (1987), and are not subject to selection pressures in the same way that small organizations are (Singh \& Lumsden, 1990). Other leading theorists in the ecology literature highlight that organizations can be proactive and are not necessarily passive (Hannan \& Freeman, 1989; Pfeffer \& Salancik, 1978).

Ergo, bio-ecological metaphors can be applied in varying ways. The result of that is seen in the different types of conclusions researchers reach in their understanding of organizations and the nature of their relationship with the environment.

To summarize the literature discussion so far, metaphors are useful for the development of theories and perspectives. They can help us to understand relationships between phenomena, but they are also biased and can be misleading. Bio-ecology metaphors can shed light into how we understand organizations, and the organizational ecology field has developed a great wealth of knowledge through the application of such metaphors. Past research has generated numerous insights into the relationship between organizations and their environment. However, perspectives on the nature of that 
relationship differ significantly, partly influenced by the ways metaphors are created and applied, and partly due to the unit of analysis adopted to studying organizations. Natural ecology is very complex, and interpretations of how the natural world operates can vary depending on what angle one inquires from. Therefore, the development of metaphors and their applications in theory development are highly determined by the lens a researcher adopts.

The different forms of lenses adopted in organizational ecology have focused on vitality rates. Through the emphasis on survival of an organization, a population of organizations, or organizational forms at the core of ecological inquiry, an application of a metaphor can be, as Morgan (2006) posits, "a way of not seeing." I orient my thesis to discuss areas not seen by the survivalist lens. I attempt to develop an ecosystem lens that can allow us to see the interactive relational aspects of ecology. To aid the development of this lens and its application to study the Enspiral case, I bring in some insights from the opensystem approach. This approach also adopts bio-ecological metaphors to generate perspectives on studying organizations as open and interrelated systems. In the section below, I examine concepts of open-systems and highlight the aspects most relevant to my thesis.

\section{A bio-ecology metaphor: Open-system approach}

An open-system approach "builds the principle that organizations, like organisms, are "open" to their environment and must achieve an appropriate relation to their environment if they are to survive" (Morgan, 2006, p. 38). An 
environment and an organization are in a "system of interaction and mutual dependence" (p. 40). Here, an environment also encompasses other organizations and entities. This framework considers interactions as exchange. Using a bio-ecological metaphor, Morgan (2006) further explains, "organic systems at the level of the cell, complex organism, and population of organisms exist in a continuous exchange with their environment. This exchange is crucial for sustaining the life and form of the system, as environmental interaction is the basis of self-maintenance." (p. 40). Miller (1989) further elucidates, "the existence and survival of any human system depends upon continuous interchange with its environment, whether of materials, people, information, ideas, values, or fantasies" (Miller, 1989, p. 11). According to Buckley (1967) "that a system is open means, not simply, that it engages in interchange with the environment, but that the interchange is an essential factor underlying the system's viability" (Buckley, 1967, p. 50). Below I present some of the principles of this approach, which derive primarily from biological systems and are applied in the study of organizations as systems (Baum \& Rowley, 2002).

A systems approach to study ecology is one that I find most relevant to my thesis. It studies interactions and interconnections as forms of exchange, a lens that I utilize to analyze interactions and interrelations in the Enspiral case study (I discuss how such exchange can be used as a framework later in this section). An open system approach places an emphasis on the interdependence that exists within systems. Morgan (2006, p. 41) explains, "The cell of a system is a system of functional interdependence that is not reducible to a system 
structure." He argues that it is limiting to reduce a system into a structure of parts and study the relations between the parts. Rather, structure, function, and behavior are highly intertwined (Baum \& Rowley, 2002; Scott, 1998). To illustrate this, let's pretend to create an anatomy of human organs. By looking at the interactions between them doesn't allow us to appreciate the complex web of relations that exist within the entire body and how they manifest in the way that the body operates as one living system. Each cell is dependent on a complex web of relations between cellular structure, metabolism, gas exchange, the acquisition of nutrients, and numerous other functions. This view provides a framework that I use when examining the relationship between interdependence and ways it facilitates exchange activities.

Moreover, a systems approach proposes that diversity of organizations is a key component for a system to operate. Morgan (2006) illustrates, "the internal regulatory mechanisms of a system must be as diverse as the environment with which it is trying to deal" (p. 41) so that it can adapt to its environment. Diversity, Morgan argues, is "an important feature of living systems of all kinds" (p. 41). This point is relevant in a systems approach because diversity allows for new organizations to be introduced, and that in turn facilitates for new exchange patterns to emerge. Below, I discuss theoretical frameworks for the concept of exchange that systems researchers have developed. 


\section{Exchange framework}

Levine and White (1961) study patterns of exchange between organizations and develop a framework of exchange that has been influential in the study of inter-organizational relations. They argue that scarcity of consumers, labor services, and other resources necessitate exchange activities between organizations. The scarcity of resources "impels organizations to restrict activity to limited specific functions. The fulfillment of these limited functions in turn requires access to certain kinds of elements which an organization seeks to obtain by entering into exchange with other organizations" (Levine \& White, 1961, p. 587). They define organizational exchange as "any voluntary activity between two organizations which has consequences, actual or anticipated, for the realization of their respective goals or objectives" (Levine \& White, 1961, p. 588).

There are key elements of their definition that are important to consider. First they refer to "activity in general and not exclusively to reciprocal activity" (p. 588). In doing so, they encompass different forms of exchange that are not transactional - for example, one organization may refer a client to another organization and get nothing in return immediately. Furthermore, they widen the concept of exchange beyond transfer of material goods and gratifications in the immediate present. As such, they allow the consideration of other dimensions of organizational interactions. This can include ideas, inspirations, and other forms of exchange that may not be 
quantified. In addition, they emphasize on exchange as a voluntary activity, and exclude exchange activities that are coercive and dominating.

This approach to understanding inter-organizational exchange has been utilized and further developed by other researchers to study concepts such as power (Jacobs, 1974), resource dependence (Aldrich, 1976), and application of exchange theory into other aspects in the study of organizations (e.g. Barden \& Mitchell, 2007; Das \& Teng, 2002; Young-Ybarra \& Wiersema, 1999; Hasenfeld, 1972; Thompson, 1967). In this research, I utilize the exchange framework to analyze interactions and interrelations in entrepreneurial ecosystems.

In sum, the open-system approach utilizes a bio-ecology metaphor to study organizations as systems that depend on being in active relations within themselves and their environments. It offers an exchange lens through which one can study how organizations interact. Following Morgan's (2006) suggestion, the complex interactions within a system are better studied by looking at the system as a whole rather than by creating an anatomy of the parts. As such, I develop an ecosystem lens, a unit of analysis that can allow the study of whole systems.

\section{"Ecosystem" as a unit of analysis}

In the study of interactions and interrelations, I propose the use of ecosystem as a unit of analysis. First, I wish to discuss briefly what an 
ecosystem means in biology, and the ways the concept has been positioned when applying a bio-ecology metaphor.

\section{Biological interpretation of ecosystem}

Study of ecology looks at the living world as a biological hierarchy: the organisms, the populations of organisms (consisting of individuals of the same species), and the communities of populations (consisting of a greater or lesser number of species populations (Begon et al., 2009). An ecosystem comprises the community together with its physical environment, and it includes interactions between living (biotic) and non-living (abiotic) components within it.

There is a stark difference between community ecology and ecosystem ecology. Community ecology is "the study of patterns in the structure and behavior of multispecies assemblages" (Begon et al., 2009, p. 467). Community ecologists utilize their understanding of the interactions between organisms in an attempt to explain the behavior and structure of a whole community. Interactions make the community more than the sum of its parts. Ecosystem ecology on the other hand is concerned with the "structure and behavior of the same systems but with a focus on the flux of energy and matter" (Begon et al., 2009, p. 467). Begon et al. (2009) argue that all biological entities require matter for their construction and energy for their activities. They explain:

"The term ecosystem is used to denote the biological community together with the abiotic environment in which 
it is set. Thus, ecosystems normally include primary producers, decomposers and detritivores, a pool of dead organic matter, herbivores, carnivores and parasites plus the physicochemical environment that provides the living conditions and acts both as a source and a sink for energy and matter" (Begon et al., 2009, p. 499).

Therefore, in biology, the study of an ecosystem comprises more than the community of organisms and their interactions; an ecosystem includes the relationship of those organisms with the environment they depend on and allows them to interact and be interdependent. The addition of the abiotic components to understanding communities of organisms is critical, because it does not only look at their co-existence, but it encompasses the mechanisms that enable that co-existence. When applied to an ecosystem unit of analysis, the study of interactions and interrelations can also include the mechanisms through which such activities happen. This is relevant because it allows us to better understand the characteristics of an ecosystem that contribute to greater or lesser levels of interactions and degrees of interrelations.

\section{Organizational interpretation of ecosystem}

Hawley (1986) and Morgan (2006) present a perspective that emphasizes on studying ecosystems as a whole. I adopt their perspectives to develop an ecosystem unit of analysis and study interactions and interrelations in the Enspiral case study.

Hawley (1986) adopts an understanding of ecosystem that is similar to the way biologists refer to the concept. He sees an ecosystem as an association 
of species and its environment between which energy and information are regularly cycled. In his theoretical framework, an ecosystem is composed of both environment and living organisms.

Hawley (1968) defines an ecosystem as "an arrangement of mutual dependences in a population by which the whole operates as a unit and thereby maintains a viable environmental relationship" (p. 26). He uses the term "arrangement" to assert the "presence of a more or less stable ordering of parts, a structure that endures through time" (p. 26). He further posits that a structure is a property of an ecosystem that cannot be divided into parts, and it is composed of a set of active parts that engage in routinized movements. The rhythms that develop through activities within an ecosystem hold those parts together in constant relation to one another, preserving their form and identity. According to Hawley (1986), ecosystems have boundaries. If an ecosystem is primarily about interactions, then the boundary line falls where the periodicity of those interactions no longer obtains - that is where the interaction frequency is close to null. Furthermore, an ecosystem has a natural history, where it moves from small beginnings and takes a complex form. He argues that one can rarely observe the beginning of an ecosystem, and the most one can get is refracted glimpses of its beginnings from a reconstructed narrative.

Hawley (1986) further propositions that both symbiotic and commensalistic relationships exist in ecosystems. Individuals enter into mutual dependencies based on their functional differences, but also share 
common interests. They create vertical functional chains in a symbiotic hierarchy and are vertically aligned according to functional similarities. A crucial point he makes here is that "power belongs to functions rather than to units. Units acquire power as they succeed to functions, and they lose it as they are displaced from functions" (1986, p. 37). When developing an ecosystem unit of analysis using this perspective, it is the functions played in an ecosystem that becomes significant, not the individual units. In other words, it is the role that organizations play that I place an importance on, and I am less concerned about the founding, transformation, and death of individual and collective organizations. It is the function that an organization plays in its larger ecosystem that creates power, not its mere existence. While the birth and death of organizations has significance on the ecosystem, my inquiry is not in using the organization being founded or dying as a focal point. The ecosystem is the subject of my inquiry, and I look at the ways that births and deaths of organizations impact the ecosystem as a whole.

As indicated in the introduction, Morgan (2006) shows the need to study the "patterns" of interactions in ecosystems and how those patterns change over time, not merely changes at an organizational level. He argues that studying ecosystems as a whole allows us to examine patterns of interactions, including collaborative patterns as well as competitive ones. Noticing how past applications of bio-ecology overly emphasize on competitive aspects of organizations, Morgan (2006) calls for more research that uses a perspective 
that studies a whole ecology. He posits that such a perspective will allow us to also understand cooperative aspects of organizations.

Adopting the contributions of Hawley (1986) and Morgan (2006), I analyze the Enspiral case study using an ecosystem unit of analysis. An ecosystem level of analysis allows the study of how interactions and relationships take place within an ecosystem. Such an approach looks at the complexities of interactions within an ecosystem. It includes both the biotic (organizations, populations of organizations, and communities of organizations) and the abiotic (mechanisms under which the biotic beings interact and relate to one another).

\section{Conclusion}

My research examines the characteristics that influence the interactions and interrelations within an entrepreneurial ecosystem. I adopt a bio-ecology metaphor to analyze the interactions and interrelations observed in the case study I focus on, and my aim is to develop a model based on the findings of such a study.

To support this inquiry, I have underscored how metaphors can be applied to study phenomena and the limitations they come with. I discussed how a bio-ecology metaphor has been applied in the organizational ecology field when studying organization-to-environment relationship. I have described how applications of a metaphor has led to opposing perspectives on 
organizations, varying interpretations of nature, and different arguments on ways organizations relate to their environments. I have also highlighted the importance of the unit of analyses used. Organizational ecologists focus on the processes that generate organizational foundings and failures (Brittain \& Wholey, 1989), while my research is concerned with the processes of interactions and interrelations. To provide a framework for my inquiry, I referred to research done on open-system approach. This field looks at systems that facilitate interactions and relations within organizations, and applies the framework of exchange to investigate inter-organizational relations. By applying this framework, I have developed an ecosystem unit of analysis to analyze interactions and interrelations within the Enspiral ecosystem. In the next chapter, I will utilize the exchange framework and ecosystem unit of analysis to present the characteristics of the Enspiral ecosystem that influence the levels of interactions and interrelations taking place. 
CHAPTER IV: DATA ANALYSIS ON ECOSYSTEM INTERACTIONS AND INTERRELATIONS

\section{Introduction}

In this thesis, I use a bio-ecological metaphor to study Enspiral, an entrepreneurial ecosystem based in Wellington, New Zealand. Through my study I develop an ecosystem unit of analysis to study interactions and interrelations that occur in an entrepreneurial ecosystem.

The question I attempt to answer in this thesis is what characteristics influence the interactions and interrelations within entrepreneurial ecosystems? In this chapter, I address this question by using the variable of exchange to uncover the interactions and interrelations taking place at Enspiral. I then identify the characteristics that influence the levels of interactions and interrelations. In doing so, I develop the following three propositions:

1) Ecosystems facilitate interdependence between organizations, and greater degrees of interdependence allow increased level of exchange activities.

2) Diversity within an ecosystem fuels an internal economy, facilitates more innovation, and allows for access to resources, knowledge, and talent, and as such it enables for more exchange activities to take place.

3) Organizational births and deaths in ecosystems augment exchange activities by composting, recycling and/or repurposing knowledge, resources, talent, organizational infrastructures, and different forms of access. 
This chapter is structured in the following way. In the first section, I illustrate how the variable of exchange can be utilized to study interactions and document the different types of exchanges observed in the Enspiral case study. In doing so, I identify some of the implications of using such a variable when using an ecosystem unit of analysis. These include a more comprehensive observation of exchange activities rather than just focusing on transactions between entities, and the challenges of measurement that come along when taking such a broad perspective. In the second section of the chapter, I identify the three key characteristics of the ecosystem observed and I analyze how each of them influences the exchange activities taking place in the ecosystem.

\section{Exchange as a form of interaction}

I use an ecosystem level analysis to research the Enspiral case study. I utilize the open-system approach of analyzing interactions as between organizations through the framework of exchange. The web of life that Darwin proposes is one that facilitates complex levels of exchange between all living beings (Hawley, 1950). The circulation of energy and matter through an ecosystem can be seen as a form of exchange, where abiotic and biotic aspects of environment are linked (Begon et al., 2009). For example, when looking at the interaction between animals and plants from a bird's eye view, that interaction can be observed as series of exchanges of primarily oxygen, carbon, and other nutrients. A similar approach can be applied when studying Enspiral, by looking at the many forms of interactions that are facilitated between

different enterprises within the ecosystem. Based on data from this research, 
interactions and interrelations within the Enspiral ecosystem can be analyzed as a form of exchange.

The study of exchange allows for a more comprehensive understanding of an ecosystem. A community level of analysis is most concerned about the rise and fall of organizational forms (Carroll, 1984). However, an ecosystem level of analysis looks beyond the types of organizational forms and includes the channels through which organizations interact, communicate, and facilitate exchange (Hawley, 1986). Hawley (1986) refers to the exchange of information and matter within an ecosystem, and that encompasses the environment organizations exist in and also the way that the environment shapes the whole ecosystem. As a very basic example, if we think of the larger ecosystem where human life exists - the ecosystem of humanity - the atmosphere around us is as much a part of that ecosystem as we are. The atmosphere influences and is also influenced by the ecosystem of humanity. When studying the interactions between humans and the atmosphere, some considerations we make is how humans breathe air in and out, how our activity impacts the atmosphere and how activities within the atmosphere affects us. We are engaged in an activity of exchange with the atmosphere. How much that exchange influences humans or the atmosphere is open for debate, but even the fact that each person breathes in oxygen and breathes out carbon dioxide is a form of exchange. There is a symbiotic relationship between humans and the atmosphere, and scientists are still studying the nature of the exchanges we are involved in and its implications. A bio-ecological metaphor can apply to the study of 
organizational ecosystems, where the concern is on the interactions and interrelations as seen through the lens of exchange.

When I study exchange at an ecosystem level, I adopt aspects of Levine and White's (1961) definition of exchange. Because the ecosystem is the unit of analysis, I study the exchange that takes place within the ecosystem, and not the specific gains and losses from an individual organization's point of view. Furthermore, I look at the exchange activities in general and not the transactions between two separate entities, or even an aggregate of all the gains and losses throughout an ecosystem because transactions do not encompass all forms and dimensions of exchange (Levine \& White, 1961).

In the first part of this section, I discuss findings on the types of exchanges I observed at Enspiral. Following that, I analyze various issues I encountered when attempting to measure exchange as a variable. In the second part of this section, I present the main characteristics of the ecosystem that influence the exchange activities at Enspiral.

\section{Types of exchange}

Exchange happens in many different ways at Enspiral. Below I outline the types of exchange observed and I provide some examples to illustrate them. 


\section{Exchange of ideas and knowledge}

Ideas are shared through in-person interactions between members of different start-ups within their shared office space. Such in-person interactions take place when individuals pass by each other and stop for quick chats, when people share common spaces such as the kitchen to have meals, and during happy hours and networking events hosted at the office. Enspiral has also created online infrastructures where the whole ecosystem can exchange ideas and knowledge. They utilize Yammer and Google+, two social networking websites, as their main platforms to share ideas, offer comments, expose the ecosystem to new knowledge, and carry out different forms of discussions.

Moreover, the Enspiral ecosystem, comprising of Enspiral companies working mostly from the Wellington office but also from remote locations, relies on social networking platforms for most of its communication. I have observed from up to a dozen separate conversations taking place on a daily basis online. Another platform used by Enspiral is Loomio. Loomio is where individuals from different organizations can share many types of ideas and get a poll from the ecosystem. While exchanges on Loomio are aimed at creating some consensus amongst the collective and subsequently lead to some form of action, participants get the opportunity to learn about new ideas and knowledge from the threads of conversations that take place.

In addition, there are organized events and activities solely aimed at facilitating the exchange of ideas and knowledge. For example, different individuals run workshops during Enspiral retreats to share some of their ideas 
with the whole ecosystem. They also host weekly lunchtime conversations targeted at facilitating the exchange of ideas on specific topics. Lastly, Enspiral launched an initiative early in 2014 called "C3" where participants create short content on a daily basis and share it with the whole ecosystem. C3 is meant to serve as a platform for exchanging ideas and knowledge within the ecosystem, with the ambition of making it available to organizations and individuals outside of Enspiral as well.

\section{Exchange of skills}

There are various ways that skills that exist in specific organizations are exchanged within the ecosystem. One of the main ways such exchange take place is when members of individual startups participate in projects or initiatives run by other startups. This happens for example when a designer from one company offers a set number of hours to work on a new website a different company is building. Another example of exchange is when a member of one initiative helps facilitate a management meeting for another company within an ecosystem. A third example is when a company hires the services of another company within the ecosystem (e.g. Enspiral Legal - a law firm within the ecosystem - helps look over the constitution and agreements that another company has developed).

Furthermore, some companies within Enspiral share team members, where individuals work for different companies on a part-time basis. Such structures facilitate the exchange of skills between separate organizations. 
Through these activities, the skills that exist within specific organizations are exchanged with other organizations in the ecosystem.

\section{Exchange of resources}

Different types of resources are exchanged in the Enspiral ecosystem. One of the ways exchange happens is when one company or individual directly invests in another company within the ecosystem. Several startups have raised early stage capital that included investments from within the ecosystem, either from individuals or companies. There are companies that own parts of other companies. Another form of resource exchange is through the Enspiral Foundation, where each company contributes a percentage of its monthly revenue to the foundation, and then the foundation utilizes that resource to support the whole ecosystem and also funds specific initiatives started by members of the ecosystem. All the money that goes into the foundation is allocated through a collaborative budgeting system, where each individual member of Enspiral (team members of the companies that have contributed part of their revenue to the foundation) use the online tool to allocate money to different "buckets" - these are expenses that members themselves propose with set budgets and seek for support from others. Such a system allows for resources to be exchanged within the ecosystem. In addition, companies and individuals exchange their access to outside talent, capital, and business leads within the ecosystem. One example that stands out is when FreeRange, one of the companies within the ecosystem, organized for a large venture capital firm from Tel Aviv to visit New Zealand. FreeRange organized for several Enspiral 
companies to pitch to this venture capital firm and seek investment. Lastly, there is an Enspiral library created where members of the ecosystem donate books and DVDs, and anyone can borrow them at their will.

\section{Exchange of energy and emotional support}

While 'energy' and emotional support are intangible, they are key forms of exchange that are highly valued at Enspiral. At times they are even more valuable than all other forms of exchange that are facilitated. One aspect of being entrepreneurial that most interviewees indicated is that it's quite hard on the individuals participating, that it can drain a lot of their energy. They recognize how entrepreneurship requires great levels of perseverance and persistence over a long period of time. For example, there are companies that are self-funded and the entrepreneurs behind them work 60-100 hours a week with little or no pay. Different companies go through their own challenges at different times. The camaraderie created between these startups and the entrepreneurs behind them has enabled for emotional support to be exchanged. They give each other energy boosts when needed, through one-onone conversations, doing shout outs when one startup achieves a goal, or by having milestone celebrations. For example, when Enspiral Dev Academy, a new startup that emerged from within the ecosystem, launched its website, a large proportion of the ecosystem made it a point to publicize the launch through their social networks and give Enspiral Dev Academy a boost. When companies celebrate their anniversaries, many members of the ecosystem come out to celebrate with them. 
In addition, Enspiral organizes retreats every six months, organized and run by members of the ecosystem. These retreats serve as a means of allowing member companies and individuals to infuse a new energy through the ecosystem.

\section{Summary}

In sum, a large part of the interactions within the Enspiral ecosystem can be studied as forms of exchange. As observed above, however, such exchange takes different forms, and that makes it challenging to standardize and measure exchange as a single unit across the board. Below I offer insights on how we can understand exchange as a variable.

\section{Exchange as a variable}

The benefit of using a broad exchange framework is that it can encompass most if not all forms of interactions. Exchange serves as a variable that helps analyze the interactions taking place within the Enspiral ecosystem. As a variable, exchange levels can increase and decrease, and this thesis aims to understand the key characteristics of an ecosystem that influence how much exchange takes place. Below, I discuss how I can treat exchange as a variable through qualitative research and the challenges in measuring it.

First, it is useful to classify the different forms of exchange described above. After analyzing data from this research two classifications of exchange 
emerged: tangible forms of exchange and intangible forms of exchange. Exchange of resources and skills can easily be isolated because we can identify with a good level of clarity when such an exchange has happened. Investments, specific services, introductions, and other examples mentioned above are tangible. Many of these can be quantified, directly analyzed, and reported to a certain extent. Levine and White (1961) would consider such forms of exchange as material goods and gratifications in the immediate present. Exchange of ideas, knowledge, energy, and emotional support are quite intangible. While they can be pointed out, they may be more abstract. Isolating that form of exchange and quantifying it can be a challenge because the effects of such exchange may take time to be noticed. Information that is shared may be partially quantified (e.g. the number of posts on the Yammer page), but it may be a lot more difficult to isolate and to quantify the ideas and knowledge shared because they represent different outcomes depending on what the readers get out of the posts. The level of energy and support exchanged during retreats may be noticed and its impact can be identified, but is difficult to isolate and quantify it.

Measuring exchange as a variable within an ecosystem becomes more complex when considering the tangible and intangible nature of forms of exchange. Creating a common unit for different forms of exchange is a challenge. For example, it will be a disservice to the different forms of exchange by placing exchange of resources and emotional support in the same category. They are of different nature, have varying consequences, and mean different 
things to the various parties involved. However, such a limitation does not create a major disadvantage in this research because of the unit of analysis I utilize.

When using an ecosystem unit of analysis, an individual organization is not the subject of inquiry and less emphasis is placed on what an organization gives or receives. Therefore the inquiry at the heart of this research is less concerned about exchanges between specific parties, but rather examines the exchange activities in an ecosystem as a whole.

At Enspiral, the term "vibrant" is used often to describe the ecosystem. The term "vibrant" is also used to describe the levels of activities that exist in other ecosystems, including entrepreneurial hubs, cities, and more (e.g. Pistrui, Blessing \& Mekemson, 2008; Isenberg, 2010; Zahra \& Nambisan, 2011; Feld, 2012). The term vibrant means full of energy and life, it means the act of pulsating. In ecosystem terms, it refers to the level of activities and interactiveness that gives the ecosystem its life. Using this frame, I place an emphasis on exchange activities from an ecosystem perspective.

Such inquiry opens the opportunity to study exchange that is not limited to give and take exchanges between two agents. A metaphor on the interaction between a cow and a small tree can help explain this point. When a cow eats leaves from the lower tree branches and walks away, that can be considered a one-way service that the tree provides to the cow. From the tree's standpoint, 
it may be challenging to consider that an exchange. However, if we consider the entire ecosystem, the cow is going around eating branches from different trees, and every few minutes it leaves manure that is a rich source of nutrients for the trees. While the cow may have not necessarily dumped its manure next to each tree it eats from, the cow is taking from but also giving to the ecosystem. We can apply such a metaphor to ecosystems of organizations. In such ecosystems, there may be various exchange activities taking place where organizations give to different parts of the ecosystem but also receive what they need. In an ecosystem, organizations can give to one organization but receive different things from another member of the group. Those exchanges may not be linked, and organizations may not give with the expectation of getting something in return from the receiver. For example, members of one organization may give advice to members of another organization but receive nothing in return. At the same time, someone from a separate organization may refer a client to their business. These two exchanges can be completely unrelated, but both are exchange activities when using an ecosystem lens.

This is a phenomenon that I observed in the Enspiral ecosystem. Exchange was not necessarily defined by a specific give and take transaction between two entities. When people exchanged knowledge through their online platforms, there were instances that specific organizations were just giving, while others were receiving, without necessarily reciprocating right away. However, when people continuously post different types of ideas on Yammer, when organizations and individuals continuously facilitate introductions for 
others and when individuals from different companies volunteer their time to the needs of the collective, the ecosystem's exchange activities are heightened.

While such framing of exchange may make it more challenging to measure exchange activities, it can capture different types of exchange taking place in an ecosystem. Adopting Levine and White's (1961) broader definition of exchange, this research incorporates many types but also incidents of exchange taking place within Enspiral, including those that may not be quantified. Therefore, instead of attempting to create a standard unit to measure exchange activities within an ecosystem, my research focuses on identifying some of the key factors that influence the level of exchange activities within an ecosystem. In the next section of this chapter, I discuss three key characteristics of an ecosystem that influence the level of exchange activity.

\section{Ecosystem characteristics that influence exchange activity}

\section{Interdependence}

A defining characteristic of an ecosystem is the fact that all organisms within it are interdependent. Organizations depend on each other, and the study of ecosystems primarily revolves around such interdependencies. Data from my research indicates that the degree of interdependence is associated with the level of exchange activities taking place within the ecosystem. Interdependence can be understood in the functional complementariness that exists within diverse groups in an ecosystem (Morgan, 2006). 
A high degree of interdependence between organizations is a key feature of the Enspiral ecosystem. Vivien Maidaborn, one of the Enspiral Foundation board members, suggests that their "uniqueness" is in them "loving each other's businesses or social innovation initiatives and really supporting them to succeed. It's much more like a garden where somebody is taking care of companion planting and somebody else is making the connection between what we're planting in that bed and what we're planting in [a different] bed and how they might be harvested together." The description of "companion planting" is one that most fits how various organizations within Enspiral see themselves. The Enspiral community is not shy about facilitating deep interdependencies amongst them, and sees interdependency as an advantage. As a matter of fact, Linc Gasking, a serial entrepreneur who has founded several initiatives within Enspiral including FreeRange, suggests:

So just because you want to work on something that matters doesn't mean that you're able to do it successfully by yourself. Startups are a team sport [...] What Enspiral did is it created a space of willing founders that were willing to help others out until they found something that they believed in enough to become their full time gig. That's the case where you see [how] BuckyBox and Chalkle and Loomio all came out. [They] would not have existed without Enspiral there, from the actual people involved and the connections that Enspiral allowed to be made through being held at Enspiral.

Various organizations within Enspiral show a natural inclination to deep interdependences. Through various interviews and observations of the interaction between individuals at Enspiral, I noticed how members of the community naturally gravitate towards getting others more involved in their projects. A term many jokingly utilize is "borging." Borging refers to the 
situation when you talk to someone about their project, get really excited about what they are doing, end up becoming part of the project and take on new responsibilities without having prior intentions to do so. Facilitating and fostering such interdependencies is a characteristic that is promoted within the community. This leads me to pose the questions, how is interdependence facilitated within an ecosystem? What are the influential characteristics that enable such a high degree of interdependence? In the section below, I attempt to answer the first question by analyzing the way interdependence is facilitated at Enspiral.

\section{How interdependence is facilitated}

Interdependence through shared skills

The functional interdependencies that are facilitated include the utilization of skilled individuals across the ecosystem, such as the Enspiral lawyer, software engineers, mobile developers, designers, online marketing consultants, events organizers, and musicians. Different startups within Enspiral have developed a level of dependency on the many skills that are available within the ecosystem, and tap into these in order to make their companies successful.

Interdependence through shared access

Another form of interdependence is in gaining access to people and resources externally. Individual startups rely on the introductions they get to 
key individuals and potential resources that will directly benefit them. It is a regular habit for individuals from the Enspiral community to introduce new people they meet to others within the ecosystem. Even from my own experience engaging with Enspiral as part of my participant observation study, I was continuously flooded with introductions to a huge range of individuals that the community had access to. Offering an introduction came naturally to most people I engaged with, and they seemed to gain pleasure in helping out by connecting me with people I would enjoy meeting.

Interdependence through shared resources

A degree of interdependence is noticed through the shared resources that members of the ecosystem actively create and depend on. This is seen in the way that each company contributes part of its revenue to the foundation. The way that those resources are spent for the well being of the ecosystem then further deepens the degree of interdependence within Enspiral. The foundation spends its resources on, staff to run operations for the ecosystem, looking after the shared office in Wellington, various types of events and activities held for the collective, and other exchanges. These services are intended to benefit everyone within the ecosystem and the absence of such services can affect members of the ecosystem.

Interdependence through advice and mentorship networks

Members of different organizations depend on the ecosystem for advice and mentorship to make their startups successful. Individual members see 
their work as being a team effort, and believe in supporting one another to succeed. This is quite common amongst the entrepreneurs within the ecosystem. As a matter of fact, the Chief Executive Officers of three startups within Enspiral created an informal support group where they meet on a weekly basis and discuss the challenges they are facing and advise one another. Furthermore, when a company is about to launch a new website, making modifications to their products or services, the inclination is to ask for feedback and advice from members of the ecosystem. They do this through the online forums or by going around the shared office and speaking to specific individuals.

Interdependence through emotional support networks

A key area of interdependency is the emotional support that members of Enspiral provide to each other. The emotional support individuals receive by becoming part of Enspiral is a key factor that drew many towards this ecosystem. One interviewee explicitly describes how she came about becoming a member of Enspiral:

For me it was the emotional support. Knowing that there was a place that you could come, where everyone would smile at you and be friendly to you and just openly help you if you needed it and I could be open because I had been, what's the word, I had very low personal resources at the time I came to Wellington and so having that was actually huge.

One theme that emerged through the analysis of the interview data is that individuals involved at Enspiral felt they could be themselves fully in that ecosystem. Joshua Vial (the founder of Enspiral) affirmed this by saying that 
Enspiral is a place where, "I can be all who I can be here." The social standard amongst individuals is to keep judgment out of their interactions and have greater acceptance. Data from this research further suggest that by becoming part of the ecosystem, individuals establish a commitment to each other first, followed by the companies and startups they are working on. Joshua Vial describes membership at Enspiral as a form of "citizenship in the collective." Enspiral aspires to create both connections between individuals and devotion to the ecosystem as a whole. Therefore, the level of support individuals within Enspiral provide to one another at a personal level results in a high degree of interdependence within the ecosystem for individual emotional support.

Interdependence through collective accountability mechanisms

The Enspiral ecosystem actively nurtures social mechanisms for accountability that influence individual and organizational behavior. This has been observed in different instances. A high level of transparency is created at Enspiral to increase accountability to fairness and equitable behavior, and Enspiral aspires to create even more transparency in the near future. For example, company accounts and the accounts of individuals that do business through the Enspiral platform are available within the ecosystem. ${ }^{20}$ Also, there is transparency of the Enspiral Foundation' financial activities, including its earnings, expenditures, how much each person employed by the Foundation is paid, and earnings of individual companies through the Enspiral contracting

\footnotetext{
20 This includes companies such as the engineering and design agencies that hold the Enspiral brand. This doesn't include companies that operate independently but are part of the Enspiral ecosystem.
} 
platforms. In doing so, everyone within the ecosystem can be aware of how much money is being contributed to the pot, who is contributing how much, who is earning how much from that pot, and how those resources are getting allocated. Rather than assigning the responsibility of ensuring accountability to an individual, the Enspiral ecosystem chose to distribute that responsibility to the collective. It increased transparency and mechanisms where participating organizations and individuals are accountable to the ecosystem and not to specific authorities. Furthermore, through the collaborative decision making tool and the lack of someone who manages the ecosystem, the well-being and health of Enspiral is distributed across the ecosystem. All individuals, either representing organizations or just themselves, vote on various actions affecting the ecosystem. Collaborative decision-making that is open and transparent to all within the ecosystem creates a high degree of interdependence within Enspiral.

Another example of an accountability mechanism is when Joshua Vial initiated, the "C3" project mentioned earlier in this chapter. Rather than creating a personal goal, he opened up the initiative to the collective and asked others who intended to join him on a daily exercise of content creation to keep one another accountable to that task. They formalized a means of sharing what they create and tracking each person's progress. As such, the ecosystem offered a platform for individuals to keep one another accountable to their own targets. 
Interdependence through shared processes and structures

A means through which the ecosystem facilitates interdependence is by focusing the collective effort through the Enspiral Foundation, the entity concerned with the health and well-being of the ecosystem. The primary focus of the foundation is to create processes and structures that enable the ecosystem to be vibrant and thrive, instead of aiming to control the activities and outcomes of the ecosystem. For example, when it comes to recruiting organizations and individuals to join the Enspiral ecosystem, the foundation has actively avoided creating a checklist of criteria to evaluate each candidate with, but rather developed a flexible recruitment process. Rochelle Furneaux, lawyer and partner at Enspiral Law and someone involved in designing recruitment of entrepreneurs and enterprises into the Enspiral ecosystem, highlights that they're "working on processes rather than criteria" because criteria “don't leave much room for judgment... it's really important to leave that open and it's really about the majority of people supporting something." The core Enspiral membership evaluates each candidate and everyone has a vote to decide who joins and who doesn't. Enspiral members recognize that evaluation of each member candidate is going to be different. As such, instead of working with pre-determined criteria that remove the individuality of each application, the membership uses a collective decision making process to say 'yes' or 'no' on who joins the Enspiral membership. The membership sees itself as a steward of the ecosystem, not its manager or director. As such, there is an inclination to create further interdependence when organizing and operating the ecosystem. Similar to recruitment, the Enspiral Foundation is continuously 
creating processes and structures that allow for greater degrees of interdependence and result in more exchange within the ecosystem.

I started the above section as an attempt to answer the question, how is interdependence facilitated within an ecosystem? I identified shared activities, processes, and mechanisms through which Enspiral facilitates greater degrees of interdependence within its ecosystem. Next, I tackle the questions of, what are the influential characteristics that enable such a degree of interdependence? In attempting to answer that question I highlight several enabling factors and characteristics identified through my research.

\section{Interdependence enablers}

Permeable organizational boundaries

One of the key characteristics of the Enspiral ecosystem is that the organizations that exist within it have more permeable organizational boundaries than most organizations. A permeable boundary makes an organization more open to its environment. It allows for a cycle of input, internal transformation, and output between an organization and its environment, where input and output exist in a state of interaction (Morgan, 2006). Such permeability allows for information, knowledge, skills, resources, and talent to flow in and out, and be shared amongst other organizations within the ecosystem and at least partially with organizations independent of Enspiral. 
Enspiral has open source values deep in its core roots because it is in the technology environment. Open source software development happens when developers make their software and source code available on the internet openly for free, both for individuals to use the software and for developers to modify the source code. The fundamental values of open source software are sharing, openness, and semi-permeable organizational boundaries (Chesbrough, 2006). These values are adopted at Enspiral and influence the ways organizational boundaries around startups are treated.

For example, an individual working in one startup may spend a few hours a week helping out a different company in an area where they can use the most help. At Enspiral, this takes place often, but arrangements are made on a case-by-case basis. There are times individuals charge for their time, or do it for free, depending on the relationship they have with one another. Most of the individuals interviewed for this research have been involved at different capacities in projects or startups independent from their primary occupation. The cross-pollination of information, knowledge, skills and talent is a key characteristic that defines the interaction between different organizations within the Enspiral ecosystem. It is common for different groups or companies to be pulled in to a project an organization is working on.

Another example of permeable boundaries is seen in a multi-year government contract called LifeHack that the Enspiral Foundation, on behalf of the ecosystem, secured in 2013. This project is supported by New Zealand 
Prime Minister John Key (Goh, 2013), and its purpose is to develop various initiatives to address youth depression. The Enspiral Foundation became the official contractor tasked with leading the project, and it created initiatives that brought in various startups and entrepreneurs from the ecosystem to support the project. This project taps into the knowledge and expertise that exist within the individual organizations and allows for greater cross-pollination within the ecosystem. These examples demonstrate how more permeable organizational boundaries enable for greater degree of interdependence.

High degrees of trust

Data from this research suggest that the level of trusting relationships established within the Enspiral ecosystem enable interdependence, thus affecting the exchange activities taking place. An open and trusting approach to engaging with one another and with external entities is a defining characteristic about Enspiral that I have observed. My first interaction with the Enspiral ecosystem was a meeting with Joshua Vial and Sam Rye. These two individuals were involved in establishing the ecosystem from the early days. I was a complete stranger coming from overseas with no common networks that we shared. Yet, after about thirty minutes of conversations, they opened up their networks and offered to introduce me to half a dozen individuals I should speak to. They then added me to their closed Yammer group and introduced me to the whole ecosystem as someone who is interested in learning about organizations. I received about half a dozen responses with a welcome note from individuals offering to discuss my interests further and willing to help out 
if I needed anything. I also observed such a trusting approach in interactions with other individuals and organizations.

Much of the interaction between organizations and individuals at Enspiral is also based on trust. Alanna Krause, the Enspiral Foundation administrator, states that, "the ingredient that [the Enspiral ecosystem needs] to have to make [it] work is very high trust." She further elaborates, "what causes people to be trustworthy is being trusted" and this encapsulates the underlying philosophy behind trust within the Enspiral ecosystem. Silvia Zuur, CEO of Chalke, ${ }^{21}$ further articulates:

When I look around the room in the member's meeting, I trust every single one of the human beings in that room and I could not question it or explain it. I might not agree with every single one of the members in the room [...] there are a whole lot of different ideologies and beliefs, but to be honest, trust is something that I just do not question. To me it is just there.

Furthermore, there is a noticeable lack of formal contract engagements when different companies work together or when individuals engage with them on various issues. For example, there are organizations that owe money to each other or to individuals, and a lot of this is arranged based on trust between people. When the foundation needs help in an area and asks individuals to contribute, they'd say, "ok people in Enspiral, just do the work and we'll pay you when we can" as Alanna Krause put it, "and people were willing to do that because of the high trust environment and we're still paying that off." Until the time that this paper was written, there hasn't been any legal

\footnotetext{
21 Chalkle (www.chalkle.com) is an Enspiral based tech startup that serves as a platform for individuals to build communities online to teach and share their knowledge and skills offline.
} 
action or litigation taken within the Enspiral ecosystem and between Enspiral companies and external entities - Enspiral was founded in 2010. As Joshua Vial put it, "Conflict has been pretty much handled by conversations, sometimes in isolation, other times with facilitation and support... they are usually resolved by people adjusting their trajectories around each other."

Rochelle Furneaux, main partner at Enspiral Legal, further made the point that working in an environment that is trust-based makes the process of work a lot more efficient. Rather than participating in work-place politics, focusing on minimizing individual liability at every corner, and spending time trying to avoid being blamed for something, Rochelle suggests that in a trusting environment she felt she could spend more of her time actually creating value. Reflecting on her experience at a conventional law firm, she describes that environment in the following way:

It was a real distrust kind of situation and I got told things like all the things that you should lie about in order to make you career go well... Don't tell the truth. Appear to be way better than you are at all times and if there's a mistake, make sure someone else gets the blame for it. Don't ever put your hand up and go "it was my fault"' and all these sort of things that just instinctively, they felt really wrong and over time I worked out why they were wrong, but it took quite a long time.

She found herself spending more time navigating her environment than serving her clients. Rochelle explains how creating a more trusting environment has impacted her work at Enspiral:

When [Enspiral members] are given the support and emotional trust to do something and what they're trusted to do is explained to them, they generally step up and do it. So if you treat people 
right, they actually turn out to be more of a star than a loser. If you treat people like losers, they will be losers.

Rochelle further sees trust connections as a form of currency, and explains,

So if you have connections with people who trust you and people who you trust then the ability to get work goes from 90\% effort to get the work in and $10 \%$ effort to do the work, to the other way around.

By being part of Enspiral, she spends less time marketing her services and more time actually doing the work.

In sum, the Enspiral ecosystem facilitates great levels of trust, and the research data suggest that trusting others is a starting point for different types of interactions. Having trusting relationships is an enabler of interdependence within the ecosystem, and contributes to greater facilitation of exchange.

Approach to collaboration and competition

There is a high emphasis placed on collaboration within the Enspiral ecosystem. This subsequently influences the approach to competition within the ecosystem and with entities outside of the ecosystem. The collaborative approach to working together amongst entrepreneurs and enterprises serves as an enabler for greater degree of interdependence, and the approach to competition highlights some of the ways in which the ecosystem is able to maintain a high degree of interdependence while allowing for some competition to take place. 
Individuals and organizations that become part of the Enspiral ecosystem have a bias towards taking collaborative approaches when trying to achieve their goals. Data from this research reveal more of how this collaboration is facilitated than why this collaboration is facilitated. Below I discuss how collaboration is facilitated within the Enspiral ecosystem and how situations where competition arises are handled. The conversations around competition and collaboration are intertwined, and rather than separating them I analyze the relationship between the two as understood and applied by members of the Enspiral community.

There is a strong emphasis on taking a collaborative approach to the entrepreneurial ventures taking place at Enspiral. Linc Gasking's message that "entrepreneurship is a team sport" is core to Enspiral, and the ecosystem's roots in the open source value system are highlighted above. Enspiral was founded based on the idea that collaboration is the way entrepreneurs and enterprises work best. "Collaboration is just a really natural thing to do," explains Joshua Vial, founder of Enspiral, "I feel like collaborative people have shown up for Enspiral because it is a collaboration and in that way people tend to be more collaborative because that is just what they do and how they work." Taking collaboration more as the norm of engagement rather than an exception, enterprises and individual entrepreneurs operate in a manner that is often open to collaborating with others. Joshua Ford, CEO or Rabid, an Enspiral based web and mobile development company, further explains that, "one of the goals of the network is to help each other at a business level." This infers that 
the purpose of having the Enspiral ecosystem is so that they can all collaborate and support one another.

Almost all the startups that have emerged within the Enspiral ecosystem have done so through collaborative efforts between different companies or between individuals from different enterprises. Alanna Krause puts it together by saying, "any project or any company that anyone's doing here; everyone else is fully behind." Several of the startups at Enspiral are developing tools for more collaborative work. For example, Loomio is used within Enspiral, and it is also adopted by companies, government initiatives, activist groups, and different types of organizations around the world. However, to learn more about the approach to collaboration at Enspiral, it is helpful to understand their approach and relationship with competition.

"A rising tide floats all boats" is the analogy that Joshua Ford utilized to explain the relationship between collaboration and competition. He says:

[Our] expectation of competition is definitely something that is different to a really popular concept that businesses exist to maximize profit and they do in many ways. But that does not mean that you maximize profit necessarily by hammering down your competition. The Wellington tech scene does not get that way by having hugely competitive narcissistic in-fights of people competing over small bodies of work. They co-operate and therefore the quality of technology work in Wellington is far better amongst small agencies than lots of other places in the world.

Here, he propositions that the success of an individual company is tied with the success of the ecosystem, and if companies work together instead of actively 
trying to undermine one another then the ecosystem flourishes. A flourishing ecosystem creates rising tides where individual companies can benefit. He is referring to both the Enspiral ecosystem and the greater Wellington ecosystem in which Enspiral exists. It does not mean that companies are not put in competitive scenarios - companies that are offering similar services often times compete - but instead of trying to crush one another and seeing their success depend on the destruction of the other, they try to cooperate and find a way to co-exist and flourish together.

This research has shown very few instances where organizations within the Enspiral ecosystem are in some form of competition. The most direct competition observed is between Rabid, Joshua Ford's company, and Enspiral Craftworks, another development company within the ecosystem. Joshua Ford discusses the nature of the competition between those two companies:

Craftworks is starting to compete with us [...] I do not view it as a negative thing [...] But fundamentally it is not the sort of work that is scarce enough that we need to worry about whether they are taking work off our plate. And Enspiral is a unique independent broker for us to talk to great people like Craig and Joshua Vial setting up Craftworks and whoever comes into their group. We just could not have access to [them] if we viewed ourselves as competitors in the same town who meet each other at presentations and had beer. We are actually collaborating more around our shared interest in the [Enspiral] network, which is kind of the shared interest in the tide, we are not actually latching our boats together [...] But our core business, which is to do software development, we are not actually collaborating that closely. Our interest is that if we feed the whole ecosystem, that will keep everyone happy and we can compete. I do not know about the capability to collaborate on a piece of work, but I do not know if that is the most valuable thing that a company could collaborate on. 
Joshua Ford expresses interest in being in dialogue and working together in ways that make sense, in this case around their shared interest in supporting the Enspiral ecosystem. He says that he's passed a few leads over to Craftworks, but has not done business with them. It is important to also note that Joshua Ford from Rabid and Joshua Vial from Craftworks have worked together directly from the early days of Enspiral and have been doing the same type of work. But their approach to competition observed through this research is not that of a zero-sum game.

Furthermore, as web developers, they operate in an industry where their skills are in high demand, and that makes it less likely for them to step on each other's feet. Therefore it is incorrect to assume that this approach to competition is consistent across different conditions in the environment they exist in. It is also inappropriate to automatically assume that the two companies would approach competition the same way if the business landscape changes. They continue to maintain a level of interdependence because they are both riding the same tide and have a shared interest in helping the tide rise.

Vivien Maidaborn, a team member of Loomio and board member of the Enspiral Foundation, points out that even when organizations within Enspiral are competing, they maintain a habit of information sharing and the "open source wisdom" that "creates a different culture than when you're in an old model, a charity model or a business model which is really based on ideas of 
individuation and competition." Vivien broadens the application of the common sense wisdom by saying:

Common sense would tell us that this is the moment to give this away rather than hold on to it because if we give this away then it's likely to come back in these ways as opposed to hold on to it and put it into IP. That's a core value that all of Enspiral shares. It meant we haven't had many conversations about competition. We more had conversations about living the value of open source. I think that leapfrogs a whole process that a sector that's already competing has to go through to stop competing.

She posits that what helps determine the collaborative aspect during times of competition is the act of sharing information and knowledge. The approach that she's describing is that of openness rather than protectiveness, that of allowing greater levels of sharing and interactions rather than creating separation and distance. While the nature of Enspiral and its culture are biased towards a collaborative approach and take a normative stance that the natural inclination of humans and organizations to collaborate, this research indicates how such a collaborative approach contributes to a greater degree of interdependence. Enspiral's approach to collaboration and competition is focused around the idea of openness and sharing, and as discussed above, such activities facilitate more interdependence within the ecosystem.

\section{Conclusion}

I began this section by asking, what are the key characteristics of an ecosystem that influence the exchange activities within it? I discussed how interdependence is a characteristic of an ecosystem, and provided evidence from research on how there is a high degree of interdependence facilitated 
within Enspiral, thus allowing for greater level of exchange activities to take place. The two main approaches I took to uncover the concept of interdependence within the case study were identifying how interdependence is facilitated, and analyzing the main factors that serve as enablers for interdependence.

In summary, my research indicates that a greater degree of interdependence is facilitated when an ecosystem has shared skills, shared resources, accountability mechanisms, access to people and additional resources, advice and mentorship networks, emotional support networks, and processes and structures. These activities promote greater degrees of interdependence. Trust based relationships, more permeable boundaries, and a collaborative approach to competition enable for interdependence to occur within the ecosystem.

In the next section, I discuss another characteristic of an ecosystem: diversity. Organizational diversity is a key component in the study of ecology and ecosystems (Hawley, 1986; Singh \& Lumsden, 1990; Reydon \& Scholz, 2009). One of the main drivers for research within the organizational ecology field has been the desire to understand why there are so many different types of organizations (Hannan \& Freeman, 1977; Carroll, 1984; Sing \& Lumsden, 1990). In my discussion of diversity, I focus on how diversity of organizations allows for more exchange activity within an ecosystem. 


\section{Diversity}

When trying to understand biological and organizational ecologies, diversity is a major component of the inquiry (Begon et al., 2009; Morgan, 2006). The study of diversity can be approached from different angles and can be as broad or specific as a researcher makes it. Such inquiry can also be used to answer a wide range of questions. In this research, I take a broader scope of diversity to look at both the different types of organizations within an ecosystem and the many aspects that distinguish one organization from another, including the available resources, knowledge, skills, structures, processes, and forms of interacting with the outside world. A broader view of diversity is able to capture more exchange activities taking place within the ecosystem. Open-system theorists posit that organizations themselves are systems, with complex sub-systems that operate and interact within one another (Morgan, 2006). I infer from this that when two organizations interact, the subsystems in those organizations participate in forms of exchange. Therefore, I find it relevant to explore the diversity of organizations and also the diversity of sub-systems of those organizations that contribute to the exchange activities in the ecosystem. I posit that exchange happens at the intersection of different units in an ecosystem, and argue that greater levels of diversity increase opportunities for more intersections between different units. As the number of unique units increase, the potential intersections also increase, thus resulting in greater levels of exchange. 
Below I present my analysis on how levels of diversity observed at Enspiral enable greater exchange activities to take place within the ecosystem. I discuss the ways diversity fuels activities within the internal economy, how it facilitates more innovation, and how it allows for organizations to access resources, knowledge, and talent within the ecosystem and also outside of it.

\section{Diversity fuels an internal economy}

Greater levels of diversity in an ecosystem allows for more complimentary relations between organizations to take place. The more diverse an ecosystem is, the greater the chance that organizations can meet many of their needs within that ecosystem. The more diverse entities that exist in an ecosystem, the greater the possible intersection combinations for those entities to exchange amongst one another. As such, diversity can create and fuel an internal economy and subsequently allows for more exchange activity. Data from my research indicate how greater levels of diversity have influenced a stronger internal economy.

One of the main values Enspiral adds to different service oriented companies is that it creates a market for them within the ecosystem. The amount of work they get through Enspiral differs depending on what the service they provide is and also the need for them. This varies quite a bit. Enspiral Legal for example has $40 \%$ of its legal work come from within the Enspiral ecosystem, and the remaining $60 \%$ of its work is from organizations outside of Enspiral. Earlier in 2013, it used to be 30\% internally sourced clients 
and $70 \%$ external, but when new types of startups emerged that provided more business for Enspiral Legal. Legal services are something most companies need and the more types of companies emerge the more the need for legal services. Having a law firm available within the ecosystem makes it much easier for the companies to access such services and maintain a relationship with a lawyer they share a physical space with. Moreover, web and mobile development companies and design agencies that are part of Enspiral also have clients within the ecosystem and participate in the internal economy. When companies need different types of help, the first place they look at is to contract staff from within Enspiral. As a matter of fact, when I noticed that when people outside of the ecosystem come and talk about a project they are working on, individuals they meet at Enspiral are fast to recommend different service providers from within the ecosystem that may be able to help them. Enspiral offers a market for companies that exist within the ecosystem, and the diversity of that ecosystem fuels such an internal economy. As seen with the Enspiral Law example, the more diverse the ecosystem gets, the more market opportunities it provides for Enspiral based startups.

Furthermore, the LifeHack project is an example where a large outside contract can boost the internal economy. Enspiral Foundation secured a NZD\$1.2 million multi-year contract to develop initiatives that addresses youth depression. The various initiatives that were developed through this contract utilized several companies and contractors within the ecosystem. Various contracts that companies took for this project distributed the resources within 
the ecosystem and utilized the infrastructure that companies had already built. The internal economy was also advantageous for the project because many of the companies within the ecosystem had already worked together at some point, the people running them are close friends and have an understanding of the different skills and capabilities that exist across all companies involved. Therefore, the cost of transacting with these entities is lowered because less time and resources are spent integrating different organizations and their technologies into the LifeHack project. Several interviewees for this research claim that the LifeHack project has a rippling effect within Enspiral and that most people within the ecosystem have been affected by it. Vivien from Loomio also suggests that the project increased the internal economic activities, creating more opportunities for exchange. The level of diversity that existed within Enspiral during the time that the government contract was secured meant that various facets of the project could remain within the Enspiral ecosystem and contribute to the internal economy.

In addition, one of the earliest technologies that came out of Enspiral is an internal accounting tool, operated through an intranet network. This tool is the primary interface for the internal economy, especially for individuals who are doing contracting work through Enspiral. Whenever individuals got paid for their work through one of the main Enspiral companies (e.g. Enspiral Services), the money would appear in their Enspiral account through this accounting tool. It stays in the Enspiral account until the individuals decided to withdraw it and deposit it in their own account. If an individual wishes to make 
a payment to a company or organization within the ecosystem, they can do it directly from their Enspiral account. This tool allows for further exchange within the ecosystem and is efficient in avoiding double taxation. For example, every company or individual has to pay for their desk rental to Enspiral Space, the company that manages the office. This monthly fee often gets paid from the internal account. When people contribute part of their revenue to the foundation, they can do that through the internal account as well. This tool therefore allows greater utilization of the diversity within the ecosystem and fuels the internal economy. In sum, greater diversity within the Enspiral ecosystem has contributed to the development of an internal economy that facilitates more exchange activities.

\section{Diversity facilitates more innovation}

There is plenty of literature that shows the relationship between diversity and organizational innovation (e.g. Aiken \& Hage; Cox, 1994; Amabile, 1996; Leonard \& Sensiper, 1998; Bassett-Jones, 2005; Coriat \& Weinstein, 2002; Forbes Insights, 2011 July). The more diversity exists within an ecosystem, the greater opportunities for innovative activities take place. A diverse ecosystem contains different types of knowledge, ideas, perspectives, resources that are directly available, resources that can be accessed, and talented individuals amongst others. Innovation takes place when these aspects intersect (Johansson, 2004; Dahlander \& Gann, 2010). Therefore, greater levels of diversity increase the likelihood for greater intersections between disparate parts. They allow for talented individuals to come across 
ideas they never thought of, which they take and turn them into products and services.

Data from my research suggests that a new form of value is created when different agents combine parts of their knowledge, resources, and capabilities in a way that allows them to come up with things they might not be able to do individually. The phrase of the whole is greater than the sum of its parts applies in such a situation. By two or more agents coming together new knowledge, new ideas, new types of solutions can be developed. Furthermore, the types of ideas and concepts that emerge within a specific organization are also not fully utilized because an organization has a limited scope of what it can do, and its resources are limited.

There are numerous ways innovation takes place within the Enspiral ecosystem, from small day-to-day activities to large projects that take place within the ecosystem. "You're in a hive of activity with entrepreneurial creative minds and a range of expertise across different sectors," explains Guy Ryan, CEO of Inspiring Stories, a charitable trust that is part of the Enspiral ecosystem but maintains a level of financial and ownership independence. Different types of companies and individuals interacting on a regular basis, sharing their lessons and ideas, giving feedback to each other, running brainstorming meetings, and engaging actively allows for new value to be created. Such crosspollination allows for innovative ideas and solutions to emerge. Richard Bartlett from Loomio explains how people "innovate a new solution that none 
of them would have on their own" by engaging with one another. He continues to explain how innovation has been taking place within groups:

It's so often that you'd start a conversation with two teams like 'no we should do this, no we should do that,' and talk, talk and [then] a solution pops out and the solution is different from anyone's at the starting point. That's the innovation and people get behind it because they watched it form and they realize that it's you're not just favoring someone else's idea, it's the group's idea and the concept of a group idea is really liberating because you saw how it formed and it's not attached to one person's ego. It's like, 'this is the best solution we can find with everyone here right now under these circumstances.

Diversity within an ecosystem provides a basis for ideas that are not applicable in one organization to be utilized and expanded to other organizations. This is an argument that has been made by organizational theorists, and also observed at Enspiral through this research. Theorists see innovation in markets occurring when products or service ideas are developed and/or adapted to new or expanded market uses (Rocha \& Miles, 2009; Miles et al., 2007; Rocha \& Birkinshaw, 2007; Schumpeter, 1934). Looking at individual firms, innovation potential can be limited because processes and systems can constrain knowledge sharing and knowledge utilization, and also because market strategies can create real or imaginary limitations by creating a narrow focus on what firms can/cannot work on (Rocha \& Miles, 2009). It is further argued that creating a community of firms that work in complimentary markets can enhance the fuller utilization of the entrepreneurial capability of all its members (Rocha \& Miles, 2009). Such communities can enable member firms to, innovate across firm boundaries, share knowledge and information, identify new markets, and facilitate unplanned innovations that individual firms might 
not realize on their own. Enspiral as an ecosystem offers a breeding ground for greater innovation by having different types of organizations in close proximity and continuously interacting with one another and sharing their resources, talent, and information. The more diverse the ecosystem is, its ability to generate new ideas and share it across the whole ecosystem is augmented.

\section{Diversity provides access}

One of the main values of a diverse ecosystem is that it gives organizations greater access to what they may not have available internally. Diversity allows organizations to access ideas, resources, skills, information, talent, and more both internally within the ecosystem and also through the external networks that are available through the ecosystem.

When looking at internal access, data from this research suggest that a more diverse ecosystem gives participant organizations greater access to different forms of resources. Joshua Ford explains, "people have a diversity of what we are constrained, in terms of what we can know and what our skill sets can be... So Enspiral can be a way for us to both access resources and people that we need." Greater level of diversity means access to a wider range of ideas, skills, information, and talent that may not necessarily be available within individual organizations. For example, BuckyBox, one of the earlier startups at Enspiral, is a company that hired all its team members directly from Enspiral. The diversity within Enspiral, even when it was small and young, allowed BuckyBox to gain access to talent through the ecosystem. Another example is 
the founding and growth of Loomio. When Jon Lemmon, Benjamin Knight, and Richard Bartlett approached Enspiral to build a collaborative decision making tool, what they were offered was a space to work and access to talented people, but they had to build the tool themselves. As three activists who hadn't spent time developing web applications, the Enspiral ecosystem offered them access to knowledge and to different sets of skills and resources. One developer from Enspiral joined their team and taught the various members how to code, and that way they were able to have enough developers to work on building the Loomio application. According to Ben Knight, other developers "pitched in some lines of code" as well and the development of the application was a collaborative project quite earlier on. Ben Knight further describes how the process of integration with Enspiral was and the different forms of access the Loomio team gained:

It felt like a really safe place, supportive place to get a project up and running [...] to figure out all the different elements of it and how they could fit together and to call on people for advice, which were mostly technical expertise and the time. But then I increasingly started having conversations with Joshua Vial and Alanna about the business model and realizing we needed a legal structure. [...] We ran a crowd funding campaign in April of that year. We went through the whole process of forming a brand identity, figuring out what we should call the thing, and figuring out what our logo would look like. Maz Herman came in and did the early design work. Aaron Thornton was in and we would just have these weekly meetings where everyone would get together in this room or the couch room or wherever and just keep the strategic thinking moving along and keep [developing] the core platform.

Access to skills, mentorship, knowledge, and talent is one of the main ways Enspiral has been valuable for the establishment of Loomio. Beyond the founding period, Enspiral became an early adopter of the Loomio application, 
where the collaborative decision making tool is still used within the ecosystem. This activity gave Loomio further access to continuous feedback and ideas on ways they could improve the product, both from users and also developers and designers.

Diversity within an ecosystem also gives organizations access to ideas, resources, skills, information, talent, and more things that are available within the outside world. Going back to the Loomio example, Enspiral became a "source of external connections" as Ben Knight put it, and it gave them the endorsement, legitimacy, and connections they needed to launch successful fundraising campaigns. Another example is an initiative that FreeRange organized to bring in Horizon Ventures to New Zealand and explore investment opportunities in startups. Horizon Ventures is a large global venture capital firm that invested in companies such as Facebook, Spotify, and Waze. FreeRange took the investor representing Horizon Ventures around the country to speak to about 80 startup entrepreneurs and organized a pitch event in Auckland. Linc Gasking, who runs the Enspiral-based company FreeRange, brought in the investor to Enspiral and exposed various startups in the ecosystem to funding opportunities. As a result Rabid and BuckyBox, two Enspiral based startups, were chosen as finalists to the pitch event that had a panel of some of the leading investors from around the world and an audience made up of the key stakeholders in the New Zealand startup community. He also hosted a private dinner with the Horizon investor primarily for the Enspiral ecosystem where members could learn and get advice about building 
successful startups. FreeRange gave the ecosystem access to external resources and knowledge.

Another example is how access through the diversity of the Enspiral ecosystem enabled for a company like Enspiral Dev Academy to emerge. Utilizing the external networks available through the ecosystem, Rohan Wakefield, co-founder of Enspiral Dev Academy, was able to secure a franchise agreement with DevBootcamp, a United States based company that develops intensive development training, to use their curriculum and run a coding school in Wellington. To establish Enspiral Dev Academy, the core team was able to access and make deals with Wellington City Council to fund part of the project. The team also enlisted several employers to partner with Dev Academy in order to hire individuals who graduate through the program. The diversity within the ecosystem provided the Dev Academy team with access to resources and partners with organizations in New Zealand and overseas.

\section{Conclusion}

In the above section, I illustrated how diversity is a key characteristic of an ecosystem and the way it allows for greater exchange activities to take place. I presented the ways that diversity can fuel an internal economy, how it can facilitate innovation and creation of new value, and how it can give organizations access to resources, knowledge, ideas, talent and information they may not have available internally. I make the proposition that diversity increases the likelihood of intersections between companies and individuals 
that are different from one another. The more diverse an ecosystem, the more exchange intersections that take place. This is because entities in the ecosystem hold different types of assets, and greater levels of diversity enable for increased opportunities of exchange of those different assets.

In the next section, I highlight another characteristic of the Enspiral ecosystem that influences the exchange activities taking place. I use a bioecology metaphor of life and death cycles to discuss this characteristic. Organisms in nature are born and they die. Those that die serve as feed to other organisms or decompose and turn into nutrients for the soil that is utilized by plants. There is a natural cycle of birth and death within ecosystems and this concept can be applied to ecosystems of organizations. Utilizing the Enspiral case study, I discuss how such cycles can augment exchange activities by composting, recycling and/or repurposing knowledge, resources, talent, organizational infrastructures, and different forms of access.

\section{Life and death cycles}

The study of bio-ecology indicates that the cycle of birth and death is a natural occurrence. Ecosystems are made of biotic and abiotic beings that pertain cycles of birth and death. As discussed in the literature chapter, ecosystems have a boundary, and the boundary line falls where the frequency of interaction between the organisms is close to zero. Within those boundaries, new life is created and existing life dies and decays. Hawley (1950; 1986) further suggests that the mutual dependencies of organisms within an 
ecosystem are based on the functions they play. He posits that the power of an ecosystem is in the functions that the organisms perform, and organisms gain power when they perform that function and lose it when they are displaced from their function (Hawley, 1986). Translating that to Enspiral, when new organizations are founded, they gain power as they start performing new functions and participate in exchange with other organizations in the ecosystem. They lose that power when the organizations die. Hawley (1986) argues that power belongs to functions rather than to organizations.

I apply the above framework of understanding the life and death cycles within an ecosystem when diagnosing the Enspiral case study. I argue that such cycles create greater exchange activities through the composting, recycling and repurposing assets of organization that is not needed to achieve the function it was playing before its death. Those organizational assets (including resources, talent, organizational infrastructures, access to outside entities, etc.) can get redistributed to the ecosystem, utilized to form new organizations, or change forms in order to play new functions. In making this argument, there are two observations about the life and death cycles I discuss. The first is the separation of power from organizations and placing it into the functions they play. This is relevant because by detaching functions from organizations we can recognize how the aspects of an organization that played a set of functions can continue to participate in exchange without the existence of that organization. It means that if an organization is in decline, it can be permitted to die, and the aspects of the organization that were playing the prior 
functions can assume different roles and take new forms. The second observation is the composting, recycling, and repurposing process of assets from a dead organization to allow for new life to emerge. I discuss both points below.

First, however, it is important to recognize assumptions of natural deaths and application of this position in the Enspiral case study. Organizational ecologists argue the environments they exist in influence organizations, and their lifespan depends on various internal and external factors. A few ecologists have argued that technically organizations may be immortal (Carroll, 1984; Kaufman, 1975). This immortality argument is mostly based on longitudinal studies of organizations that have remained alive for a long time. There are however a lot more theorists who argue that organizations do die (Hannan \& Freeman, 1984; Hawley, 1986; Singh \& Lumsden; 1990). Furthermore, Stinchcombe (1965) presents an argument about the liability of newness, suggesting that newer organizations die faster than older ones. This is a point of view that is widely accepted by organizational ecologists (Wholey, Christianson \& Sanchez, 1992, 1993; Singh, 1990; Hannan, 2005). Applying this understanding of organizations to young startups, it is a reality that new companies are more likely to die, and this applies to organizations existing within the Enspiral ecosystem.

Data on Enspiral was collected over a nine month time period, and my research is not an attempt to prove or disprove whether all organizations die or 
whether they can achieve immortality. Rather, I adopt the premise that in entrepreneurial ecosystems, new startups emerge often and most young startups are likely to die. When utilizing the bio-ecology metaphor, birth and death are seen as natural occurrences in ecosystems. Thus, I focus on examples of organizational foundings and death in the Enspiral ecosystem and draw attention to how births and deaths of organizations influence the exchange activities within an ecosystem. Below, I discuss three observations that can contribute to our understanding of birth and death in an ecosystem.

\section{Allowing organizations to die}

Various organizations have died within the Enspiral ecosystem, while new ones have also emerged. The deaths that have occurred at Enspiral were not always mourned or considered as failures. To the contrary, these deaths were quite celebrated, and individuals involved in them took some pride for allowing those organizations to die. I will shed light on three examples of organizations that have died and discuss how facilitating death of organizations in decline can allow for new life to emerge. I highlight the creation of compost, recycled and repurposed assets that other organizations in an ecosystem can utilize.

ReGeneration: creating space for new life to emerge

ReGeneration is an organization that put together retreats and events for young people working on social/environmental projects, and it developed video content that shared their stories online. ReGeneration existed before 
Enspiral emerged as an ecosystem, and many of the Enspiral founding members met each other through the ReGeneration retreats. ReGeneration was considered to be highly successful, reaching thousands of people through its activities and many more online. It ran from 2009 to 2013 . It had a decent amount of funding to perform its activities, and in 2013, the organizing team got together and agreed that ReGeneration had accomplished its purpose and that if it continued for the sake of continuing it would be going through a slow decline where its effectiveness would diminish. The team agreed it was about time for them to "complete" the project. Rather than striving to exist for as long as it could, the team had a consensus to close shop, and share the lessons that they learned from the ReGeneration experience so that new and better types of initiatives can emerge through the group involved. They asked their sponsors to allow them to end the project, and asked for a grant to host a large event to celebrate the life of ReGeneration and mark its death. Many claim that ReGeneration is one of the main breeding grounds that has enabled for Enspiral to emerge. Individuals who were involved in ReGeneration have gone to work on other ventures in government, business, and non-profit sectors, many utilizing the lessons and experiences they gained from ReGeneration. The death of ReGeneration allowed for new life to emerge elsewhere.

Support Crew: removing barriers to exchange

Support Crew is a team that was put together to look after the Enspiral ecosystem. Richard Bartlett, who was part of this team, suggests that while different organizations and individuals worked on their startups, "Support 
Crew was in charge of cultivating that garden for all these things to grow in." Richard and the rest of Enspiral saw the Support Crew getting larger and becoming the team that looks after everything to maintain the ecosystem. According to him, it was turning "into this weird bureaucracy that was holding all this power [...] just like any other organization where you have management and the staff hate the management" rather than a self-supporting ecosystem. They "intentionally pressed the self-destruct button" and said, "this is not right, let's cut loose and do something different." He recounts that there was a certain amount of trauma when an organization that served as the "gardener" for the ecosystem disassembles quite fast. Instead, what they created is a oneperson team, Alanna Krause, whose role became to "design the systems so that the stuff gets done by everyone" instead of actually doing it herself. The Support Crew as an organization with 5 team members, a budget, and a specific mandate to serve the ecosystem, was killed, and instead Alanna began developing channels through which members of the ecosystem could participate in self-support and self-governance. For example, the adoption of Loomio as a means through which everyone at Enspiral could participate and make decisions is one of the ways responsibilities became distributed. Rather than having the Support Crew looking after the working space, that responsibility became a lot more distributed to the entire ecosystem. In addition, instead of a central body creating a budget for foundation expenses, Alanna helped create a collaborative budgeting tool where members of Enspiral allocate funding to different initiatives they want to see happen. In summary, in allowing the Support Crew to die, Enspiral removed a central body that was 
serving as a barrier to exchange within the ecosystem. Instead, they focused on developing channels of exchange through which the ecosystem was close to self-managing and self-supporting. The transition was not easy and they are still iterating on those self-management mechanisms. However, that transition created more channels for new forms of exchange to take place within the ecosystem.

CodeSourced: composting an organization

CodeSourced is a recruiting company that Rohan Wakefield and Joshua Vial started at Enspiral, with the goal of placing IT specialists for contract and permanent positions at companies around New Zealand. The company was set up based on Rohan's experience in recruiting and Joshua's experience as a programmer. There is a nation-wide shortage of developers and programmers, and CodeSourced was created to meet that need. During the startup phase, they build relationships around Wellington and other parts of the country with potential clients and candidates, developed a deep understanding of the skills shortage and the needs of employers. However, CodeSourced struggled to operate as a viable business due to the big shortage of talented individuals to place at companies. The Wellington talent pool was too small for them to build a sustainable business through placement fees. Realizing that, they let CodeSourced die. However, by utilizing the relationship and knowledge infrastructure they had built during that process, Rohan and Joshua founded a new company, Enspiral Dev Academy. Dev Academy provides intensive programming training and places its graduates at different companies around 
New Zealand. CodeSourced was not completely left to rot, but part of it was composted, which then served as fertile land for a company like Dev Academy to emerge. Below I discuss further on the concept of composting organizations.

\section{Composting organizations}

In a biological ecosystem, when something dies, it breaks down, decomposes, and its nutrients are absorbed by the soil. It turns into compost and the decomposed organic matter fertilizes the soil. Those nutrients are absorbed by plant roots under the soil and become a source of life for those plants that then feed animals, birds, and insects. In a closed ecosystem, much of what decomposes is absorbed by the biota. Utilizing an ecological metaphor, we can apply the concept of compost to better understand the birth and death cycles of organizations. In the example of CodeSourced, I present the concept of relationships and knowledge infrastructures being recycled and used to launch a new startup.

There are other ways that such recycling and composting can happen as well. Linc Gasking explains how capital to support the early stages of startups is an important form of compost that is necessary for the success of new startups. He identifies the lack of such compost as inhibiting for new startups to emerge and grow because there are few recycled resources. He further explains this concept and provides his own account below:

A permaculture [design] of Enspiral's ecosystem provides enough funding from previously successful ventures in order to support the next generation. So because we're still in Generation 
One of startups, the money isn't there to support the next ones, which is what would naturally happen in Enspiral in maybe two years' time. What I would predict is that as startups become more successful and exits start to happen and acquisitions start to happen and money starts to be injected into the system, those new start-ups will find money from those successful entrepreneurs that give back. In fact, that's how I've been able to support myself working on FreeRange and before that Chalkle. It's because of my ability to do that through successful investments and entrepreneurial acquisitions previously and without that, I wouldn't have been able to even be involved in Enspiral. So as more people have that experience, more recycling will happen and that has been a successful model as shown with Xero, the local cloud accounting company, but also with international ecosystems like Tel Aviv and Silicon Valley that are much further down the line of that recycling where entrepreneurs are in there coming from three, four, five generations of startups before them and entrepreneurs before them supporting each other.

Recycling of resources is an important component for more entrepreneurial activities to occur within an ecosystem. Capturing that compost created when an organization in an ecosystem dies and utilizing it to nurture other organizations to emerge is a component of the birth and death cycle. To clarify, death of an organization could take place in different ways, including dissolution, merger absorption, and owner transfer through acquisition (Freeman \& Hannan, 1983; Carroll, 1984). Compost creates space for new life to emerge. Issues arise if most of the compost is utilized to fertilize soil outside of the ecosystem, because the ecosystem may become more and more nutrient deficient and the life that turns into that compost is only taking and not giving back to the ecosystem. In such a case, the process of recycling and fertilizing may not have a positive influence on the exchange activities within that ecosystem. As argued above, greater exchange activities take place when the ecosystem is more diverse, and if the birth-death cycle does not 
contribute to greater levels of diversity then that may inhibit augmentation of exchange activities within the ecosystem. Furthermore, the process of recycling resources, knowledge, information, talent, and ideas is a form of exchange, and when part or all of that compost remains in an ecosystem, it allows for more exchange to take place.

\section{Summary}

In the above section, I discussed the birth and death cycles that take place in ecosystems and I argue that those cycles augment the levels of exchange activities in an ecosystem. Separating an organization from its function allows us to observe how the assets of the organization that performed its initial functions can be composted, recycled and repurposed within the ecosystem. The activity of composting, recycling and repurposing itself is a form of exchange. I posit that the more that declining organizations are allowed to die and new ones to emerge, the greater the levels of exchange can take place.

\section{Conclusion}

I began this chapter by asking what characteristics influence the interactions and interrelations within entrepreneurial ecosystems? I adopt an ecosystem lens to study Enspiral, and I utilize the exchange lens to study interactions and interrelations. By focusing on overall exchange activities that take place in the Enspiral ecosystem, instead of transactional exchanges, I illustrate different types of exchange activities observed at Enspiral: exchange 
of skills, knowledge and ideas, resources, and energy and emotional support. By studying exchange as a variable, I identify three key characteristics that influence the levels of exchange activities: interdependence, diversity, and birth and death lifecycles. These three characteristics serve as mechanisms for interactions and interrelations.

I offer three propositions that indicate how these characteristics influence the levels of exchange activities in an ecosystem. I theorize these propositions into a model that can be used to better understand entrepreneurial ecosystems and identify the influencers of interaction and interrelations within them. As such, I begin a theoretical conversation that invites future research to further develop and test this model. 


\section{CONCLUSION}

\section{Discussion}

Bio-ecology metaphors open up the possibilities to learn from the natural ecology around us and create parallels between natural systems and our world of organizations. Yet, natural systems are very complex and multifaceted. As a result we may observe different characteristics. This is the case in the organizational ecology field. Researchers have constructed metaphors based on varying interpretations of the natural world. Even Darwin's perspectives on natural systems are adopted differently: Hawley (1986) assumes the perspective that all living and non-living systems are a web of life, and they are highly interdependent, while Freeman and Hannan (1977) consider life to be in constant struggle with the environment where only the fittest survive.

Metaphors are ways of seeing and thinking (Morgan, 2006). They provide a lens through which we can observe and understand complex relationships between phenomena (Cornelissen \& Kafouros, 2008). However, they can also limit our perspective because they ignore differences between phenomena. They are a way of not seeing as well as seeing (Morgan, 2006). I apply this perspective about metaphors as a double-edged sword. On one side, I shed light on the collaborative aspects of organizations, an area that organizational ecologists do not see much when using their versions of bio- 
ecological metaphors. Organizational ecologists traditionally focus on survival rates of organizations. This is partly because the metaphors they use are those of organisms fighting for survival while existing in populations and communities. The metaphor of 'survival of the fittest' is one way of seeing organizations but leaves out the parts where organizations co-exist in relations with one another and continuously interact. A large part of my thesis focuses on the aspects that are not seen through such an application of metaphors. On the other side, even though I am using a different metaphor, I remain liable to the same pitfalls of metaphor use that I critique organizational ecologists for. I adopt the ecosystem metaphor and provide an alternative lens to the study of organizations. I offer a perspective on the ways organizations interact and are interrelated, one that differs the conclusions from what previous organizational ecologists have come to. I contend that the metaphors I apply and ways I apply them lead me to generate perspectives that differ from those organizational ecologists arrive to, and that results in emphasis on different aspects of organizations. What this shows is that metaphors can be helpful in serving as conceptual building blocks of organizational theory (Weick, 1989), and the variation in the perspectives they help generate adds to the wealth of knowledge researchers can generate about organizations. Metaphors allow us to study the world of organizations from different angles.

Such an understanding of metaphors helps to clarify how my research can contribute to knowledge on organizations. Findings from this research shed light on some of the ways organizations interact and relate to one another 
when studied through an ecosystem lens. This thesis avoids making overarching claims about all organizations, but rather it highlights the ways some organizations can co-exist when they are part of an ecosystem.

My research findings propose that three key characteristics of an entrepreneurial ecosystem influence the relations and interactions between organizations. I use exchange as a variable to analyze types of interactions in an all-encompassing way. In doing so, I articulate the interrelatedness that is part of and further enhanced through exchange activities. I claim that the ecosystem characteristics of interdependence, diversity, and life and birth cycles identified in this research have large influence over the levels of exchanges taking place in ecosystems. I argue that greater facilitation and manifestation of these characteristics enhance the levels of exchange activities in ecosystems. These findings make numerous contributions to the way we understand organizations.

Firstly, greater exchange activities of skills, resources, ideas, knowledge, energy and emotional support reflect collaborative aspects of organizational relationships. The more exchange activities take place in an entrepreneurial ecosystem, the more organizations are helping each other achieve their goals. When organizations share different types of ideas, resources, talents and knowledge, they are helping each other succeed. Therefore, collaborative behaviors of organizations can be better observed when using an ecosystem lens. By recognizing how exchange activities may be augmented, management 
practitioners can better understand the factors that influence how organizations collaborate in entrepreneurial ecosystems. It can shift the attention from the idea of 'everyone is against me and I have to survive' to 'I am part of a larger interconnected and always interacting ecosystem.'

Secondly, the ecosystem unit of analysis I develop in this thesis offers a framework through which organizations can be studied. Instead of focusing on founding and failure rates of organizations I study organizations as part of a larger ecosystem. This helps uncover the ways organizations interact and relate to one another. I do not dispute the importance of studying survival rates but I offer a framework through which we can examine what organizations do when they are not appearing and disappearing. Open-system theory supplements organizational ecology to place emphasis on both survival rates and active interactions between organizations. By combining these two fields, I propose a unit of analysis that reveals more complexity of the organizational 'web of life.' This serves as a contribution to organizational ecology and helps revive conversations that Hawley starts in 1986 about ecosystems and that Morgan (2006) highlights a need for.

Management practitioners and policymakers can benefit from the application of an ecosystem lens. A greater understanding of the types of exchange activities and the factors that influence the levels of such activities can help shed light on what makes entrepreneurial ecosystems continue to exist. For example, to increase or create new exchange activities, managers can 
help create new links of interdependence between organizations, introduce different types of organizations to increase the diversity of the ecosystem, and compost aspects of organizations that are in decline. Another example is that if a city like Wellington makes it a priority to increase technology-based entrepreneurial activities, it can decide to look at how to achieve that goal by applying an ecosystem lens. An initial inclination may be to bring engineering talent to the city as a way of promoting entrepreneurialism, or the city administration may focus on attracting investors to provide funding for entrepreneurs. But an ecosystem perspective can help them focus on the forms of exchange taking place and ways to increase that exchange, rather than just increasing a certain population. In practice, this may be asking how different industries interact with one another and generate new ideas for technological innovations - for instance, greater interaction with software engineers interacting with farmers can result new farming software tools being created. The city administration may also seek to understand how resources get circulated when technology companies get acquired - for instance, if successful entrepreneurs start investing in new startups and advising new entrepreneurs, their resources, knowledge, networks, and other assets can circulate through the ecosystem. But if the team and capital of recently acquired businesses take their talent elsewhere or if there are few acquisitions taking place, then more value is extracted than being added to the ecosystem, and the city can create incentives to keep them in Wellington. Therefore, an ecosystem perspective allows practitioners to understand the interactive and interdependent nature 
of ecosystems, and orient their attention to the factors that influence levels of exchange activities.

\section{Limitations and opportunities for research}

One of the main limitations of this research is that findings are primarily based on insights from one case study. Generalizing findings from Enspiral to other entrepreneurial ecosystems may be problematic as the characteristics highlighted and the phenomena observed may be specific to Enspiral. Conducting additional research on other types of ecosystems can support some of the arguments I make in this research, contribute new insights, further develop my findings and/or counter to the claims I make in this thesis.

Researching entrepreneurial ecosystems that have been in existence longer than Enspiral might offer richer data to better understand whether certain characteristics become important than others, inquire if and how ecosystems exhibit different stages of development and maturity, and identify

different types of challenges they experience overtime. An advantage of researching more seasoned ecosystems is that it might provide data on ecosystem evolution trends. This can help us understand how an ecosystem and the patterns of exchange in it evolve with the changing environment. Another advantage to studying an older ecosystem is that it can also provide historical data on ways organizational assets are composted, recycled, or repurposed. It allows us to explore the impact on an ecosystem when the compost of an organization leaves the ecosystem - an area where Enspiral has 
limited experience. A further advantage is that it allows us to explore Hawley's (1986) proposition that bounded ecosystems work towards equilibrium. Data from Enspiral are insufficient to assess the application of that proposition in entrepreneurial ecosystems due to the fact that Enspiral is quite young and in a growth stage during the time of this research. Ecosystems that have been in existence for much longer may provide insights on such a proposition.

Furthermore, Enspiral attracts individuals and organizations that are driven to make positive social and environmental impact through business. By researching other types of ecosystems, it may be possible to identify whether that aspect of Enspiral has strong relations to the way it facilitates interactions and interrelations at such a high degree. A study of another ecosystems that has an even more diverse set of organizations may clarify more the level of influence certain value systems may have on the levels of exchange that take place. Are values-driven ecosystems more likely to increase exchange activities? What types of characteristics do such ecosystems exhibit? These are some of the questions I would ask if given an opportunity to do a comparative study.

Moreover, it may be wise to study ecosystems based in different geographic locations, pertaining to other cultural and social practices. Such a study can shed light on the relationship between cultures of entrepreneurial ecosystems and cultures of the larger ecosystems they exist in. How does the 
local culture influence the ways ecosystems can facilitate interactions and interrelations?

In addition, applying and testing the ecosystem unit of analysis to other organizational ecology studies can help further develop such a unit of analysis. New insights from future applications of the ecosystem unit of analysis can strengthen and legitimize it, further distinguishing it from population and community level units of analysis. This can potentially reignite theoretical conversations in organizational ecology, where Carroll (1984) is the last ecologist to introduce a new unit of analysis.

To summarize, there remains much research to be done on entrepreneurial ecosystems. Management practitioners are embracing the concept and applying it to describe concentrated and bounded forms of entrepreneurial activities (Kanter, 2012a, 2012b; Isenberg, 2011). They are also applying bio-ecological metaphors to describe characteristics of entrepreneurial ecosystems. New technologies are facilitating interactions faster and cheaper than ever before. The Internet is providing unprecedented access to global talent, knowledge, and resources at people's fingertips. Companies that have emerged in entrepreneurial ecosystems are influencing billions of people at a global scale (e.g. Google, Facebook, Apple), and they are fueling growth of more ecosystems around the world. Yet, more research is needed to better understand how the emergence of such ecosystems affects the ways organizations interact with one another. Further studies that pay 
particular attention to the collaborative aspects existing in such ecosystems can contribute knowledge that can fill existing knowledge gaps in academia (Morgan, 2006) and can heavily influence management practice around the world. 


\title{
APPENDICES
}

\section{Appendix A: Letter of request to conduct research at Enspiral}

\section{Letter of Request for Personal Interviews with Enspiral Members}

April 30, 2013

\author{
Joshua Vial \\ Founder, Enspiral \\ 18-24 Allen St \\ Wellington \\ Dear Joshua
}

I would like the opportunity to interview you and 10+ members of the Enspiral community as part of my Master of Commerce in Management thesis research. I also kindly request permission to rent a temporary desk at the Enspiral offices, similar to how other entrepreneurs do when joining the community, in order to collect data as a participant observer. The research is concerned in understanding how networks of entrepreneurs and Small and Medium-sized Enterprises can facilitate continuous innovation. Enspiral will be the central case study for my research. Each interview is designed to take between 60-90 minutes. I also plan to use the desk space at Enspiral to do my own work and observe the Enspiral team without disrupting the work of others. While a minimum of 5 weeks will be ideal for my research, I leave to you the decision on the length of time possible to hold a desk space at Enspiral.

This research aims to highlight lessons learned from Enspiral. If members of the community decide to be interviewed, I may quote opinions and ideas shared during interviews directly in the final thesis. Individuals have the right to withdraw from the interview at any point. I aim to use data collected through participant observation to better understand how Enspiral operates and inform interview questions with specific individuals. In addition, interview tapes and transcriptions will be kept in a locked office and will be destroyed 10 years after the conclusion of this research. The research findings will be published in the Victoria University library and excerpts or summaries may be published in academic and non-academic journals and presented during conferences. A summary of the research will also be provided to interviewees.

The Victoria University of Wellington Human Ethics Committee has granted 
approval as a teaching activity and Master of Commerce (Management) Programme Director has reviewed this project.

With your permission, the interviews with Enspiral members will be recorded and a transcript will be provided for their approval upon their request. If for any reason you would like to reach out regarding this research, please contact one of the following:

Yoseph Ayele

Yoseph.ayele@vuw.ac.nz

+64275206860

Yours sincerely

Yoseph Ayele
Dr. Todd Bridgman

todd.bridgman@vuw.ac.nz

$+64444635118$ 
Appendix B: List of interviewees and organizations

\begin{tabular}{|l|l|l|}
\hline & Name & Organization (s) \\
\hline 1 & Enspiral members & \\
\hline 2 & Will Lau & $\begin{array}{l}\text { Enspiral Foundation, Craftworks, Dev } \\
\text { Academy, Enspiral Board }\end{array}$ \\
\hline 3 & Samson Ootoovak & BuckyBox \\
\hline 4 & Jon Lemon & BuckyBox \\
\hline 5 & Benjamin Knight & Loomio \\
\hline 6 & Vivien Maidaborn & Loomio \\
\hline 7 & Richard Bartlett & Loomio, Enspiral Board \\
\hline 8 & Alanna Krause & Loomio \\
\hline 9 & Chelsea Robinson & Enspiral Foundation, Loomio \\
\hline 10 & Silvia Zuur & GenerationZero, LifeHack, Loomio \\
\hline 11 & Linc Gasking & Chalkle, Enspiral Board \\
\hline 12 & Anthony Cabraal & FreeRange, Chalkle \\
\hline 13 & Guy Ryan & Live The Dream \\
\hline 14 & Rochelle Furneaux & Inspiring Stories \\
\hline 15 & Rebeka Whale & Enspiral Legal \\
\hline 16 & Sam Rye & Enspiral Spaces \\
\hline 17 & Joshua Ford & LifeHack \\
\hline 18 & Rohan Wakefield & Rabid \\
\hline & & Dev Bootcamp, \\
\hline & Non-Enspiral members & \\
\hline 19 & Alex Hannant & Hikurangi Foundation \\
\hline 20 & Philippa Bowron & Wellington City Council \\
\hline
\end{tabular}




\section{Appendix C: Interviewee information sheet}

\section{To Enspiral Community Members and Affiliates}

I am a student researcher working towards the completion of a Masters degree in Commerce with a concentration in Management at Victoria University of Wellington. I would like to invite you to participate in my research on collaborative entrepreneurship. The aim of this research is to better understand how collaborative communities between Small and Medium-sized enterprises can facilitates continuous innovation. I will pursue this inquiry by focusing on Enspiral as my main case study. The Victoria University of Wellington Human Ethics Committee has approved the research.

I will present the findings by main themes and categories identified in both the literature and the interviews. The research will contribute significantly by crystallizing the concept of collaborative entrepreneurship and highlighting lessons from an existing community of SMEs and entrepreneurs. As entrepreneurs in knowledge-based industries are exploring ways to enhance their innovation capabilities through collaboration, this research could offer frameworks to inform such efforts.

I would like to conduct an interview with you of approximately 30 to 90 minutes and scheduled at a time that suits you. The interview will be audio-recorded and notes taken throughout. I would like to interview you to discuss your experience as part of the Enspiral community. Your contributions will be very important to the outcome of this research and our broader understanding of collaborative entrepreneurship. A summary of the research will be provided to you, and at your request, I will provide a copy of your interview transcript. I will also be available to discuss the research findings with you after 21 February 2014 if you are interested.

Your participation is completely voluntary. However, if you agree to be interviewed I will ask you to fill in a consent form that, in addition to this information sheet, outlines your role in the project and how I will respect your rights as a research participant. If you agree to participate in this research, I may also quote your opinions and ideas directly in the final thesis. You may decide not to answer any of the questions I will ask you during the interview, and you have a right to withdraw from this research at any point.

Only my supervisor and I will have access to the research data collected during the interview. These materials will be stored securely in locked electronic and paper files. I will destroy these ten years after the conclusion of the research, as I may use the data in further research or publications. I will present the 
research as a final thesis for my Masters in Commerce degree. I may also distribute findings of this research (not the raw data) during academic or professional conferences, on blog and journal articles (academic and nonacademic publications). In addition, the final thesis may be deposited in the Victoria University library.

Thank you very much for your time and valuable contribution to this research. If you have any questions, please contact myself or my supervisor, Dr. Todd Bridgman.

Yoseph Ayele

Yoseph.ayele@vuw.ac.nz

$+64275206860$
Dr. Todd Bridgman

todd.bridgman@vuw.ac.nz

$+64444635118$ 


\section{To members of the wider entrepreneurship community}

I am a student researcher working towards the completion of a Masters degree in Commerce with a concentration in Management at Victoria University of Wellington. I would like to invite you to participate in my research on collaborative entrepreneurship. The aim of this research is to better understand how collaborative communities between Small and Medium-sized enterprises can facilitates continuous innovation. I will pursue this inquiry by focusing on Enspiral as my main case study. The Victoria University of Wellington Human Ethics Committee has approved the research.

I will present the findings by main themes and categories identified in both the literature and the interviews. The research will contribute significantly by crystallizing the concept of collaborative entrepreneurship and highlighting lessons from an existing community of SMEs and entrepreneurs. As entrepreneurs in knowledge-based industries are exploring ways to enhance their innovation capabilities through collaboration, this research could offer frameworks to inform such efforts.

I would like to conduct an interview with you of approximately 30 to 90 minutes and scheduled at a time that suits you. The interview will be audio-recorded and notes taken throughout. I would like to interview you to discuss your views about collaborative entrepreneurship and innovation. Your contributions will be very important to the outcome of this research and our broader understanding of collaborative entrepreneurship. A summary of the research will be provided to you, and at your request, I will provide a copy of your interview transcript. I will also be available to discuss the research findings with you after 21 February 2014 if you are interested.

Your participation is completely voluntary. However, if you agree to be interviewed I will ask you to fill in a consent form that, in addition to this information sheet, outlines your role in the project and how I will respect your rights as a research participant. If you agree to participate in this research, I may also quote your opinions and ideas directly in the final thesis. You may decide not to answer any of the questions I will ask you during the interview, and you have a right to withdraw from this research at any point.

Only my supervisor and I will have access to the research data collected during the interview. These materials will be stored securely in locked electronic and paper files. I will destroy these ten years after the conclusion of the research, as I may use the data in further research or publications. I will present the research as a final thesis for my Masters in Commerce degree. I may also distribute findings of this research (not the raw data) during academic or 
professional conferences, on blog and journal articles (academic and nonacademic publications). In addition, the final thesis may be deposited in the Victoria University library.

Thank you very much for your time and valuable contribution to this research. If you have any questions, please contact myself or my supervisor, Dr. Todd Bridgman.

Yoseph Ayele

Yoseph.ayele@vuw.ac.nz

+64275206860
Dr. Todd Bridgman

todd.bridgman@vuw.ac.nz

+64444635118 


\section{Appendix D: Interview consent form}

I have read the Research Project Information Sheet for this study and have had the details of the study explained to me. My questions about the study have been answered to my satisfaction, and I understand that I may ask further questions at any time.

I also understand that I am free to withdraw from the interview or to decline to answer any particular questions in the study. I may withdraw from this project up to 30 November 2013. I agree to participate in the study and have the interview digitally recorded, and provide information to the researchers under the confidentiality conditions set out on the Information Sheet.

Participant:

Signed:

Name:

Date:

Researcher:

Signed:

Name:

Date: 


\section{Appendix E: Interview guide}

\section{Interview schedule}

0-5 minutes: Introductions, explanation of research goals, interview procedures, and answer questions about the information sheet and/or the consent form.

0-85 minutes: parts of the following predetermined questions will be tailored to each individual depending on their role at Enspiral, years of experience, and level of engagement with the community. Ad hoc questions will also be asked.

Note: a research subject will not be asked all the questions listed below, but most questions asked to any subject will be from the following interview guide.

\section{Involvement with Enspiral}

1. Please describe what Enspiral is in your own words. What purpose does Enspiral serve?

2. How did you first get involved with Enspiral? How long have you been involved for? What is your current involvement with Enspiral?

3. How many days and hours each day do you spend at the Enspiral office?

4. How often do you exchange email/Yammer communications with the Enspiral community? Roughly, what percentage of those communications is directly useful to your specific enterprise? What percentage is useful to you as an individual? And what percentage is not useful to you at all?

5. What are your commitments to the Enspiral community? (time/resources/skills/financial/other]

6. How often do you meet those commitments? What are the consequences when you meet those commitments? What are the consequences when you don't?

7. So far, what have been your main contributions to the Enspiral community? What compelled you to make those contributions to the community?

8. How often do you interact with members of the Enspiral community that are not part of your enterprise? (number of times a day/week on average) 
9. Who do you interact with the most at Enspiral? Why?

10. What does Enspiral mean to you?

11. What is the nature of your relationship with other individuals from the Enspiral ecosystem?

\section{Value of Enspiral to your startup}

1. Please walk me through your thought process joining the Enspiral ecosystem. Why did you do it?

2. How satisfied are you with your involvement in Enspiral? Please explain.

3. How does your startup benefit from the Enspiral ecosystem? How do you personally benefit from the Enspiral ecosystem?

4. In your opinion, who benefits the most from Enspiral? Why?

5. In your opinion, who benefits the least from Enspiral? Why?

6. If Enspiral ceases to exist tomorrow, how will your enterprise be affected overall? Why? What aspects of your enterprise will be affected the most? And what aspects of your enterprise will be affected the least? Why?

7. How relevant is Enspiral to the wider Wellington entrepreneurial ecosystem? How about the general New Zealand entrepreneurial ecosystem?

8. What contextual factors make Enspiral relevant to the entrepreneurial ecosystem?

\section{How does Enspiral work?}

1. How is currently Enspiral structured? Why is it structured that way?

2. How to startups interact with one another at Enspiral?

4. What role does Enspiral play in facilitating such interactions?

5. How far do startups collaborate with one another? How far do they compete with one another?

6. What is the role of the Enspiral admin team? 
7. How are member enterprises and individuals entrepreneurs selected to become part of the Enspiral ecosystem?

8. Has Enspiral turned down some individuals/enterprises from becoming members? If so, why?

\section{Strategy and planning}

1. What does success mean in your (and your startup's) involvement in Enspiral?

2. How do you define success for Enspiral?

3. Where do you see Enspiral in one year from now? How about 3 years? And 5 years?

4. Do you think you will continue with your involvement in Enspiral? Why? Under what conditions/circumstances?

5. How satisfied are you with your current involvement in Enspiral? Please explain.

6. If there are aspects of the ecosystem you will change, what will those be? Why?

7. Do you foresee a time when your startup will start benefiting less from the Enspiral community? Why?

8. If there are aspects of the community you would want to change in general, what will those be? Why?

9. Is there anything I did not ask that you would like to share?

10. Do you have any questions for me?

\section{Additional questions to members of the wider entrepreneurship community}

1. In your opinion, how can enterprises increase their innovation capability?

2. How much can enterprises collaborate with one another?

3. What are the key ingredients for enterprises to collaborate with one another? 
4. Based on your knowledge and experience, what are the best forms that collaboration between enterprises has taken place?

5. In your opinion, can collaboration between enterprises help each enterprise be more innovative? Why? Why not?

If yes, what organizational forms can facilitate such collaboration? How much of an impact does the industry context have on enterprises' ability to collaborate? How about the stage of an enterprise's life cycle? How about the organizational structure of individual enterprises?

6. What organizational context is most conducive for collaboration between enterprises?

7. What form of collaboration between enterprises is most conducive for continuous innovation?

8. In your opinion, do you believe the Enspiral model of collaboration helps facilitate innovation between enterprises on a continuous basis?

9. Can the Enspiral model of collaboration be replicated? Why? Why not?

10. What future do you foresee for collaborative entrepreneurship in the next decade? 


\section{Appendix F: Enspiral Ventures list, 2014}

Source: www.enspiral.com

\section{BuckyBox}

Bucky Box is building cloud software for an emerging food system, one that solves the food distribution problem in ways that foster earth-friendly farming and resilience. It's a social enterprise on a mission to foster a human food system that is supportive of the long term health of all living systems. A minimum of $67 \%$ of profits is reinvested into projects that further the company's mission.

\section{Chalkle}

Chalkle ${ }^{\circ}$ makes it easy for anyone to stand up and say "I have a skill and I want to share it with others", and in doing so it tips the education model on its head. Chalkles are fun and social!

\section{Loomio}

Loomio is an online tool for everyday democracy developed by a cooperative social enterprise in Wellington, New Zealand.

\section{Rabid}

Rabid is a Wellington-based software firm that works with organizations and entrepreneurs to envision and develop new products and services. We use open-source technologies to develop useable solutions with clients and products that span business, NGO, and community sectors. Experts in web development, Rabid actively contribute to open source and projects that make a positive impact in people's lives and the community.

\section{Metric Engine}

Metric Engine is an app that helps similar organizations compare their performance and see how they can improve.

Metric Engine had its roots in an earlier project called Parks Base, which was used by Australian councils to compare the performance of their parks and 
recreation spaces. Parks Base pre-dated Enspiral but later was placed into the network and with some collaboration and a bigger team, the venture evolved into Metric Engine, which is set to expand into new industries. The Metric Engine team want their app to help organizations with a social purpose thrive.

\section{Enspiral Accounting}

Enspiral Accounting provides professional accounting services to individuals and organizations who value social responsibility and who are not just financially motivated to be in business.

\section{Enspiral Legal}

Enspiral Legal specializes in supporting tech startups, social enterprise and charities on structures, commercial advice, and legal documentation, copyright and licensing.

\section{Enspiral Space}

Enspiral Space, located in the CBD of Wellington, is the physical hub where many in Enspiral network collaborate in person. The co-working space caters especially for tech startups, social enterprises, non-profits, and ethically focused freelance professionals.

\section{Enspiral Dev Academy}

New Zealand's first Developer Academy. 


\section{REFERENCES}

Aiken, M., \& Hage, J. (1971). The organic organization and innovation. Sociology, $5(1), 63-82$.

Aldrich, H. (1976). Resource Dependence and in Inter-organizational Relations Local Employment Service Offices and Social Services Sector Organizations. Administration \& Society, 7(4), 419-454.

Aldrich, H. (1979). Organizations and environments. Englewood Cliffs, NJ: Prentice-Hall.

All together now: What entrepreneurial ecosystems need to flourish. (2014, January 18). The Economist. Retrieved February 26, 2014 from http://www.economist.com/news/special-report/21593582-whatentrepreneurial-ecosystems-need-flourish-all-together-now.

Amabile, T. M. (1996). Creativity and innovation in organizations (Vol. 5). Boston: Harvard Business School.

Amburgey, T. L., \& Rao, H. (1996). Organizational ecology: Past, present, and future directions. Academy of Management Journal, 39(5), 1265-1286.

Angell, R. C. (1954). Comment on discussions of the analytic induction method. American Sociological Review, 19(4), 476-477.

Anselm, Strauss L. and Juliet M. Corbin. 1990. Basics of Qualitative Research: Grounded Theory Procedures and Techniques. Newbury Park, CA: Sage Publications.

Astley, W. G., \& Fombrun, C. J. (1983). Collective Strategy: Social Ecology of Organizational Environments. Academy of management review, 8(4), 576587. 
Astley, W. G., \& Van de Ven, A. H. (1983). Central perspectives and debates in organization theory. Administrative science quarterly, 245-273.

Audia, P. G., Freeman, J. H., \& Reynolds, P. D. (2006). Organizational foundings in community context: Instruments manufacturers and their interrelationship with other organizations. Administrative Science Quarterly, 51(3), 381-419.

Barden, J. Q., \& Mitchell, W. (2007). Disentangling the influences of leaders' relational embeddedness on interorganizational exchange. Academy of Management Journal, 50(6), 1440-1461.

Bassett-Jones, N. (2005). The paradox of diversity management, creativity and innovation. Creativity and innovation management, 14(2), 169-175.

Bastedo, M. N. (2006). Open systems theory. The Sage encyclopedia of educational leadership and administration. Thousand Oaks, CA: Sage.

Baum, J. A., \& Rowley, T. J. (2002). Companion to organizations: An introduction. The Blackwell companion to organizations, 1-34.

Begon, M., Townsend, C. R., \& Harper, J. L. (2009). Ecology: from individuals to ecosystems. John Wiley \& Sons.

Berg, B. L., \& Lune, H. (2004). Qualitative research methods for the social sciences (Vol. 5). Boston: Pearson.

Bloor, M. (1978). On the analysis of observational data: a discussion of the worth and uses of inductive techniques and respondent validation. Sociology, 12(3), 545-552.

Bourgeois, L. J. (1984). Strategic management and determinism. Academy of Management review, 9(4), 586-596.

Bryman, A. (2012). Social research methods. Oxford university press. 
Bryman, A., \& Burgess, B. (Eds.). (1994). Analyzing qualitative data. Routledge.

Buckley, W. (1967). Sociology and modern systems theory.

Burgelman, R. A. (1991). Intraorganizational ecology of strategy making and organizational adaptation: Theory and field research. Organization science, 2(3), 239-262.

Carroll, G. R. (1984). Organizational ecology. Annual review of Sociology, 71-93.

Chesbrough, H. W. (2006). The era of open innovation. Managing innovation and change, 127(3), 34-41.

Child, J. (1972). Organizational structure, environment and performance: the role of strategic choice. Sociology, 6(1), 1-22.

Coffman, S. L., \& Eblen, A. L. (1987). Metaphor use and perceived managerial effectiveness. Journal of Applied Communication Research, 15(1-2), 53-66.

Cook, K. S. (1977). Exchange and power in networks of interorganizational relations*. The Sociological Quarterly, 18(1), 62-82.

Cook, K. S. (1977). Exchange and power in networks of interorganizational relations*. The Sociological Quarterly, 18(1), 62-82

Coriat, B., \& Weinstein, O. (2002). Organizations, firms and institutions in the generation of innovation. Research Policy, 31(2), 273-290.

Cornelissen, J. P. (2004). What are we playing at? Theatre, organization, and the use of metaphor. Organization Studies, 25(5), 705-726.

Cornelissen, J. P. (2005). Beyond compare: Metaphor in organization theory. Academy of Management Review, 30(4), 751-764. 
Cornelissen, J. P., \& Kafouros, M. (2008). Metaphors and Theory Building in Organization Theory: What Determines the Impact of a Metaphor on Theory?*. British Journal of Management, 19(4), 365-379.

Cox, T. (1994). Cultural diversity in organizations: Theory, research and practice. Berrett-Koehler Publishers.

Creswell, J. W. (2002). Educational research: Planning, conducting, and evaluating quantitative and qualitative research. Upper Saddle River, NJ: Pearson Education.

Dahlander, L., \& Gann, D. M. (2010). How open is innovation?. Research policy, 39(6), 699-709.

Das, T. K., \& Teng, B. S. (2002). The dynamics of alliance conditions in the alliance development process. Journal of Management Studies, 39(5), 725746.

Denzin, N. K. (1970). Denzin, N. K. (1970). The research act in sociology: A theoretical introduction to sociological methods. Chicago: Aldine.

Denzin, N. K., \& Lincoln, Y. S. (Eds.). (2005). The Sage handbook of qualitative research. Sage.

Dey, I. (1993). Qualitative data analysis: A user friendly guide for social scientists. Routledge.

Feld, B. (2012). Startup communities: Building an entrepreneurial ecosystem in your city. John Wiley \& Sons.

Forbes Insights. (2011, July). Global Diversity and Inclusion: Fostering Innovation Through a Diverse Workforce. Retrieved February 25, 2014 from

http://images.forbes.com/forbesinsights/StudyPDFs/Innovation_Through _Diversity.pdf 
Freeman, J. (1977). The Population Ecology of Organizationsl. American journal of sociology, 82(5), 929-964.

Goh, E. (2013). Lifehack: tackling youth mental health head on. Idealog. $\begin{array}{llll}\text { Retrieved } & \text { February } & 25, & 2014\end{array}$ http://www.idealog.co.nz/blog/2013/03/lifehack

Grant, D., \& Oswick, C. (Eds.). (1996). Metaphor and organizations. London: Sage.

Hammersley, M., \& Atkinson, P. (2007). Ethnography: Principles in practice. Routledge.

Hannan, M. T. (2005). Ecologies of organizations: Diversity and identity. The Journal of Economic Perspectives, 19(1), 51-70.

Hannan, M. T., \& Freeman, J. (1984). Structural inertia and organizational change. American sociological review, 149-164.

Hannan, Michael T. and John Freeman. 1989. Organizational ecology. Cambridge, MA.: Harvard University Press.

Hasenfeld, Y. (1972). People processing organizations: An exchange approach. American Sociological Review, 256-263.

Hawley, A. H. (1986). Human ecology: A theoretical essay. University of Chicago Press.

Hawley, Amos H. 1950. Human Ecology: A Theory of Community Structure. New York, NY: Ronald.

Hawley, Amos H. 1968. "Human Ecology." in International Encyclopedia of the Social Sciences, edited by David L. Sills. New York, NY: Macmillan, 328-37 
Hrebiniak, L. G., \& Joyce, W. F. (1985). Organizational adaptation: Strategic choice and environmental determinism. Administrative science quarterly, $30(3)$.

Hurley, B. (2009). Enabling the Creative Entrepreneur: Business Ecosystems. Open Source Business Resource, (August 2009). Retrieved from http://timreview.ca/article/276.

Isenberg, D. J. (2010). How to start an entrepreneurial revolution. Harvard Business Review, 88(6), 40-50.

Jacobs, D. (1974). Dependency and vulnerability: An exchange approach to the control of organizations. Administrative science quarterly, 45-59.

Johansson, F. (2004). The Medici effect: Breakthrough insights at the intersection of ideas, concepts, and cultures. Harvard Business Press.

Jorgensen, D. L. (Ed.). (1989). Participant observation: A methodology for human studies (Vol. 15). Sage.

Kasarda, J. D., \& Bidwell, C. E. (1984). A human ecological theory of organizational structuring. Sociological human ecology: contemporary issues and applications, 183-236.

Katz, D., \& Kahn, R. L. The social psychology of organizations. New York: Wiley, 1966.

Kaufman, H. (1975). The Natural History of Human Organizations. Administration and Society, 7(2), 131-149.

Kaufman, H. (1976). Are government organizations immortal?. Washington, DC: Brookings Institution.

Kelly, J. G. (1966). Ecological constraints on mental health services. American Psychologist, 21(6), 535. 
Kelly, J. G. (1970). Antidotes for arrogance: Training for community psychology. American Psychologist, 25(6), 524.

Kelly, J. G. (1971a). Qualities for the community psychologist. American Psychologist, 26(10), 897.

Kelly, J. G. (1971b). The quest for valid preventive interventions. Current topics in clinical and community psychology, 2, 183-207.

Kelly, J. G. (1971c).The socialization of competence as an ecological problem. Paper presented at a symposium on Social Competence and Mental Health at the 79th Annual Meeting of the American Psychological Association, Washington, D. C., September

Kelly, J. G. (1979a). Tain't what you do, it's the way that you do it. American Journal of Community Psychology, 1979, 7, 239-261.

Kelly, J. G. (1979b). Adolescent boys in high school: A psychological study of coping and adaptation. Halsted Press.

Kelly, J. G. (1983). Consultation as a process of creating power: An ecological view. The mental health consultation field, 153-171.

Lakoff, G. (1993). 'The contemporary theory of metaphor'. In A. Ortony (ed.), Metaphor and Thought, 2nd edn,. 202- 251. Cambridge: Cambridge University Press.

Lakoff, G., \& Johnson, M. (2008). Metaphors we live by. University of Chicago press.

Leonard, D., \& Sensiper, S. (1998). The role of tacit knowledge in group innovation. California management review, 40(3).

Levine, S., \& White, P. E. (1961). Exchange as a conceptual framework for the study of interorganizational relationships. Administrative science quarterly, 583-601. 
Lieblich, A., Tuval-Mashiach, R., \& Zilber, T. (Eds.). (1998). Narrative research: Reading, analysis, and interpretation (Vol. 47). Sage.

MacMillan, I. C. (1978). Strategy formulation: Political concepts. St. Paul, MN: West Publishing Company.

Malthus, T. R., \& Hollingsworth, T. H. (1973). An essay on the principle of population (p. 381). London: Dent.

McCourt, W. (1997). Discussion note: using metaphors to understand and to change organizations: a critique of Gareth Morgan's approach. Organization Studies, 18(3), 511-522.

McIntosh, R. P. (1987). Pluralism in ecology. Annual Review of Ecology and Systematics, 321-341.

McIntosh, R. P. (Ed.). (1986). The background of ecology: concept and theory. Cambridge University Press.

Merriam, S. B. (1998). Qualitative research and case study applications in education. San Francisco: Jossey-Bass.

Miles, R. E., Snow, C. C., \& Miles, G. (2007). The ideology of innovation. Strategic Organization, 5(4), 423.

Miles, R. H., \& Cameron, K. S. (1982). Coffin nails and corporate strategies. Englewood Cliffs, NJ: Prentice-Hall.

Miller, E. J. (1989). The'Leicester'model: experiential study of group and organizational processes. London: Tavistock Institute of Human Relations.

Miller, G. T. (1974). Living in the environment: concepts, problems, and alternatives. Wadsworth Publishing Company.

Morgan, G. (1980). Paradigms, Metaphors, and Puzzle Solving in Organization Theory. Administrative science quarterly, 25(4). 
Morgan, G. (2006). Images of organization. Thousand Oaks, CA: Sage.

Morgan, G. (2011). Reflections on Images of Organization and Its Implications for Organization and Environment. Organization \& Environment, 24(4), 459-478.

Moss Kanter, R. (2012a). Enriching the Ecosystem-A four-point plan for linking innovation, enterprises, and jobs. Harvard Business Review, 140. Retrieved from http://hbr.org/2012/03/enriching-the-ecosystem/ar/1

Moss Kanter, R. (2012b). The Business Ecosystem. Harvard Magazine. Retrieved from http://harvardmagazine.com/2012/09/the-businessecosystem.

O'Leary, Z. (2010). The Essential Guide to Doing Your Research Project (2nd ed.). Thousand Oaks, CA, United States of America: Sage.

Oswick, C., \& Jones, P. (2006). Beyond correspondence? Metaphor in organization theory. Academy of Management Review, 31(2), 483-485.

Palmer, I., \& Lundberg, C. C. (1995). Metaphors of hospitality organizations: an exploratory study. The Cornell Hotel and Restaurant Administration Quarterly, 36(3), 80-85.

Patterson*, G. (2004). Harmony through diversity: exploring an ecosystem paradigm for higher education. Journal of Higher Education Policy and Management, 26(1), 59-74.

Péli, G., Bruggeman, J., Masuch, M., \& Nualláin, B. O. (1994). A logical approach to formalizing organizational ecology. American Sociological Review, $571-$ 593.

Péli, G., Bruggeman, J., Masuch, M., \& Nualláin, B. O. (1994). A logical approach to formalizing organizational ecology. American Sociological Review, 571593. 
Pfeffer, Jeffery and Gerald. R. Salancik. (1978). The External Control of Organizations: A Resource Dependence Perspective. New York, NY: Harper and Row.

Phillips, A. (1960). A Theory of Interfirm Organization. The Quarterly Journal of Economics, 74(4), 602-613.

Pistrui, D., Blessing, J., \& Mekemson, K. (2008, June). Building an entrepreneurial engineering ecosystem for future generations: The Kern Entrepreneurship Education Network. In ASEE Annual Conference.

Potter, J., \& Wetherall, M. (1994). Analyzing discourse. In A. Bryman \& R. Burgess (Eds.), Analyzing qualitative data (pp. 47- 68). London: Routledge.

Reydon, T. A., \& Scholz, M. (2009). Why organizational ecology is not a Darwinian research program. Philosophy of the Social Sciences, 39(3), 408439.

Robinson, W. S. (1951). The Logical Structure of Analytic Induction. American Sociological Review 16(6): 812-818.

Rocha, H., \& Birkinshaw, J. (2007). Entrepreneurship Safari. Now Publishers Inc.

Rocha, H., \& Miles, R. (2009). A model of collaborative entrepreneurship for a more humanistic management. Journal of business ethics, 88(3), 445-462.

Roughgarden, J. (1979). Theory of population genetics and evolutionary ecology: an introduction. New York: Macmillan

Rubin, H. J., \& Rubin, I. S. (2012). Qualitative interviewing: The art of hearing data. Sage Publications.

Ruef, M. (2000). The Emergence of Organizational Forms: A Community Ecology Approach1. American Journal of Sociology, 106(3), 658-714.

Schumpeter, J. A. (1934). The theory of economic development: An inquiry into 
profits, capital, credit, interest, and the business cycle (Vol. 55). Transaction Publishers.

Scott, W. R. (1987). The adolescence of institutional theory. Administrative science quarterly, 32(4).

Scott, W. R. (1998). Organizations: Rational, Natural and Open Systems, 4th edn. Englewood Cliffs, NJ: Prentice Hall.

Scott, W.R. and Davis, G.F. (2007). Organizations and organizing: Rational, natural, and open systems perspectives. Upper Saddle River, NJ: Prentice Hall.

Singh, J. V. (Ed.). (1990). Organizational evolution: New directions. Newbury Park, CA: Sage Publications.

Singh, J. V., \& Lumsden, C. J. (1990). Theory and research in organizational ecology. Annual review of sociology, 16(1), 161-195.

Stake, R. E. (1994). Case studies. In N. K. Denzin, \& Y.S Lincoln (Eds.), Handbook of qualitative research (pp. 236-247). Thousand Oaks, CA: Sage.

Stake, R. E. (1995). The art of case study research. Thousand Oaks, CA: Sage.

Stake, R. E. (2000). The case study method in social inquiry. In Gomm, R., Hammersley, M., \& Foster, P. (Eds.). (2000). Case study method: Key issues, key texts. Sage. (pp. 20-26). London: Sage. (Original work published 1978 Educational Researcher (7), 5-8).

Stake, R. E. (2005). Qualitative case studies. In N. K. Denzin, \& Y.S. Lincoln (Eds.), The Sage handbook of qualitative research (3rd ed., pp. 443-466). Thousand Oaks, CA: Sage.

Stake, R. E. (2008). Qualitative case studies. In N. K. Denzin, \& Lincoln, Y. S. (Eds.), Strategies of qualitative inquiry (pp. 119-149). Los Angeles: Sage. 
Stanley, S. M. (1979). Macroevolution, pattern and process. San Francisco: Freeman.

Stinchcombe, A. L. (1965). Social structure and organizations. Handbook of organizations, 142, 193.

Strauss, A., \& Corbin, J. (1994). Grounded theory methodology. Handbook of qualitative research, 273-285.

Tedlock, B. (1991). From participant observation to the observation of participation: The emergence of narrative ethnography. Journal of anthropological research, 69-94.

The Irish Department of Jobs, Enterprise and Innovation (2014, January). $\begin{array}{llll}\text { Entrepreneurship in } & \text { Ireland. } & \text { Retrieved }\end{array}$ http://www.enterprise.gov.ie/en/Publications/GEM-Report.pdf

Thomas, D. R. (2006). A general inductive approach for analyzing qualitative evaluation data. American journal of evaluation, 27(2), 237-246.

Thompson, James D. (1967). Thompson, J. D. (1967). Organizations in action: Social science bases of administrative theory. New York: McGraw-Hill

Tolich, M., \& Davidson, C. (1999). Starting Fieldwork: An Introduction to Qualitative Research Work in New Zeland. Oxford University Press.

Trickett, E. J. (1984). Toward a distinctive community psychology: An ecological metaphor for the conduct of community research and the nature of training. American Journal of Community Psychology, 12(3), 261-279.

Trickett, E. J., Kelly, J. G., \& Todd, D. M. (1972). The social environment of the high school: Guidelines for individual change and organizational redevelopment. Handbook of community mental health, 331-406.

Trist, E. (1977). A concept of organizational ecology. Australian journal of management, 2(2), 161-175. 
Turchin, P. (2001). Does population ecology have general laws?. Oikos, 94(1), 17-26.

University of Auckland Business School. (n.d.). Entrepreneurial ecosystem. $\begin{array}{llll}\text { Retrieved } & \text { February } & 25, & 2014\end{array}$ http://www.business.auckland.ac.nz/en/about/the-businessschool/entrepreneurial-ecosystem.html

Van Manen, M. (1990). Researching lived experience: Human science for an action sensitive pedagogy. London, Ontario: Althouse Press.

Van Witteloostuijn, A., \& Boone, C. (2006). A resource-based theory of market structure and organizational form. Academy of Management Review, 31(2), 409-426.

Walck, C. L. (1996). Organizations as places: a metaphor for change. Journal of Organizational Change Management, 9(6), 26-40.

Weaver-Hightower, M. B. (2008). An ecology metaphor for educational policy analysis: A call to complexity. Educational researcher, 37(3), 153-167.

Webb, E. J., Campbell, D. T., Schwartz, R. D. and Sechrest, L. (1966). Unobtrusive Measures: Nonreactive Measures in the Social Sciences. Chicago: Rand McNally.

Weick, K. E. (1989). Theory construction as disciplined imagination. Academy of management review, 14(4), 516-531.

Wengraf, T. (2001). Qualitative research interviewing: Biographic narrative and semi-structured methods. Sage.

Wholey, D. R., \& Brittain, J. (1989). Research Notes: Characterizing Environmental Variation. Academy of Management Journal, 32(4), 867-882. 
Wholey, D. R., Christianson, J. B., \& Sanchez, S. M. (1992). Organization size and failure among health maintenance organizations. American Sociological Review, 829-842.

Wholey, D. R., Christianson, J. B., \& Sanchez, S. M. (1993). The effect of physician and corporate interests on the formation of health maintenance organizations. American Journal of Sociology, 164-200.

Wolcott, H. F. (1990). Making a study "more ethnographic". Journal of Contemporary Ethnography, 19(1), 44-72.

Yin, R. K. (1981). The case study crisis: some answers. Administrative science quarterly, 26(1), 58-65.

Yin, R. K. (1994). Case study research: Design and methods (2nd ed.). Thousand Oaks, CA: Sage.

Yin, R. K. (1999). Enhancing the quality of case studies in health services research. Health Services Research, 34(5 Pt 2), 1209.

Yin, R. K. (2003). Applications of case study research (2nd ed.). Thousand Oaks, CA: Sage.

Yin, R. K. (2005). Introduction. In R. K. Yin (Ed.), Introducing the world of education: A case study reader (pp. xiii-xxii). Thousand Oaks, CA: Sage.

Young-Ybarra, C., \& Wiersema, M. (1999). Strategic flexibility in information technology alliances: The influence of transaction cost economics and social exchange theory. Organization science, 10(4), 439-459.

Zahra, S. A., \& Nambisan, S. (2011). Entrepreneurship in global innovation ecosystems. AMS review, 1(1), 4-17.

Znaniecki, F. (1934). The method of sociology (p. 12). New York: Farrar \& Rinehart. 